\title{
4 Fiktion und Wirklichkeit in ausgewählten japanischen Literaturtheorien der Jahre 1850 bis 1890
}

Der Zeitraum 1850-1890 scheint in japanischen Literaturtheorien zur Dichotomie „Fiktion - Wirklichkeit“ von integrativen Tendenzen geprägt zu sein: Wurde zuvor in einzelnen Texten eine inhaltliche Beziehung zwischen dem fiktionalen Text und der außerliterarischen Welt (etwa „Empfinden“ oder „Wahrheit“) betont, postuliert eine Theorie nun häufiger gleichzeitig derer mehrere. So kann etwa das „Empfinden“ nun die „Wahrheit“ sein, kann die „Gestalt“ (kei und katachi 形) den „Sinn“ ( $i$ 意) verkörpern. Freilich war im vorigen Abschnitt die Annahme von Schwerpunkten nur unter der Voraussetzung möglich, dass man die Uneindeutigkeit von Terminologie und Syntax der gesichteten Theorien so weit als verantwortbar ausblendet. Umgekehrt soll nun vor allem die Satzlogik cum grano salis ermöglichen, etwa „Empfinden“ und „Wahrheit“ als Synonyme zu behandeln.

Bevor wir in die Details gehen, sei so viel vorweggenommen: Die bei der Konstruktion semantischer Beziehungen von „Leere“ und „Fülle“ in Literaturtheorien vor 1850 realisierten thematischen Schwerpunkte („Wahrheit“, „Empfinden“, „Gestalt“ und „Dynamik“) sind auch in den Jahren 1850 bis 1890 in Literaturtheorien zu beobachten. Diese Beobachtung soll im folgenden nachvollzogen werden, denn die Feststellung von Kontinuitäten, die über den gesellschaftlichen und kulturellen Umbruch in der Mitte des 19. Jahrhunderts hinweggehen, verspricht die Erkenntnis von Grundwerten in der japanischen Literaturanschauung und der Literaturtheorie. Darüber hinaus aber gilt das Augenmerk eventuellen Veränderungen und Erweiterungen des Kanons der thematischen Schwerpunkte, also dem Entwicklungspotenzial. Es geht mithin in der Feststellung und im Vergleich von Kontinuitäten und Veränderungen um nichts geringeres als um die eingangs der Abhandlung (Abschnitt 1.1) erwähnte kulturanthropologische Bedeutung der japanischen Literaturtheorie. 


\section{1 ,Wahrheit" in „Leere“ und „Fülle“ der japanischen Literaturtheorien der Jahre 1850-1890}

\subsubsection{Fiktionalität dient der ethischen Unterweisung: Ishikawa Teisais Vorwort zu Kimura Mokurōs Kokuji shōsetsu tsū (1849)}

Der Politiker und Verwaltungsbeamte Kimura Wataru Mokurō 木村亘黙老 (1774-1856) war eng befreundet mit Takizawa Bakin, dem bereits erwähnten Nestor der gehobenen Erzählprosa der späten Edo-Zeit. Kimura legte 1849 mit Kokuji shōsetsu tsū 国字小説通 ([Durchgehende Darstellung der Erzählliteratur in Landessprache], 1849) ${ }^{207}$ ein kritisch annotiertes Verzeichnis der bis 1849 erschienenen Erzählliteratur vor und sprach darin seinem ein Jahr zuvor verstorbenen Freund Bakin recht eindeutig die Rolle des Nestors der yomihon-Literatur zu. Traditionsgemäß bestellte Kimura zur Anhebung des Prestiges seiner Unternehmung ein Vorwort bei dem hier mit Kangeki dōjin 観劇道人 signierenden konfuzianischen Gelehrten Ishikawa Teisai 石川艇斎 (fl. 1849). ${ }^{208}$ Wir haben den inhaltlichen Kern des Textes bereits in der einführenden Beispielsammlung (S. 9) kennengelernt. In der Tat setzt der Text den engen Bezug zwischen dem fiktionalen Text und der extratextuellen Wirklichkeit gleichsam als naturgegebenes Prinzip voraus und spricht der fiktionalen Literatur didaktischen Wert für Ungebildete zu. Beachtung verdient aber gerade darum die folgende Fortsetzung aus dem eingangs zitierten Vorwort.

Nun mag es zwar so sein, dass herkömmliche und gewöhnliche Alte und Junge alle [diese Literatur] lieben, doch erkennen sie nicht, dass es bei diesen Schriften im geschickten und ungeschickten Verändern und Übereinanderlegen von Altem und Jetzigem ${ }^{209}$ einen Klassenunterschied gibt - solche Leute schauen sich [diese Literatur] einfach an, und darin erschöpft es sich. [...] Ich wünsche mir, dass man die Alten und Jungen, die Frauen und Kinder, welchen das Unterscheidungsvermögen fehlt, zu umfassendem Wissen über Geschick und Ungeschick beim Verändern und Decken kommen lassen möge. ${ }^{210}$

207 Neben einer vom Philologen und Sinologen Urushiyama Tendō 漆山天童 (1873-1948) angelegten undatierten Abschrift (digitale Kopie über KSDB erreichbar) steht mit KIMURAIWAMOTO-HiRotani 1927 ein moderner Druck zur Verfügung.

208 Von Ishikawa Teisai 石川艇斎 ist nicht mehr bekannt, als dass er während der Ansei-Ära (1854-1860) als Samurai und konfuzianischer Gelehrter im Fürstentum Owari diente.

209 „Altes und Jetziges“ (kokin 古今) meint den meist historischen (beispielsweise bei Bakin häufig der Zeit vom 13. bis zum 17. Jahrhundert entnommenen) Ausgangsstoff einerseits und dessen fiktionale Umgestaltung zu einem Gegenwartsstoff andererseits.

210 Kimura-Iwamoto 1927 [1849]: 246. 
Zur Ausbildung des Unterscheidungsvermögens, so Ishikawa weiter, sei Kimuras Verzeichnis bestens geeignet. Bemerkenswert daran ist, dass Ishikawa den didaktischen Wert der Romane nicht etwa mit einer größtmöglichen Nähe zur außerliterarischen Realität verknüpft, sondern mit der Geschicklichkeit darin, den Unterschied zwischen Fiktion und Realität für ungebildete (aber durch Kimuras Kommentare instruierte) Leser wahrnehmbar zu machen. Der didaktische Wert läge demnach nicht in der direkten Vermittlung der Realität, sondern in der Entwicklung des Sinnes für Realität gerade durch Abweichungen von ihr.

Der in diesem Text entfaltete Wahrheitsbegriff ist uns schon aus Abschnitt 3.4.1 bekannt. Neu ist allerdings die Aufwertung der Fiktionalität zu einem erkenntnisfördernden Moment der fiktionalen Literatur. Das Neuartige daran wird besonders im Kontrast zur folgenden, absolut konventionellen Rollenzuschreibung der fiktionalen Literatur offenbar.

\subsubsection{Romane als Förderer der Wissenschaft: Das Osana etoki bankoku banashi (1861) von Kanagaki Robun}

Kanagaki Robun 仮名垣魯文 (Nozaki Bunzō 野崎文蔵, 1829-1894) kommt aus der Tradition derjenigen Autoren, welche Prosa angeblich „zum Spaße verfassten“ (gesaku), in Wirklichkeit aber aus kommerziellem und vor allem nicht aus wissenschaftlichem Interesse. Damit begann er 1849 durch Veröffentlichung narrativ anspruchsloser Heftliteratur (kusazōshi). Erfolgreich war Robun aber erst 1851 mit Flugschriften (kawaraban 瓦版), die er zunächst im Auftrag und später selbstständig verfasste. 1853 eröffnete er sein erstes eigenes Verlagsgeschäft und strebte nach seinem eigentlichen Ziel, dem dauerhaften Erfolg als gesaku-Autor. Aber erst seine Ansei kenmon shi 安政見聞誌 (Berichte über Gesehenes und Gehörtes aus der Ansei-Zeit, 1855) betitelte Schilderung des großen Erdbebens des Jahres 1855 verhalf ihm zu einiger Bekanntheit, ${ }^{211}$ während er

\footnotetext{
211 Zum Katastrophenbericht Ansei kenmon shi siehe KöHN 2002 insgesamt, zur Biografie Kanagakis siehe KöHN 2002: 14-26 und SCHAUMANN 1981. Beruflich war für Robun das von ihm selbst miterlebte Erdbeben ein Glücksfall, weil es ihm den Stoff für kommerziell erfolgreiche Veröffentlichungen im Grenzgebiet zwischen Literatur und Journalistik lieferte - die pseudowissenschaftlichen Veröffentlichungen zur Dreifachkatastrophe von Fukushima (2011) haben also ihren Vorläufer in der japanischen Literaturgeschichte und sind noch nicht einmal von ihrer „Infotainment“-Anlage her neu.
} 
literarisch nur mit seinem kokkeibon (,Ulkbuch“) Kokkei Fuji mōde ([Lustige Pilgerwanderung zum Berg Fuji], 1860) erfolgreich war und bald danach wieder in Vergessenheit geriet. Die gesaku-Texte Robuns gehören zur literaturgeschichtlichen Hauptströmung der Zeit, welche sich in der Nachwirkung der verschärften literarischen Zensur des Politikers Mizuno Tadakuni 水野忠邦 (1794-1851) auf als Tatsachenberichte (jitsuroku 実録) und moralische Belehrungen getarnte Produktionen der Unterhaltungsliteratur beschränkte und nach dem Tod der drei marktführenden Autoren Ryūtei Tanehiko (1842), Tamenaga Shunsui (1843) und Takizawa Bakin (1848) nur noch billige Neubearbeitungen bereits bekannter Stoffe hervorbrachte. ${ }^{212}$ Die zeitgenössischen Autorenkollegen wandten ihren Blick von den turbulenten gesellschaftlichen Entwicklungen der Gegenwart ab und beschränkten sich in der Literatur auf gossip über ihre direkte soziale Umgebung. ${ }^{213}$ Robuns Katastrophenbericht Ansei kenmon shi (1855) hingegen kann als Frühwerk des Journalismus gesehen werden und wird zusammen mit seinen Berichten über das im kollektiven Bewusstsein der Zeit immer präsentere Ausland zu denjenigen Prosawerken gezählt, die historische, politische, topografische und kulturgeschichtliche Fakten in der Zeit des Übergangs vom Feudalismus zur Moderne Japans narrativ aufbereiten und so einem bildungsfernen Publikum näherzubringen versuchen.

Ein solcher Bericht über das Ausland ist das in vier Bänden zusammengefasste, aus 16 Kapiteln bestehende Osana etoki bankoku banashi 童絵解万国噺 ([Geschichten aus den Zehntausend Ländern - Für Kinder anhand von Bildern $^{214}$ erläutert], 1861), eine Bildergeschichte des Genres gōkan. Im Vorwort zu Band 3 berührt Robun das Thema der Fiktionalität wie folgt.

212 Drastisch schildert dies nach literarischen Genres getrennt OKITSU 1960: 2-17.

213 Es ist allerdings methodisch problematisch, wie Okitsu Kaname in diesem Zusammenhang von Bewusstseinslosigkeit (mujikaku 無自覚), von auf Spaß konzentriertem Leben (yūgi seikatsu 遊戯生活), Dekadenz (taihai 頽廃; OKITSU 1960: 3) und Abwesenheit von Denken (mushisōsei 無思想性, OKITSU 1960: 14) der Autoren zu sprechen, denn eine solche Bewertung geht an den Ursachen der Entwicklung vorbei und appliziert überdies unvermittelt Maßstäbe des Jahres 1960 auf historische Gegebenheiten des Jahres 1861. Auch sei darauf hingewiesen, dass die von Okitsu aufgestellte Behauptung einer Abwesenheit jeglichen Denkens nicht argumentiert und daher nicht überzeugend ist.

214 Die Bebilderung schuf nach traditioneller ukiyoe-Art der Künstler Utagawa Yoshitora 歌川 芳虎 (= Nagashima Tatsugorō 永島辰五郎, fl. 1836-1877). 
Es ist die Domäne der den Sinn auslegenden Romane, ${ }^{215}$ das Allgemeine aus dem Nahegelegenen zu nehmen, ${ }^{216}$ den $\operatorname{Sinn}^{217}$ durch Beförderung und Geißelung ${ }^{218}$ hervorzubringen, und gerade darin liegt die Aufmerksamkeit des Verfassers; doch mag dies sein wie es ist: Dies Schriftwerk ist zwar in seiner Aufmachung den bekannten historisierenden Romanen ${ }^{219}$ nachempfunden, verwendet aber weder Metaphern ${ }^{220}$ noch in der Luft Befestigtes, ${ }^{221}$ vielmehr stützt es sich vor allem auf jenes [Werk], welches ursprünglich der Holländer Herr Kramers verfasst hatte, ${ }^{222}$ sowie die Übersetzung des Haiguo tuzhi eines Menschen von Qing, ${ }^{223}$ außerdem auf das Vermehrte und erläuterte Sairan igen ${ }^{224}$ oder auch

215 „Den Sinn auslegende Romane“ für engi shōsetsu 演義小説 (chin. yuanyi xiaoshuo): aus China „importiertes“ Genre der literarischen Erzählprosa, in dem historische Fakten (angeblich) zur Belehrung breiter Leserschichten narrativ aufbearbeitet werden. Wesentliches Merkmal ist die der Umgangssprache angenäherte Schriftsprache. In dieser chinesischen Tradition stehen insbesondere die hier gemeinten yomihon des Kyokutei Bakin und die gōkan des Ryūtei Tanehiko.

216 „Das Allgemeine aus dem Nahegelegenen entnehmen“ für ōyoso no chikaku ni torite (KANAGAKI 1861-III: 1a).

217 „Sinn“ für gi 義, womit die verallgemeinerbare Bedeutung historischer Ereignisse gemeint ist.

218 „Beförderung und Geißelung“ für kanchō 勧懲, einer Kurzform des Slogans kanzen chōaku 勧善懲悪 („Beförderung des Guten, Geißelung des Schlechten“).

219 „Historisierende Romane“ für haishi 稗史, eine andere Bezeichnung für die „den Sinn auslegenden Romane“ (Anm. 216), im engeren Sinne die yomihon.

220 „Metaphern“ für gūgen 寓言, ein schon im Zhuangzi (3. Jhdt. v. Chr.; siehe S. 68) verwendeter Ausdruck zur didaktisch argumentierenden Rechtfertigung vergleichender und bildlicher Redeweise.

221 „In der Luft Befestigtes“ für kakū 架空, Metapher für „nicht durch Fakten Belegbares“.

222 Der hier erwähnte niederländische Wissenschaftler Jacob Kramers (1802-1869) war in Europa vor allem als Lexikograf bekannt. Als Auszug aus seinem weltgeografischen Handbuch Geografisch-statistisch-historisch handboek, of beschrijving van het wetenswaardigste uit de natuur en geschiedenis der aarde en harer bewoners (Gouda: Van Goor, 1850) hatte 1855 der Hollandwissenschaftler Ozeki Takahiko 小関高彦 (fl. 1855) unter dem Titel Gasshū koku shōshi 合 衆国小誌 ([Kleine Topographie der Vereinigten Staaten]) den entsprechenden Textanteil übersetzt, den Ōtsuki Takashi 大槻崇 (fl. 1855) um Illustrationen ergänzte.

223 „Qing“清 hier im Sinne von „China der Qing-Dynastie (1662-1911)“. Das chinesische Haiguo tuzhi 海国図志 ([Topografische Abhandlung der Länder [jenseits] der Meere]) des Wei Yuan 魏源 (1794-1856) erschien 1842 kurz nach dem Ende und unter dem Eindruck des Opium-Krieges, 1854 in der japanischen Übersetzung von Shionoya Tōin 塩谷宕陰 (1809-1867) und Mitsukuri Genpo 箕作阮甫 (1799-1863) unter dem sinojapanischen Titel Kaikoku zushi, nur ein Jahr nach dem Auftauchen der „Schwarzen Schiffe“ des Commodore Perry in Edo im Verlag Suwaraya Ihachi. Das Erscheinen des Gasshū koku shōshi (Anm. 223) und des Kaikoku zushi hängt ursächlich mit dem starken Eindruck von der bedrohlichen militärtechnischen Überlegenheit ausländischer Mächte (die Briten gegenüber China, die USA gegenüber Japan) und mit dem dadurch gestiegenen Bedarf an aktuellen Informationen über diese Mächte zusammen. Es soll festgehalten werden, dass Robun sich nicht die Mühe macht, den von ihm behaupteten nichtfiktionalen, rein faktenbasierten Charakter der beiden zitierten Werke zu plausibilisieren.

224 Der volle Titel lautet Teisei zōyaku Sairan igen 訂正増訳采覧異言 ([Korrigierte, vermehrte und erläuterte < Ausgabe > des Sairan igen], 1802). Grundlage dieser von Yamamura Saisuke 山 
die Abhandlung über das geeinte Amerika, ${ }^{225}$ die Vermischten Aufzeichnungen über Länder westlich des Ozeans ${ }^{226}$ und allerlei andere Schriften, und im Bestreben, auch für Kinder und Frauen [das Buch] leicht einsehbar zu machen, verwendete ich die Sprache unseres ehrenwerten Kaiserreichs; $;^{227}$ erläuterte ich in kana-Schrift ${ }^{228}$ und milder Form seltene Geschichten und außergewöhnliches Hörensagen, forschte nach tatsächlichen Sachverhalten $^{229}$ in jenen neuen Ländern; ${ }^{230}$ die neu gedruckten Werke aber, welche die aufgezählten ergänzen, brachte man gleichzeitig mit dem dritten Bande des Verfassers, der in dieser Welt ${ }^{231}$ nicht einmal zum Tabak-Rauchen Zeit fand, in den Verkauf, so dass er sich bei aller Bescheidenheit beeilen musste, [die Vorlagen] auf die Druckplatten zu bringen. Im Frühling des ersten Jahres Bunky $\bar{u}^{232}$ verfasste dies Kanagaki Robun.

Im Zusammenhang der vorliegenden Abhandlung ist ein Dilemma Robuns von besonderem Interesse: Einerseits will er durch einen einzigen Text gleichzeitig

村才助 (1770-1807) erstellten weltgeografischen Abhandlung ist das Sairan igen 采覧異言 ([Fremde Worte nehmend und schauend], 1713; Titelübersetzung nach der Deutung im Vorwort des Textes), die gesammelten und um Karten ergänzten Aufzeichnungen der Gespräche, die Arai Hakuseki 新井白石 (1657-1725) mit dem zu missionarischen Zwecken nach Japan gekommenen Giovanbattista Sidotti (1668-1714) über die Welt außerhalb Japans geführt hatte - die erste in Japan erschienene systematische Weltgeografie in japanischer Sprache.

225 „Abhandlung über Einheit Amerikas“ für Amerika ittō shi 亜墨利加一統志, ein unter den 364 mit dem Titelbestandteil Amerika im KTSM nachgewiesenen Schriften nicht identifizierbares Werk.

226 „Vermischte Aufzeichnungen über Länder westlich des Ozeans“ für Seiyō zōki 西洋雑記, womit vor allem Amerika und Europa gemeint sind. Mit der Standardlesung Seiyō zakki 西洋雑 記 sind zwei in Frage kommende Titel verifizierbar: (a) die 1808 verfasste, in nur einer einzigen Abschrift verifizierbare Abhandlung des Mathematikers und Wirtschaftstheoretikers Honda Toshiaki 本多利明 (1743-1821), (b) die 1801 von Yamamura Saisuke 山村才助 (1770-1807) verfasste geografische Abhandlung, von der neben Abschriften auch ein auf 1852 datierter Druck nachweisbar ist. Wahrscheinlich meint Robun das Werk Yamamuras, dessen Teisei zōyaku Sairan igen (Anm. 225) er schon als Quelle nannte (Yamamuras Seiyō zakki erschien übrigens 1866 erneut im Druck.)

227 „Sprache unseres ehrenwerten Kaiserreichs“ für mikuni kotoba 皇国言葉, womit hier die japanische Sprache gemeint ist. Der altjapanische Anteil mikuni [御国] („ehrenwertes Land“) wird häufig in den „Landesstudien“ (kokugaku) zuzuordnenden Abhandlungen verwendet und kann einen sinophoben Akzent haben, der sinojapanische Anteil [kōkoku] 皇国 („Kaiserreich“) ist Bestandteil der vom sinophilen Neokonfuzianismus geprägten Normalsprache. Die Doppelschreibung kommt einer Verbeugung in beide Denkrichtungen gleich.

228 Kana-Schrift: die im Verhältnis zur logografischen Schrift des Chinesischen (kanji) leicht erlernbare Silbenschrift des Japanischen.

229 „Tatsächliche Sachverhalte“ für jijitsu 事実.

230 „Neue Länder“ für shinkoku 新国.

231 „Diese Welt“ für shaba 梁婆, ein aus dem indischen sahā abgeleiteter buddhistischer Terminus zur Bezeichnung der gegenwärtigen Welt, hier pathetischer Ausdruck für „politisch wie ökonomisch geschäftige Gegenwart“.

232 „Bunkyū“ 文久: Regierungsdevise des Zeitraums 1861-1864. 
mit fiktionaler Erzählliteratur im Stile der untergehenden Edo-Kultur kommerziellen Erfolg erzielen, andererseits durch wissenschaftlich fundierte Information über das Ausland den Anschluss an die utilitaristische Literaturanschauung der sich ankündigenden neuen Zeit gewinnen. Die moralisierende und an historischen Fakten orientierte Ausrichtung beanspruchte auch Kyokutei Bakin für seine Texte und war, so gesehen, utilitaristisch. Anders als Bakin aber orientierte sich Robun nicht an mehrere Jahrhunderte zurückliegenden Ereignissen, ${ }^{233}$ um aus ihrem Verlauf moralische Lehren für den gegenwärtigen Leser zu gewinnen. Er orientierte sich vielmehr an dem, was er aufgrund der zurategezogenen wissenschaftlichen Literatur für die gegenwärtige Realität hielt, um daraus eine lebenspraktisch nutzbare Narration zu gestalten. Kurz: Robun versuchte, Fiktion und Realität im Grenzgebiet von Wissenschaft und Kunst zusammenzuführen, und dies erklärtermaßen im Dienste der Erkenntnis.

Dass die Erkenntnis auch jenseits solch positivistischer Orientierung gewonnen werden kann, behauptet die im folgenden besprochene Literaturtheorie.

\subsubsection{Wissenschaft erzeugt Erkenntnis, Dichtung erzeugt Erleuchtung: Das Shōfū mukaku ben (1864-1865) von Soshitsu Kyūan}

Soshitsu Kyūan 蘇室久安 (fl. 1864-65) war ein Haikai-Dichter und -Theoretiker, von dem nicht mehr bekannt ist als die im Folgenden behandelte Sammlung. Spekulativ bleibt die Annahme, dass es sich um jenen Mönch Kyūan handelt, nach dem seit 1868 die in der Edo-Zeit noch Etchūbashi 越中橋 genannte Brücke im Tōkyōer Stadtviertel Hatchōbori benannt wurde, weil in deren Gegend das dem Mönch geschenkte Grundstück lag. ${ }^{234}$

Die von Kyūan stammende dreibändige Sammlung Shōfū mukaku ben 蕉風 無格弁 ([Darlegungen zur Maßbefreitheit des Bashō-Stils], 1864-1865) enthält außer der Abhandlung Shōfū mukaku ron 蕉風無格論 ([Über die Maßbefreitheit des Bashō-Stils]) eine Reihe weiterer Abhandlungen rund um die Dichtung des Matsuo Bashō. ${ }^{235}$

233 Bakin verwendete Stoffe aus kriegerischen Auseinandersetzungen aus der Zeit vom 13. bis zum 16. Jahrhundert, auch um - wie von der Zensur vorgeschrieben - auf gebührendem Abstand zu gegenwärtig Herrschenden zu bleiben (MAY 1983: 67-80).

234 Dass der Name Kyūan 久安 auf die Regierungsdevise der Jahre 1145-1151 und damit vielleicht auf die Waka-Anthologie Kyūan rokunen onhyakushu 久安六年御百首 ([Sammlung von Hundert Waka des Jahres Kyūan 6]) anspielen mag, bleibt Spekulation.

235 Im einzelnen sind das eine Kareno 枯野 ([Verdorrtes Feld], 1864) betitelte Sammlung von Haikai des Kyūan, das Fūgashin 風雅心 ([Herz der Eleganz], eine Anleitung zum Lesen poetischer 
Kaku im Titel Shōfū mukaku ben übersetze ich mit „Maß“. Die Etymologie des zugrundeliegenden chinesischen Wortes ge 格 (jap. kaku) legt als Grundbedeutung ein langes Stück Holz und davon abgeleitet die Deichsel eines Wagens oder allgemein einen Stab als Signifikate nahe. ${ }^{236}$ Die im DKJ hiernach genannten Konkreta (Zaun, Stütze) und Abstrakta (Regelung, Qualitätsstufe) mögen als Ableitungen der Grundbedeutung gesehen werden. Das trägt allerdings kaum zur Interpretation des Titels Shōfū mukaku ben bei. Auch die Orientierung am folgenden Diktum aus dem Haikai ichiyō shū 俳諧一葉集 ([Sammlung einzelner Haikai], 1827), der ersten Gesamtausgabe der Werke Bashōs, bringt uns dem Begriffsgehalt von kaku im literaturtheoretischen Sinne (,Maß“) nur wenig näher.

Wenn man in das Maß hineingeht, aber nicht wieder heraus, so wird es eng; geht man aber nicht in das Maß, so läuft man auf einem Irrwege dahin. Erst, wenn man in das Maß hineingeht und wieder heraus, so kann man Freiheit erreichen. ${ }^{237}$

Bashō bezieht sich dabei offensichtlich auf die produktive (und nicht auf die rezeptive) Seite der Haikai-Lyrik und meint, dass man sich bei der Produktion über die Form (= das Maß) erst hinwegsetzen darf, wenn man es beherrscht. Freilich ist auch damit der Begriffsgehalt des Wortes kaku (Maß) nicht geklärt, weswegen wir in der Begriffsgeschichte weitere Schritte zurückgehen müssen.

Sowohl im chinesischen Neokonfuzianismus als auch im Chan-Buddhismus bezeichnet ge das Streben nach Erkenntnis eines Urprinzips. ${ }^{238}$ Locus classicus des hierauf bezogenen Ausdrucks gewu zhizhi格物致知 (jap. kakubutsu

Texte), den Jo 序 ([Prolegomena]) betitelten kanbun-Text von Rai Shihō 頼支峰 (1823-1889), die Abhandlung Shōfū mukaku 蕉風無格 ([Die Maßbefreitheit des Bashō-Stils], 1864-1865), das Shōfū dan 蕉風談 ([Gespräche über den Bashō-Stil], 1865), das Shōfū dan shūi 蕉風談拾遺 ([Nachlesen zu den Gesprächen über den Bashō-Still]), das Shōfū nikki 蕉風日記 ([Tagebuch zum Bashō-Stil]) sowie verschiedene kleinere, unbetitelte Notizen. Der Eigner des ursprünglichen Druckstocks war der Waka-Dichter Tōutei Kagawa Kagetsune 東塢亭香川景恒 (1823-1866), Sohn des Waka-Dichters und -Theoretikers Kagawa Kageki 香川景樹 (1768-1843).

236 DKJ 6-14749.

237 Kaku ni irite kaku wo idezaru toki wa semaku, mata kaku ni irazaru toki wa jaro ni hashiru. Kaku ni iri, kaku wo idete hajimete jizai wo ubeshi. 格に入りて格を出ざる時は狭く、また格に 入ざる時は邪路にはしる。格に入り、格を出てはじめて自在を得べし。 (BASHŌ-KOGAKUKAN 1827-V: 1a; BASHŌ-KogaKUKAN 1925 [1827]: 513).

238 Zhang Jiucheng 張九成 (1092-1159), hochrangiger Beamter im Amt für Riten und gleichzeitig Schüler des Chan-Mönchs Dahui Zonggao 大慧宗杲 (1089-1163), verfasste in seiner kritischen Haltung gegenüber dem als impraktikabel empfundenen Buddhismus einerseits und dem in seiner analytischen Logik als destruktiv empfundenen Konfuzianismus andererseits Kommentare zu den konfuzianischen Klassikern (Lunyu, Mengzi), in denen er versuchte, Buddhismus und Konfuzianismus einander näherzubringen. Prinzipiell trat auch Zhang Jiucheng für die Ergründung des innersten Prinzips der Dinge ein, war allerdings der Ansicht, dass die 
chichi, „das Prinzip der Dinge ergründen und das Wissen zum Äußersten steigern") ist das Loblied auf die moralisch läuternde Wirkung der Ergründung des Prinzips und der dadurch entstehenden vollkommenen Weisheit im Daxue 大学 (The Great Learning, 5. Jh. v. Chr.). ${ }^{239}$ Auf dieser Passage basierend propagiert der in Japan intensiv rezipierte chinesische Philosoph Zhu Xi die völlige Durchdringung des allen Dingen innewohnenden Prinzips. ${ }^{240}$

Nun liegt es wohl nahe, dass Bashō schon von seiner nachhaltigen Prägung durch den Zen-Buddhismus her mit dem soeben zitierten Diktum die Ergründung des Prinzips der Dinge (der Gegenstände seiner Dichtung) als wichtiges Durchgangsstadium im dichterischen Schaffensprozess postuliert und gleichzeitig davor warnt, in der Herausarbeitung dieses Prinzips verhaftet zu bleiben. Auch die Zhu-Xi-konfuzianische Staatsdoktrin dürfte nicht völlig an ihm vorbeigegangen sein. Worin aber besteht das Prinzip jener Dinge, die das Referens des literarischen Textes bilden?

Die erste auf die Literatur bezogene Verwendung des Wortes kaku dürfte die auf Seite 98 zitierte Passage aus dem Bunkyō hifu ron (810-824; S. 81 ff.) sein, die „Maß“ (kaku) und „Sinn“ ( $i$ 意) gleichsetzt, damit den noch nicht versprachlichten, erst gedachten Gehalt der Dichtung ${ }^{241} \mathrm{zu}$ dessen dimensionalem Außenmaß macht und letztlich nichts anderes ist als das im Daxue beschriebene und von

Ergründung eines einzigen Prinzips ausreiche, um zur chan-buddhistischen Erleuchtung (wu 悟, jap. satori) zu gelangen. Hierin folgte ihm Zhu Xi nicht (GoTō 1991).

239 古之欲明明德於天下者、先治其國。欲治其國者、先齊其家。欲齊其家者、先修其身。欲 修其身者、先正其心。欲正其心者、先誠其意。欲誠其意者、先致其知、致知在格物。物格而 後知至、知至而後意誠、意誠而後心正、心正而後身修、身修而後家齊、家齊而後國治、國治 而後天下平。(Liji zhushu 禮記註疏 60: 1a-2a, SKQS-Edition). „The ancients who wished to illustrate illustrious virtue throughout the kingdom, first ordered well their own states. Wishing to regulate their families, they first cultivated their persons. Wishing to cultivate their persons, they first rectified their hearts. Wishing to rectify their hearts, they first sought to be sincere in their thoughts. Wishing to be sincere in their thoughts, they first extended to the utmost their knowledge. Such extension of knowledge lay in the investigation of things. Things being investigated, knowledge became complete. Their knowledge being complete, their thoughts were sincere. Their thoughts being sincere, their hearts were then rectified. Their hearts being rectified, their persons were cultivated. Their persons being cultivated, their families were regulated. Their families being regulated, their states were rightly governed. Their states being rightly governed, the whole kingdom was made tranquil and happy“ (LEGGE 1900: 310-314).

240 Zhu Xis auf dem Daxue basierende Apologie der moralisch läuternden Durchdringung der Gegenstände ist in den Kapiteln 14-18 des Zhuzi yulei 朱子語類 ([Gesammelte Worte des Meisters Zhu], 1270; 1a-63b, SKQS-Edition) enthalten. Ausführliche Erläuterungen zu den dortigen, häufig unter dem Slogan gewu zhizhi 格物致知 (jap. kakubutsu chichi) zusammengefassten Argumenten bieten UsAmI u. a. 2009-2013.

241 Der grundsätzlichen Frage, ob Denken ohne Sprache überhaupt möglich sei, kann hier nicht weiter nachgegangen werden. 
Zhu Xi in den Mittelpunkt gestellte, zu ergründende Prinzip der Dinge oder die Ergründung selbst. ${ }^{242}$

Der in Japan intensiv rezipierte chinesische Dichter Su Dongpo 蘇東坡 (1037-1101) verwendet den Ausdruck juge 句格 („Maß der Dichtung“, jap. ku$k a k u)$ im Sinne von technischer Norm. ${ }^{243}$ Und auch im Japan der späten EdoZeit bezieht das Wort kaku sich bei der Erforschung der Dichtung des Altertums auf das der sprachlichen Materialisierung vorausgehende Stadium des dichterischen Produktionsprozesses. So propagiert etwa der bereits in Abschnitt 3.4.3.3 erwähnte kokugaku-Gelehrte Tachibana Moribe, dass das „Maß der Verse“ (ku$k a k u$ 句格) des Altertums (und insbesondere des Man'yōshū) das Ideal seien, ${ }^{244}$ wobei kaku dem Begriff shirabe 調 („Rhythmus“ im klanglichen Sinne) ${ }^{245}$ ge-

242 Dass es sich bei „Sinn“ (i) um ein Substantiv mit statischem Charakter, bei „Ergründung“ (kaku) aber um ein wegen des verbalen Anteils dynamisch anmutendes Substantiv handelt und deswegen die Annäherung oder Gleichsetzung inkonsistent erscheint, ist nur ein Problem der deutschen Sprache - das Chinesische und das Sinojapanische fassen ganze Wortfelder zusammen und lassen die gegebene Interpretation ohne weiteres zu.

243 Dies wird in einem Zusatz zu einem Gedicht von Cheng Zhengfu 程正輔 offenbar. Das von Su Dongpo erweiterte Gedicht trägt den Titel Xihe zhengfu yizi yun 戯和正輔一字韻 ([Zum Spaße einem auf Wortanfänge reimenden Gedicht des Zhengfu hinzugefügt], [nicht datiert]) und lautet: 故居劍閣隔錦官、柑果姜蕨交荊菅。奇孤甘掛汲古綆、僥覬敢揭鉤金笔。已歸耕稼 供槁秸、公貴幹疊高巾冠。改更句格各赛吃、姑因狡獪加間關。(Dongpo quanji 東坡全集 26: 14a, SKQS-Edition). „'Meine alte Bleibe war jenseits des [Berges] Jiange, von welchem mich die Burg von Jinguan trennte und wo Zitrusfrüchte, Ingwer, Farn und Dornensträucher durcheinanderwuchsen. Ich war von sonderbarer Art und einsam, und so begnügte ich mich damit, in vergangenen Dingen zu schöpfen. Sollte mir das unverdiente Glück zuteil werden, dass man mir die Fesseln abnimmt, so würde ich, schließlich heimgekehrt, Feldarbeit aufnehmen und hätte [nur] trockenes Stroh anzubieten, Ihr Ehrenwerter hingegen habt bezauberndes Talent und traget eine hohe [Rang-]Mütze.' Ich habe nun die Regeln der Dichtung verändert und ein Gedicht aus Lautpaaren verfasst. An und für sich humpelt und stottert es. Es ahmt die Durchtriebenheit der [Hexe] Magu nach, was für den Dichter aufwendig war." Dongpos Zusatz zu dem Gedicht ist kursiv gesetzt. Die Besonderheit des Gedichts und des von Dongpo stammenden Zusatzes bestehen in der Wahl von ausnahmslos mit dem Phonem $k$ - anlautenden Wörtern. Dies und Dongpos Verstoß gegen die Regeln zur wechselnden Abfolge chinesischer Töne werden allerdings nur in der originalchinesischen Lautung hörbar.

244 Kakareba uta no takumi wa, Senzai Shin kokin no koto to narite, komayaka ni narinu tomo, kukaku no hon’i ni itaku semuke kitsuru nari. か れ八歌の巧み八。千載新古今のころとなり て。こまやかになりぬとも。句格の本意にハいたく背け来つる也。 (TACHIBANA 1885 [1875]-I: 14b). „Die [handwerkliche] Geschicklichkeit verfeinerte sich in der Zeit des Senzai [Wakashū] 千載[和歌集] [7. kaiserliche Waka-Anthologie, 1184-85] und des Shin kokin [Wakashū] [8. kaiserliche Waka-Anthologie, 1205], doch wendete man [ab hier] dem Grundsinn, dem Maße der Verse in spürbarem Grade den Rücken zu.“.

245 ÁROKAY 2010. 
genüberstehe und die Ordnung der Gestaltungselemente oder die Strukturierung der Dichtung, also den der Versprachlichung vorausgehenden intellektuellen Prozess innerhalb der Produktion meine. ${ }^{246}$ Das Wort kakuchō 格調 („Maß und Rhythmus") fasst als Kompositum der beiden Begriffe innere (gedankliche, $k a k u$ ) und äußere (handwerkliche, chō) Merkmale des dichterischen Werkes zusammen. Der kokugaku-Gelehrte Mutobe Yoshika 六人部是香 (1798-1864) definiert in Chōka tamagoto 長歌玉琴 ([Jade-Zither der Langgedichte], 1861) kaku als von diachronen Entwicklungen unabhängigen Gehalt der Dichtung im Gegensatz zu deren von der Historie abhängigen dichterischen Sprache. ${ }^{247}$ Den Kernpunkt bei der Gestaltung des von der Historie unabhängigen Gehaltes sieht Mutobe dabei in der richtigen Paarung von Versen und widmet diesem Problem das zentrale Kapitel [5] „Wendungen in Verspaaren“ (Tsuiku kiten 対句 機転). Verspaare, in denen unterschiedliche Inhalte gegeneinandergesetzt werden, wären vor diesem Hintergrund als „analytisch“, wissenschaftlich oder „maßvoll“, die von Kyūan konstatierte „Maßbefreitheit“ in der Dichtung Bashōs wäre dann als Suspension obligatorischer Kontrastierungen, im Grunde also als Synthese der Elemente zu sehen. ${ }^{248}$ Wie die später folgende Übersetzung zeigt, scheidet Kyūan dabei deutlicher noch als der verehrte Meister wissenschaftliche und nichtwissenschaftliche Literatur voneinander. ${ }^{249}$

Schließlich legen der Terminus yige hua 逸格画 (,aus dem Maße gefallene Bilder") zur Bezeichnung komischer und gegen alle Regeln verstoßender Kunst im China des 7. bis 10. Jahrhunderts sowie der in PoHL 2007 für den Fall der chinesischen Ästhetik analysierte Begriff der „Regel der Regellosigkeit“ ( $w u$ fa zhi fa 無法之法, jap. muhō no hō) nahe, mukaku als sprachlich variierte Bezeichnung eben dieser Maß- und Regellosigkeit aufzufassen. Pohl beschreibt Zhuang Zhou als Urheber der Vorstellung, ein Kunstwerk solle wie das unergründliche Werk der Natur (dao) entstehen, also ohne bewusstes Steuern ganz von selbst

\footnotetext{
246 HiSAMATSU 1952: 231.
}

247 Sate, sono kokaku ni yotte fu totonouru toki wa, kaerite kotoba wa kōsei no kotoba wo mote fu nasu tomo, sono kakuchō kokaku ni ninau toki wa, sono shirabe uruwashiku, teisai fūchi mo inishie no mama nareba, sunawachi kofū no uta to koso iu bekere. さて其古格に依て賦整ると きは、却りて詞は後世の詞をもて賦成すとも、其格調古格に荷ふ時は、其調豊麗しく、体裁 風致も古のまっなれば、則古風の歌とこそ云べけれ。 „Nun, wenn die Rhapsodie einerseits anhand jener alten Maße geordnet wird, andererseits man in der Sprache Worte späterer Zeiten verwendet, um eine Rhapsodie zu dichten, dann ist der Rhythmus glanzvoll und liebreizend, auch wenn Maß und Rhythmus auf alten Maßen fußen; Form und Stil sind dann unverändert aus alter Zeit, weswegen man wahrhaftig von einem Lied in altem Stile sprechen kann“ (MUTOBE 1861: [8b]).

248 Zum buddhistischen Identitätsgedanken siehe Anm. 506.

249 Quelle: SosHITSU 1865-I. 
(ziran 自然). ${ }^{250}$ Zhuang Zhous diesbezügliche Gedanken hätten enormen Einfluss auf die chinesische Kunsttheorie und Ästhetik ausgeübt und dort als Argumente für den Bruch des Künstlers mit der zur Regel erstarrten Tradition gedient. ${ }^{251}$ Hierzu passt der Bruch Bashōs mit der Danrin-Tradition (KoNISHI 1963), durch welchen er erst zu seinem eigenen Stil gefunden hatte. Die folgende Übersetzung versucht, die Zen-buddhistische wie auch die antitraditionalistische Richtung zu berücksichtigen.

\section{Erläuterung der Maßbefreitheit des Bashō-Stils}

[A] Zwischen den Haikai des Altmeisters und den Haikai der heutigen Menschen besteht nicht grundsätzlich ein Unterschied. Worin ein Unterschied besteht, das ist bei der Maßbefreitheit ${ }^{252}$ und beim wundersam Neuen. ${ }^{253}$ Die heutigen Menschen haben Maße, das wundersam Neue haben sie nicht. Der Altmeister hatte keine Maße, er hatte nur das wundersam Neue. Was die Maßbefreitheit betrifft, so ist es ein wenig schwer zu fassen, wie schwierig aber ist es doch, den Weg des wundersam Neuen zu erklären! Ach, das wundersam Neue ist ein Verstehen des Herzens und schwer in Gedanken zu fassen! Beim Haikai sollte man vergessen und nicht vergessen, und es kommt vor, dass der Kommentator an sich davon nichts weiß. ${ }^{254}$ Was er ursprünglich im Sinne hatte, kann aber, wer ein Meister

250 „Wenn die letztendliche Wahrheit bei Zhuangzi eine Nicht-Wahrheit ist und wir im Grunde gar nicht darüber sprechen können, so kann eine Methode oder ein Weg, zu dieser Nicht-Wahrheit zu gelangen, wohl ebenfalls nur ein Nicht-Weg oder eine Nicht-Methode ( $w u$ fa) sein. Aus dem Daodejing ist diese Nicht-Methode als „Nicht-Tun“ (wuwei) bekannt, womit ein nicht absichtvolles Eingreifen in den natürlichen Lauf der Dinge gemeint ist. So heißt es im Kapitel 48: ,Praktiziere das Nicht-Tun und es wird nichts geben, das ungetan bleibt' (wuwei er wu bu wei). Ein anderer Aspekt des gleichen Ansatzes ist der, die Dinge aus sich selbst heraus geschehen zu lassen, wobei sich diese Maxime ebenfalls auf einen zentralen Satz des Daodejing bezieht: ,Die Regel/Methode ( $f a$ ) des Dao ist: von selbst so sein' (dao fa ziran). Angewandt auf die Frage der Kunst bedeutet dies zunächst eine Sicht künstlerischen Schaffens analog zum spontanen Wirken der Natur.“ (PoHL 2007: 66).

251 PoHL 2007: 376-385 (Exkurs 3, „Die Regel der Nicht-Regel“ - Ästhetik der Malerei in der Qing-Zeit).

252 „Maßbefreitheit“ für mukaku 無格. Es ist nicht auszuschließen, dass mukaku hier auch die „Abwesenheit von Forschungs[drang]“ meint und dann dem auch von japanischen Neokonfuzianern propagierten Ideal, „in der Durchdringung der Dinge zu Wissen gelangen“ (kakubutsu chichi 格物致知), widersteht, also den Verzicht auf die analytische Durchdringung der Gegenstände der Poesie bezeichnet. Dies entspräche dem auch im Kegon-Buddhismus propagierten Ideal der Einheit von „Leere“ und „Fülle“ (Abschn. 4.3.2), im Grunde die Zen-buddhistisch motivierte Demontage der Grenze zwischen Subjekt und Objekt der Wahrnehmung.

253 „Wundersam Neues“ für kishin 奇新, die überraschende Wendung in einem Gedicht.

254 „Kommentator“ für chūshi 註師, in der Haikai-Dichtung häufiger in jener Rolle des Schiedsrichters, in welcher der Altmeister Bashō selbst im Inaka no kuawase auftritt (siehe Abschn. 3.4.2.4). Kyūan nimmt hier vorweg, was er in Teil [B] in einen kanbun-Text kleidet. 
ist, im entscheidenden Moment unmöglich vergessen. ${ }^{255}$ Deswegen sagte der Altmeister: „Was Haikai betrifft, so ist es unmöglich, ein altes Mütterchen vor der Haustüre darüber zu befragen, handelt es sich doch um Worte des Zen, also um Worte der Wahrheit, bei denen man nicht leicht sein Wissen vergisst und in Vulgarität verfällt.“ Damit ist es wie bei den üppig aufgewachsenen Bambuszweigen des Gartens. So wie es kurze gibt, gibt es hoch aufgewachsene und niedrig aufgewachsene, und darin liegt das Wahrhaftige. ${ }^{256}$ Der Alte von der Bambushütte ${ }^{257}$ ist von eleganter Feinheit, ${ }^{258}$ und sein Maß ist die Maßbefreitheit. Er hat also Maß, und doch wieder nicht. Schafft man es, Maßbefreitheit anzunehmen, so ist es das Maß des Seins aus sich selbst, ${ }^{259}$ und dies bedeutet wohl, dass Qualen wie heftige Abneigungen nicht vorkommen. ${ }^{260}$ Aus jenen weltabgewandten, ${ }^{261}$ tiefen Empfindungen, welche es in jedem Bande in wahrlich großer Zahl gibt, habe ich die besonders schönen in vier Bänden ausgewählt, und dass diejenigen, welche die Maßbefreitheit zum Ausdrucke bringen, darunter die hervorragendsten sind, dürfte wohl unvermeidlich sein. ${ }^{262}[\mathrm{~B}]$ Bei stimmhaften Bildern, bei stimmlosen Gedichten vergisst man das Wissen, man vergisst seine Ansichten, man vergisst seinen Verstand, man vergisst das Weiterreichen. ${ }^{263}$ Dieses Stadium der Achsenlosigkeit, dieses Wunder der Maßbefreitheit! Bei der Sammlung, an deren Zusammenstellung ich just arbeite, sitze ich alleine in meiner kleinen Kammer und trete schweigend in das Stadium der Erleuchtung ein. ${ }^{264}$ [Die Sammlung] ist dazu angetan, in der Stille den Anfang und das Ende der Dinge zu bedenken ${ }^{265}$ und sich daran zu bilden.

255 Anspielung auf das Diktum Jiji no shoshin wasuru bekarazu 時々の初心忘るべからず。 („Man soll nicht vergessen, was man zuerst im Sinne hatte“) des Zeami Motokiyo. Der locus classicus dieses Ausspruches ist das Kakyō 花鏡 (Mirror Held to the Flower, 1424) (NKBT 65: 437). Thomas Rimers Übersetzung lautet: „[The actor] must never forget the fresh experiences he went through as a young performer.“ (RIMER 1984: 107).

256 Die hier angesprochene Relativität des Maßes meint die Auflösung jedweder begrifflicher Dichotomie und das dadurch erreichte Wahrhaftige.

257 „Alter von der Bambushütte“ für Bashōan no ō 芭蕉庵の翁: eine auf den Dichter Matsuo Bashō 松尾芭蕉 (1644-1694) verweisende Synekdoche.

258 „Elegante Feinheit“ für füga 風雅.

259 „Sein aus sich selbst“ für shizen 自然.

260 Meint die entlastende emotionale Distanz des lyrischen Subjekts gegenüber dem Objekt.

261 „Weltabgewandt“ für in’itsu 隠逸.

262 Teil [B] ist im Original in kanbun verfasst.

263 „Weiterreichen“ für jun'okuri 順送, die weitere sprachliche Bearbeitung des lyrischen Objekts.

264 „Eintreten in die Erleuchtung“ für gonyū 悟入. Der aus dem Zen-Buddhismus entliehene Ausdruck stellt Bashōs Dichtung Meditationspraktiken der Zen-Schule gleich und entrückt damit Haikai-Dichtung deutlich der Sphäre gehobener Unterhaltung.

265 „Anfang und Ende der Dinge bedenken“ für tangei su 端倪. Im Zusammenhang mit der vorher gelobten Vergessenheit des Dichters klingt nun mit dieser Vokabel die folgende Passage aus dem Abschnitt Da zongshi 大宗師 (The Great and Venerable Teacher / Der wahre Mensch und der Sinn) des Zhuangzi an. Dort ist die Rede von der stoischen Gelassenheit des „wahren Menschen“ (zhenren 真人), der wie folgt beschrieben wird: 彼以生為附贅縣疮、以死 為決揭潰㿈。夫若然者、又惡知死生先後之所在。假於異物、託於同體、忘其肝膽、遺其耳目、 反覆終始、不知端兒。芒然彷彺乎塵垢之外、逍遙乎無為之業。(Zhuangzi zhu 莊子注 3: 14a-14b, 
Kyūan unterscheidet klar zwischen wissenschaftlicher und dichterischer Literatur: Wissenschaftliche Literatur gebe die Distanz gegenüber den Dingen preis und ergründe deren Prinzip, die dichterische Literatur des Bashō bewahre die Distanz zu Objekt und (!) Subjekt der Lyrik und hebe die logischen Grenzen zwischen ihnen auf. Die hier so hoch gepriesene Literatur Bashōs, welche nach Kyūan den Verstand des Lesers außer Kraft setzt, ist demnach nichts weniger als das ganze Gegenteil wissenschaftlicher Literatur und vermittelt gleichwohl Erkenntnisse, die hier satori (,Erleuchtung“) genannt werden. Demgegenüber habe die (von Kyūan nicht näher spezifizierte) Dichtung seiner Zeitgenossen zwar „Maß“ (kaku), sei aber überrational und nicht zur Überraschung fähig - was wiederum einer unwillkommenen Annäherung an die Wissenschaft gleichkommt.

Eine zweite Besonderheit des Shōfū mukaku ben ist das in den Begriffen „stimmhafte Bilder“ (yūsei no $e$ 有声之画) und „stimmlose Verse“ (musei no ku 無声之句) zutage tretende integrale, gewissermaßen intermediale Kunstverständnis, welches Bild und Ton umfasst und in seiner Abstraktheit auf Grundsatzfragen der Kunst verweist. In Abschnitt 4.3.1 werden wir mit dem Tansō shiwa (1856) des Hirose Tansō zwar ein ähnliches, aber eben doch anders gelagertes Beispiel kennenlernen: Dort werden Bildhaftes und Gedichthaftes ineinander verschränkt, aber es ist nicht auszumachen, dass es dort wie hier tatsächlich um die Rezitation eines gedichthaften Kunstwerks ginge.

Insgesamt stellt Kyūans Text eine bemerkenswerte theoretische Leistung dar: Kunst wird zum einen aus der Rolle der gehobenen oder allgemeinverständlichen moralischen Belehrung befreit, zum anderen der Wissenschaft gleichrangig zur Seite gestellt.

\subsubsection{Regenwolken und fiktionale Literatur sind Verdichtungen des kosmischen Äthers: Das Vorwort zu Band 54 (1864) des Shiranui monogatari (1849-1885)}

Von literaturhistorischem Interesse ist das Shiranui monogatari 白縫譚 ([Erzählungen vom weißen Eingarnen], 1849-1885) als bebilderte Abenteuererzählung des Genres gōkan weniger wegen des enormen Umfangs von 90 Bänden, als vielmehr weil sie über das Ende der Edo-Zeit hinaus in Fortsetzungen erschien

SKQS-Edition). „The True Man of ancient times knew nothing of loving life, knew nothing of hating death. He emerged without delight; he went back in without a fuss. He came briskly, he went briskly, and that was all. He didn't forget where he began; he didn't try to find out where he would end. He received something and took pleasure in it“ (WATSON 1968 [ca. 130 v. Chr.]: 78). 
und somit einen tiefen Einblick in die lange literaturhistorische Phase des Übergangs von der vormodernen zur frühmodernen Literatur ermöglicht. Von Anfang an vertraten die zahlreichen an der Produktion beteiligten Text- und Bildautoren die zum Stereotyp erstarrte defensive These, dass gesaku-Literatur ihren Wert in der moralischen Unterweisung der Ungebildeten habe und vor allem Kindern und Frauen, die wissenschaftliche Schriften geistig nicht verarbeiten könnten, einen Ersatz dafür biete. ${ }^{266}$

Am Vorabend der Meiji-Restauration verfasst Ryūtei Tanehiko II 柳亭種彦 (alias Ryūtei Senka 笠亭仙果 alias Takahashi Hiromichi 高橋広道, 1804-1868) das Vorwort zu Band 54 des Shiranui monogatari und nimmt darin eine im eigentlichen Sinne universale Perspektive ein.

\section{Shiranui monogatari, Vorwort zu Band $54(1864)^{267}$ von Ryūtei Tanehiko II}

[1] Was man die Welt nennt, was man die Zehntausend Dinge ${ }^{268}$ nennt, das ist ursprünglich Leere, ${ }^{269}$ hat nicht Farbe, hat nicht Geruch und gebiert in der Leere ${ }^{270}$ den Äther. ${ }^{271}$ [2] Der Äther hat anfangs keine Gestalt. ${ }^{272}$ [3] Verdichtet er sich aber und wird zu Dunst, so hat er schon eine Form. ${ }^{273}$ [4] Wenn dieser Dunst zu Wolken wird, lässt er Regen fallen, lässt auch den Drachen reiten. ${ }^{274}$ [5] Wird der Äther zu einem distinkten Gegenstand ${ }^{275}$ und fest, dann werden daraus Länder, ${ }^{276}$ werden daraus Menschen. [6] Allein der Schöpfergott der Verbindung und Beherrscher des Universums ${ }^{277}$ begreift dies. [7] Ein in Worten

266 Ryūkatei Tanekazu 柳下亭種員 (= Sakamotoya Kinshichi 坂本屋金七, 1807-1858), Autor der ersten 38 Bände, geht gleich zu Beginn des Unternehmens in die Defensive gegenüber Verächtern der unterhaltenden Erzählprosa: Es sei die Aufgabe guter Autoren, den Text durch ethisch-moralische Anleitungen so zu gestalten, dass die Ungebildeten durch Metaphern und haltlose Worte (gūgen mōgo 寓言妄語) keinen Schaden nehmen, etwa indem sie zur Hölle fahren müssen oder deren Nachkommen stumm geboren werden (RYŪKATEI-UTAGAWA-RYŪTEI 1849-I: 1a).

267 Vorlage der Übersetzung: Faksimile des Originals (RYŨTEI-UTAGAWA 1863).

268 „Zehntausend Dinge“ für banbutsu 万物: die Gesamtheit der Einzelerscheinungen der Erscheinungswelt.

269 „Leere“ für kūjaku 空寂, im Buddhismus die vollkommene Leere, in der es weder formhafte noch formlose Gegenstände gibt.

270 „Leere“ für $k \bar{u}$ 空.

271 „Äther“ für $k i$ 気 (chin. qi).

272 „Gestalt“ für katachi 象.

273 „Form“ für katachi 形.

274 „Einen Drachen mit sich führen“ für tatsu wo nosu 竜を騎す, worin nach dem Volksglauben der Drache jenes Fabelwesen ist, das die Wolkenbildung und den Regen hervorruft.

275 „Distinkter Gegenstand“ für kuwashiki mono 精しき物.

276 „Länder“ für kuni 国.

277 „Gott der Verbindung“ für sumubi [sic!] no kami 造化真宰, worin sumubi ein auf Silbenvertauschung beruhender Schreibfehler ist. Die korrigierte Version musubi no kami 造化真宰 ist eine Verbindung aus musubi no kami [結びの神, „Gott der ehelichen Verbindung“] und [zōka shinsai] 造化真宰 („Schöpfergottheit und Beherrscher des Alls“). 
nicht zu beschreibendes, geheimnisvolles Wunder, ${ }^{278}$ etwas Unermessliches und Undenkbares! ${ }^{279}[8]$ Nimmt er das Nichts und verwandelt es in ein Sein, ${ }^{280}$ so wird aus der unwahren Leere ${ }^{281}$ des Anfangs am Ende die Fülle der Wahrheit. ${ }^{282}$ [9] Wenn aus haltlosen, unwahren Worten ${ }^{283}$ nicht die Wahrheit ${ }^{284}$ hervorginge, könnte man eine Sache nicht zu Ende führen, sagte auch Herr Yura. ${ }^{285}$ [10] Geschichtchen und historisierende Erzählungen ${ }^{286}$ sind alle provisorische Unwahrheiten. ${ }^{287}$ [11] Es gibt auch Menschen, die es

278 „Geheimnisvolles Wunder“ für genmyō 玄妙.

279 „Unermessliches und Undenkbares“ für fushigi 不測, eine Verbindung aus fushigi [不思 議, „Undenkbares“] und [fusoku] 不測 (“Unermessliches,).

280 „Nichts“ für $m u$ 無, „Sein“ für $y \bar{u}$ 有.

281 „Unwahre Leere“ für uso 虚, eine Verbindung aus uso [嘘, „Lüge“] und [kyo] 虚 (,Leere“). Das Wort uso nuanciert Tanehiko im Folgenden durch die Beigabe inhaltlich vom einfachen Begriff der Lüge abweichender chinesischer Zeichen (Anm. 284, 288, 290 und 298).

282 „Fülle der Wahrheit“ für makoto 実, eine Verbindung von makoto [真, „Wahrheit“] und [jitsu] 実 („Fülle“).

283 „Haltlose, unwahre Worte“ für uso 妄語, eine Verbindung aus uso [嘘, „Lüge“] und [mōgo] 妄語 (,haltlose Worte“).

284 „Wahrheit“ für makoto 真諦, eine Verbindung aus dem umgangssprachlichen makoto [真, „Wahrheit“] und dem schriftsprachlichen (buddhistischen) [shintai] 真諦 („Wahrheit“).

285 Original: Uso kara deta makoto de nakereba ne ga togenu to Yura san mo ieri. 妄語から出 た真諦でなければ根が遂ぬと由良さんも云へり。(RYŪKATEI-UTAGAWA 1863: 1a). Wörtliches Zitat aus Akt 7 des Jōruri-Stücks Kanadehon Chūshingura 仮名手本忠臣蔵 (Chūshingura: The Treasury of Loyal Retainers; 1748) von Takeda Izumo II 竹田出雲 (1691-1756). Das Chūshingura verarbeitet die historische Geschichte der 47 treuen Samurai von Akō, welche für die tödliche Beleidigung ihres Fürsten Rache nehmen. Ihr Anführer ist Ōboshi Yuranosuke, der in Akt 7 die junge Frau Okaru zu sich lockt, ein erotisch-obszönes Gespräch mit ihr beginnt und ihr schließlich einen Heiratsantrag macht. Okaru hält Yuranosuke vor, sein Antrag sei gelogen (uso), worauf dieser antwortet: Uso kara deta makoto de nakereba ne ga togenu. 嘘から出た真 でなければ根がとげぬ。(NKBT 51: 345). „The truth may have started as a lie, but if I didn’t really mean it, I couldn’t go through with it“ (TAKEDA-KEENE 1971 [1748]: 117). Yura verspricht ihr daraufhin, sie aus dem Bordell freizukaufen. Tanehiko assoziiert hier Yuras Heiratsantrag mit seinem Versuch, den Leser anzulocken und an sich zu binden.

286 „Geschichtchen“ für shōsetsu 小説, ursprünglich pejorativer Ausdruck für fiktionale Prosa, der erst in der Meiji-Zeit zu einer wertneutralen Bezeichnung für „Romane“ wurde. „Historisierende Erzählungen“ für haishi 稗史, womit hauptsächlich moralisierende Abenteuerromane vor historischer Kulisse des Genres yomihon gemeint sind. Beide Bezeichnungen ordnen fiktionale Prosa unter Texten niedrigen sozialen Prestiges ein, haishi steht dabei allerdings über den „Geschichtchen“.

287 „Provisorische Unwahrheiten“ für uso 仮設, eine Verbindung von uso [嘘, „Lüge“] und [kasetsu] 仮設 („Provisorium“). 
für glaubwürdige Wahrheit nehmen, ${ }^{288}$ wenn man vorspiegelnde Worte ${ }^{289}$ mit großer Geste vor ihnen ausspuckt, und was die Unterweisungen Buddhas angeht, so lässt er darin gar Monstergestalten vor den Augen erscheinen, ${ }^{290}$ doch die Unwahrheiten aus losem Mundwerke, welche wir Einfältigen zum Spaße verfassen, ${ }^{291}$ [sind wie] die Neujahrsgrußworte, welche sogleich abblättern. [12] Schreibe ich „Wie glücksverheißend, wie glücksverheißend!“292 und komme damit zum Ende, so strecke ich allemal den Pferdefuß vor; ${ }^{293}$ die Dinge passen hinten und vorne nicht zusammen, und was die Vielzahl der Dinge betrifft, welche unterwegs verpuffen, so sind sie der Unausgereiftheit und Ärmlichkeit bei der Verdichtung des Äthers ${ }^{294}$ [geschuldet]; so setzte ich allen Äther und alle Wurzeln ein, ${ }^{295}$ und das Shiranui [umfasst nun] in seiner Gesamtheit sechsundfünfzig Bände. ${ }^{296}$ [13] Nun, da es sich so lange hingezogen hat, finde ich es für mich selbst interessant, wie viel Wurzelloses und Unwahres ${ }^{297}$ man doch fabrizieren kann, doch was soll ich damit anfangen, wenn die ehrenwerte Leserschaft das nicht interessant findet?

Im Sommer des vierten Jahres [1864]

Ryūtei Tanehiko 298

Die Sätze [1] bis [5] sind deutlich erkennbar an das Weltbild des chinesischen Neokonfuzianers Zhu Xi angelehnt - angesichts der im Haupttext entfalteten,

288 „Glaubwürdige Wahrheit“ für makoto 信, eine Verbindung von makoto [真, „Wahrheit“] und [shin] 信 („Vertrauen“).

289 „Vorspiegelnde Worte“ für uso 寓言, eine Verbindung von uso [嘘, „Lüge“] und [gūgen] 寓言 („Metapher“). Gūgen 寓言 wird schon im Zhuangzi als legitimes Mittel der Wahrheitsvermittlung gekennzeichnet (Anm. 153).

290 Anspielung auf das Sprichwort Uso mo hōben, das Buddhas metaphorische Redeweise in Predigten als Argument für fiktionale Literatur verwendet.

291 „Zum Spaße verfassen“ für gesaku 戯作, gleichzeitig die schon erwähnte captatio benevolentiae der Autoren von Unterhaltungsprosa und die gängige Bezeichnung des Genres „Unterhaltungsprosa“.

292 „Wie glücksverheißend“ für medetashi, eine in der gesaku-Literatur häufig verwendete Formel zur Abrundung des happy end einer Erzählung.

293 „Den Pferdefuß vorstrecken“ für o wo dasu 尾を出す („Schwanz hinausstrecken“), bildlich für „Schwachstellen offenbaren“.

294 Rückbezug auf die eingangs (Sätze [1] bis [3]) eingeführte Herleitung der Entstehung der Erscheinungswelt, deren Teil in der Logik der Argumentation auch der fiktionale Text wird.

295 „Allen Äther und alle Wurzeln aufbieten“ für kikon wo tsukusu 気根を罄す. Mit dem umgangssprachlich im Sinne von „alle Kräfte“ gebrauchten Ausdruck $k i$ 気 greift Tanehiko II hier die oben eingeführte Bezeichnung der kosmischen Urkraft auf. Durch deren Assoziation mit Tanehikos II Werk wird das Shiranui monogatari neben Dingen wie Regenwolken Teil der Erscheinungswelt in ihrer Gesamtheit. Gleichzeitig weist Tanehiko II damit indirekt die Verantwortung für die Unvollkommenheit des (von der Urkraft zumindest mitgestalteten) Textes von sich.

296 Gemeint ist hier die bis zu Band 56 gehende Planung.

297 „Wurzelloses und Unwahres“ für uso 無根, eine Verbindung von uso [嘘, „Lüge“] und [mukon] 無根 („Wurzelloses“).

298 Ryūtei Senka unterzeichnet hier mit dem „ererbten“ Namen „Tanehiko“, um sich das Prestige seines „Erblasser“ zueigen zu machen. 
episodalen und stereotypen, äußerst schlichten Narration eine verdächtig anspruchsvolle intellektuelle Steilvorlage. Die Sätze [9] bis [11] bieten denn auch nicht mehr als ein argumentatives Stereotyp und keine Differenzierung des literaturtheoretischen Systems.

Insbesondere die Zuordnung der fiktionalen Prosa zur Welt der „leeren“, Ursprungsenergie $k i$ 気 (chin. $q i$, „Äther“) mag man als Versuch sehen, sich unter den schützenden Schirm des (sich wiederum deutlich an die daoistische Philosophie des Zhuangzi anlehndenden) Neokonfuzianismus zu begeben. Damit unterscheidet sich der fiktionale Text prinzipiell nur durch den Aggregatzustand von Naturerscheinungen wie Regenwolken - ein brillianter Schachzug des Autors! Man kann allerdings nur spekulieren, inwieweit diese philosophische Tiefgründigkeit bei Tanehikos Lesern ankam, und selbstverständlich ist es für uns dabei unerheblich, ob Tanehiko II in der Tradition der gesaku-Autoren mit der Vieldeutigkeit des philosophischen Grundbegriffs ki nur spielt - das Ergebnis ist jedenfalls die Einbindung der Unterhaltungsprosa in ein universales Weltbild und wird damit zu einer Vorausdeutung auf einen Text des Jahres 1878 von Nakamura Keiu (siehe Abschn. 4.1.7).

Jedenfalls ist als Besonderheit des Texts festzuhalten, dass Tanehiko die auf den gesellschaftlichen Nutzen zulaufende Rechtfertigung seiner Fiktion („Leere“) um den Verweis auf eine metaphysische und nicht direkt utilitaristische „Wirklichkeit“ („Fülle“) erweitert - eine beinahe geräuschlose Rückwendung von der neuen „Religion“ des Kapitalismus zur alten „Religion“ des Konfuzianismus.

\subsubsection{Im Flunkern ist Wahrheit: Das Seiyō dōchū hizakurige (1870-1876) des Kanagaki Robun}

Kanagaki Robun ist uns schon aus Abschnitt 4.1.2 als literarischer Wanderer zwischen zwei Welten bekannt. Der 1861 für ihn absehbare große politische und ökonomische Wandel Japans war neun Jahre später weit vorangeschritten ganz im Gegensatz zu Kanagakis Anpassung seiner literarischen Produktion daran. Denn Kanagaki versuchte, Stil und Inhalt seiner Werke in traditioneller Weise beizubehalten und in dieser Form den neuen Herrschenden anzudienen. Das Bankoku kōkai Seiyō dōchū hizakurige 万国航海西洋道中膝栗毛 ([Eine Seefahrt zu den Zehntausend Ländern - Auf Schusters Rappen durch die westlichen Länder, 1870-1876) ist eine gezielt und explizit an die Tradition der Edo-zeitlichen kokkeibon (,Ulkbücher“) anknüpfende Fortsetzung des Tōkaidō chū hizakurige 東海道中膝栗毛 (Auf Schusters Rappen unterwegs auf der Ostmeerstraße, 1802-1831) von Jippensha Ikku 十返舎一九 (1765-1831), in welcher die Protagonisten Yaji und Kita bei ihrer Reise durch Japan allerlei Abenteuer und lustige 
Pannen erlebt hatten. Kanagaki wollte an Ikkus durch landeskundlich ergiebige Slapstick-Komik erzielten kommerziellen Erfolg anknüpfen, indem er als Protagonisten die Enkel von Yaji und Kita durch westliche Länder reisen ließ. Sprache und Komik waren diejenigen Ikkus, neu einzig die Orte der Handlung, mit deren Wahl Robun dem aktuellen Bedürfnis ungebildeter Leser nach Informationen über das westliche Ausland zu entsprechen hoffte. ${ }^{299}$

Mitten in die laufende Veröffentlichung des Seiyō dōchū hizakurige hinein erließ 1872 das neu geschaffene „Lehrministerium“ (Kyōbu shō 教部省) die „Drei Paragrafen zur Regelung der Unterweisung“(Sanjō no kyōsoku 三条の教則, auch Sanjō no kyōken 三条の教憲), das als wichtigste Ziele der Erziehung Götterfurcht und Vaterlandsliebe, Erkenntnis von Himmelsgesetz und Menschenweg sowie Ehrerbietigkeit und Gehorsam gegenüber dem Kaiser formulierte. ${ }^{300}$ Kanagaki Robun und Jōno Saigiku 条野採菊 (1832-1902) als mutmaßlich letzte Vertreter der Edo-zeitlichen gesaku-Autoren erklärten sogleich in einer Eingabe, bei der Umsetzung behilflich sein zu wollen. ${ }^{301}$ Ziel dieser Unterwerfungsgeste war die Rettung der eigenen Einkommensquelle. Es wundert zwar vor diesem Hintergrund nicht, dass auch die im Folgenden auszugsweise übersetzten Vorworte zu den Bänden 1 und 3 keinen Beitrag zu einer Modernisierung der Literaturtheorie enthalten - deren Behandlung der Dichotomie „Fiktion - Wirklichkeit“ ist allerdings bemerkenswert.

„Im Flunkern ist Wahrheit“. Die Vorworte zu den Bänden 1 und 3 des Seiyō dōchū hizakurige (1870-1876)

Das Vorwort zu Band 1 des Seiyō dōchū hizakurige gibt, ganz in der Tradition der Edo-zeitlichen kokkeibon, nicht nur einen Ausblick auf die zu erwartenden Referentia, sondern durch bildliche Sprache und komplexe Doppelschreibungen auch eine Probe des im Haupttext gepflegten Stils. Besonderes Augenmerk verdient im Kontext dieser Abhandlung Robuns Umgang mit den Begriffen „Fiktion“

299 Robun wurde zu einem derjenigen gesaku-Autoren der späten Edo-Zeit, welche ihre Begabung zur Vermittlung des Nützlichen in unterhaltsamer Form nutzten, um in populären Zeitungen der frühen Meiji-Zeit (koshinbun 小新聞, „Zeitung [für die] kleinen [Leute]“) als Journalisten beruflich Fuß zu fassen (О̄мото 2012: 99-103).

300 Originaltext in OKITSU 1960: 22.

301 Für eine Zusammenfassung der „Drei Paragrafen“ und der schriftlichen Unterwerfungserklärung von Robun und Jōno siehe SCHAMONi 1975: 17-19. Eine Einleitung und eine englische Übersetzung bietet TsUNODA-DE BARY-KEENE 1958-II: 139-140. Eine kritische Auseinandersetzung mit der bisherigen Forschungsliteratur zu diesem literaturgeschichtlichen Ereignis bietet MIKAWA 2012-2013. 
(uso 忘語 [,,vergessene Worte“], wohl eine Falschschreibung für uso 妄語 [,haltlose Worte“]) und „Wirklichkeit“ (makoto 正説 [„Korrekte Darlegungen“]). ${ }^{302}$

\section{Auf Schusters Rappen unterwegs in den Ländern des Westens - Vorwort zum ersten Band}

[1] Vergleicht man den Stil des Romanschreibers ${ }^{303}$ mit einem Dampfschiff, ${ }^{304}$ so ist das ausgestaltete Manuskript ${ }^{305}$ der Mast, die große Ähnlichkeit ${ }^{306}$ das Feuerrohr, ${ }^{307}$ [2] Bildarrangements geben der Turbine Schmieröl und bringen sie so zum Laufen, ${ }^{308}$ Pinsel bilden die beiden Antriebsräder, ${ }^{309}$ jene unwahren und haltlosen Worte ${ }^{310}$ gleichen dem Kohlenqualm, aufrichtige und korrekte Darlegungen ${ }^{311}$ sind darin miteinander vermischt und gegeneinander ausgetauscht; ${ }^{312}$ [3] Ich trachtete, meine Landungsboote wo immer

302 Vorlage der folgenden Übersetzung sind die beiden ersten Seiten des Vorwortes von Band 1 des über KSDB erreichbaren digitalen Faksimiles. Der moderne Typendruck KanAGAKI-IWASHIRO 1884 ist wegen zahlreicher Umsetzungsfehler unbrauchbar.

303 „Romanschreiber“ für sakusha 稗官者, eine Verbindung des allgemeinsprachlichen sakusha [作者, „Verfasser“] mit dem hochsprachlichen [haikansha 稗官者, „Historienschreiber“], hier als Bezeichnung für den Verfasser von auf historischen Fakten beruhender fiktionaler Prosa. Im Folgenden werden diese Doppelschreibungen nach Möglichkeit vollständig übersetzt.

304 Dampfschiffe waren zur Schreibgegenwart (1870), 17 Jahre nach dem Auftauchen der Dampfschiff-Armada des Commodore Perry in der Bucht von Uraga, der Inbegriff moderner Technologie und damit in der Wahrnehmung der Japaner einer der Motoren des gesellschaftlichen Fortschritts. Durch den im Folgenden detaillierten Vergleich will Kanagaki auch die Autoren von Unterhaltungsliteratur zu einem Motor des gesellschaftlichen Fortschritts stilisieren. 305 „Ausgestaltetes Manuskript“ für shikumi no tanebon 脚色の原稿, eine Verbindung aus shikumi [仕組み, „Mechanismus“] und [kyakushoku] 脚色 („motivische Gestaltung“) sowie aus den Synonymen tanebon [種本] und [genkō] 原稿 (,Quellenschrift“).

306 „Große Ähnlichkeit“ für sate mo nitari 彷彿, eine Verbindung aus sate mo nitari [さても 似たり] („Na, so was von ähnlich!“) und [hōfutsu] 彷彿 („Ähnlichkeit“), umgangs- und schriftsprachlicher Verweis auf die Übereinstimmung der literarischen Fiktion mit der außerliterarischen Realität.

307 „Mast“ für hobashira 檣, „Feuerrohr“ für hizutsu 火箭 im Sinne von „Schornstein“.

308 „Bildarrangement“ für ekumi 絵組: Kontextualisierung von Bild und Text. Die „Turbine“ ( $k i k a i$ 器械) steht hier bildlich für die kommerziell verwertbare Nachfrage durch die Leser.

309 „Die beiden Antriebsräder“ für kuruma no ryōrin 車の両輪: hier bildlich für die Fortbewegung des Textes durch fremde Meere und Länder. „Pinsel“ (fude): hier bildlich für „Text“ und „Stil““. 310 „Unwahre und haltlose Worte“ für uso 忘語 [mōgo], eine Verbindung aus uso [嘘]

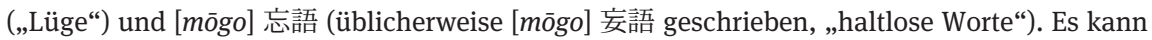
sich aus textlogischen Gründen bei der vorliegenden Schreibung [mōgo] 忘語 (,vergessene Worte“) nur um eine auf dem Gleichlaut mō beruhende Lehensschreibung oder einen Fehler handeln.

311 „Aufrichtige und korrekte Darlegungen“ für makoto 正説, eine Verbindung aus makoto [真] („Aufrichtigkeit“) und [seisetsu] 正説 („,korrekte Darlegungen“).

312 „Miteinander vermischt und gegeneinander ausgetauscht“ für torimazete 換骨奪体, eine Verbindung aus torimazete [取り混ぜて, „miteinander vermischt“] und [kankokutsu dattai] 換 骨奪体 (,die Knochen ausgetauscht, der Gestalt beraubt“). Das in dieser Doppelschreibung 
möglich einzusetzen ${ }^{313}$ die Bedürfnisse der Leser zu ermessen, Applaus versprechende Pointen $^{314}$ aus dem tausende Meilen entfernten Ausland aufzugreifen und so Zehntausende Meilen währenden Ruhm zu erlangen.

Hiernach geht Robun auf uns hier nicht weiter interessierende inhaltliche Details seines Textes ein. Der erste Blick fällt auf die geschickte Verbindung von Grundinformationen zu ausländischem Schiffsbau und Unterhaltsamkeit. Freilich ist für uns wichtiger, dass Robun hier auch ein Meisterstück defensiver Literaturtheorie gelungen ist: Seine an sich stereotype Rechtfertigung fiktionaler, unterhaltender Prosa als Mittel der Belehrung des mit wissenschaftlicher Literatur vermeintlich überforderten einfachen Volkes bedient sich modernster Bilder und zieht überdies in Teil [2] des komplexen Satzgefüges die kategorische Trennung von Fiktion und Wirklichkeit durch die Behauptung ihrer Vermischung grundsätzlich in Zweifel. Oder anders gesagt: Die Wirklichkeitsnähe liegt in der angeblich belehrenden Wirkung des Textes, nicht in dessen Bezug zur außerliterarischen Wirklichkeit. Kanagaki meint also mit Wirklichkeit die instrumentalisierbare, fruchtbringende (jitsu) Wirkmacht seines Textes. ${ }^{315}$

Zentraler noch als das soeben besprochene Vorwort zu Band 1 des Seiyō dōchū hizakurige ist für Robun die Frage des Verhältnisses zwischen Fiktion und Wirklichkeit im Vorwort zu Band 3 (1875). ${ }^{316}$ Das hängt auch damit zusammen, dass in der Zwischenzeit viel beachtete Veröffentlichungen wie Gakumon no susume 学問ノススメ (Fukuzawa Yukichi's An Encouragement of Learning, 1872-1876) von Fukuzawa Yukichi die Abwertung fiktionaler Prosa und die Aufwertung „fruchtbringender Gelehrsamkeiten“ (jitsugaku 実学) forciert hatten und der daraus entstandene zensorische und soziale Druck die Autoren fiktionaler Prosa immer mehr in die Defensive drängte. Der gesaku-Autor mag sich aber zu seiner im Folgenden präsentierten Argumentation auch durch den im April 1871 erschienenen Erlass zum Zeitungswesen ermutigt gefühlt haben. Denn dort werden amtlicherseits zwar die Vermittlung faktenbasierten Wissens, andererseits aber ein nicht allzu trocken-realistischer und somit den durch-

konstruierte Bild verweist gleichzeitig auf die diffuse begriffliche Abgrenzung zwischen Fiktion und Wirklichkeit wie auch auf die vollkommene Umkehrung der Begriffsinhalte.

313 „Landungsboote“ für battēra バッテーラ (< portug. bateira), hier bildlich für die Mittel der ersten Erkundung des Auslandes durch die verwendeten Berichte über die Verhältnisse in Übersee. 314 „Applaus versprechende Pointen“ für ochi 喝采, eine Verbindung von ochi [落ち, „Pointe“] und [kassai] 喝采 (,Applaus“).

315 Diese These basiert auf Mikawa Tomohisas Darlegungen zum für Robun und Saigiku anzunehmenden Realitätsbegriff (MiKAWA 2012: 130-131).

316 Vorlage der folgenden Übersetzung sind die Seiten 3a-6a von Band 3 des über KSDB erreichbaren digitalen Faksimiles. 
schnittlichen Leser nicht ermüdender, an den traditionellen Abenteuerromanen orientierter Stil verlangt. ${ }^{317}$ Robun bedient sich dieser amtlichen Schützenhilfe auch außerhalb der Zeitung, wie das im Folgenden übersetzte Vorwort zu Band 3 (S. 1a-6a) des Seiyō dōchū hizakurige zeigt.

\section{Auf Schusters Rappen unterwegs in den Ländern des Westens - Vorwort zum dritten Band}

[1] Bei Autoren von Unterhaltungsliteratur ${ }^{318}$ und bei Freudenmädchen ${ }^{319}$ ist das Unwahre die Wahrheit, ${ }^{320}$ das Ernsthafte sind die haltlosen Worte. ${ }^{321}$ [2] In sittenlosen und unbeständigen ${ }^{322}$ Geschichtsheftchen ${ }^{323}$ sind unverständliche, aus zweiter Hand den offi-

317 Die vom Beamten dajōkan daishi 太政官大史 an die Präfektur Kyōto überstellte Mitteilung Shinbunshi zasshi hakkō ni kansuru jōreigaki wo mōketaru mune 新聞紙雑誌発行二関する条例 書ヨ設ケタル旨 ([Hauptpunkte, weswegen bezüglich der Herausgabe von Zeitungen und Zeitschriften Vorschriften eingerichtet wurden]) lautet an der einschlägigen Stelle: Mata ichibu no haikan shōsetsu wo tsukuru to minasu beshi. Shikarazareba hōsei kajitsu ni sugite rikō no jiboku ni teki shigatashi, shinbunshi wo sensuru wa tsutomete dokusha wo shite umazarashimen koto wo $y \bar{o} \mathrm{su}$. 亦一部ノ稗官小説 $习$ 作ルト見做スヘシ然ラサレハ方正仮実ニ過キテ里巷ノ耳目二適シ 難シ、新聞紙ヨ選スルハ務メテ読者ヨシテ倦マサラシメンコトヨ要ス。 (Zitiert nach MikAWA 2013b: 131). „Auch sollte man [den Stil] so halten, als schriebe man einen historisierenden Roman. Hält man ihn nicht so, gehen Aufrichtigkeit und Wirklichkeitsnähe zu weit, so dass es den Ohren und Augen [des Mannes] auf dem Dorf und auf der Straße nicht angemessen ist. Wenn man eine Zeitung zusammenstellt, so erfordert es ein Bemühen darum, den Leser nicht in den Überdruss zu treiben.“.

318 „Unterhaltungsliteratur“ für gesaku 戯作 („Zum Spaße Geschriebenes“), ein ursprünglich von Autorenseite entschuldigend eingesetzter Ausdruck insbesondere für fiktionale Prosa in Abgrenzung zur wissenschaftlichen Literatur.

319 „Freudenmädchen“ für keisei 娼妓, eine Verbindung der schriftsprachlichen Ausdrücke keisei [傾城, „Frau, welche Burgen zum Einsturz bringen kann“] und [shōgi] 娼妓 („Freudenmädchen“).

320 „Unwahres“ für uso 虚誕, eine Verbindung des umgangssprachlichen uso [嘘, „Unwahrheit“] mit dem schriftsprachlichen [kyotan] 虚誕 („Inhaltsleeres und Lügen“). Robun grenzt uso später gegen itsuwari 虚誕 (,,boshafte Lüge“) ab. Beiden steht dann „Wahrheit“ (makoto 誠実 [seijitsu, „Ehrlichkeit“]) gegenüber. Uso, makoto und insbesondere itsuwari sind mit starken moralischen Implikationen aufgeladen.

321 „Ernsthaftes“ für makoto 真面目 [majime, „Ernsthaftigkeit“]. „Haltlose Worte“ steht für uso 妄語 [mōgo]. Durch diese Schreibung ergibt sich eine Nuancenverschiebung: Der Verfasser von Unterhaltungsliteratur wird nicht moralisch gegeißelt, seine Texte werden lediglich als sich nicht an die Realität haltend und darum „haltlos“ gekennzeichnet.

322 „Unmoralisch und unbeständig“ für hakanashi 不倫, eine Verbindung des umgangssprachlichen hakanashi (,nicht von Dauer sein“) mit dem schriftsprachlichen [furin] 不倫 (,Sittenlosigkeit“). Es handelt sich weniger um eine Verbindung von Synonymen als vielmehr um eine Gegenüberstellung einander nivellierender Begrifflichkeiten.

323 „Geschichtsheftchen“ für sōshi 草史, eine Verbindung von sōshi 草紙 („Heftchen“) und shi 史 („Historie“), wobei letzteres auf historische Fakten als szenischen Hintergrund der meist haishi 稗史 („historisierende Romane“) genannten Unterhaltungsliteratur verweist. 
ziellen Historien ${ }^{324}$ entnommene chinesische Wörter wie eine Stimmenimitation, dasselbe wie das Nachplappern nicht entschlüsselbarer Gedichte der Tang, ${ }^{325}$ die jenes Freudenmädchen ${ }^{326}$ in großem, aufrichtigem Ernst ${ }^{327}$ ihrem Freier ${ }^{328}$ bietet: Weil das nicht interessant ist, kommt man nicht in Stimmung. [3] Als neulich Menschen, welche schon nicht mehr waren, zu neuem Leben erwachten, erhielt ich unerwarteterweise Neuigkeiten ${ }^{329}$ aus der Hölle und bin in der neu erstarkten Unterhaltungsliteratur zu Bekanntheit gekommen. [4] Damals, als die großen Meister Kyōden, Bakin, Sanba und Ikku ${ }^{330}$ sich dem Schattenreich ${ }^{331}$ zuwandten, ${ }^{332}$ gab es weit zurückliegende Beispiele für die Sünde des Verfassens haltloser Worte im Shuihu zhuan und im Genji, ${ }^{333}$ so dass sie ohne Umschweife

324 „Offizielle Historie“ für seishi 正史, hier im Sinne von im staatlichen Auftrag erstellte, wissenschaftlich intendierte Historiografien im Gegensatz zu den zuvor erwähnten „Geschichtsheftchen“ (Anm. 324).

325 „Gedichte der Tang“ für Tōshi 唐詩, eine strengen prosodischen und semantischen Regeln unterworfene Gattung der chinesischen Poesie, hier Synekdoche mit dem Signifikat „schwieriger Text“.

326 „Freudenmädchen“ für oiran 娼婦, eine Verbindung des umgangssprachlichen oiran („Freudenmädchen“) mit dem schriftsprachlichen Synonym [shōfu] 娼婦.

327 „Großer, aufrichtiger Ernst“ für majime 篤実, eine Verbindung von majime [真面目, Ernsthaftigkeit“] und dem schriftsprachlichen [tokujitsu] 篤実 („Aufrichtigkeit“).

328 „Freier“ für kyaku 遊郎, eine Verbindung von kyaku [客, „Gast“] und [yūrō] 遊郎 („Gespiele“).

329 „Neuigkeiten“ wörtlich für shinbun 新聞, zur Schreibgegenwart bereits die Bezeichnung für das neue Medium Zeitung. Kanagaki reüssiert in diesem Medium mit seinen unterhaltenden Aufbereitungen von Kriminalfällen und Skandalen, welche die Massenleserschaft mit „kleiner“ Bildung in den „kleinen Zeitungen“ (koshinbun 小新聞) mit unterhaltend-leichter Sprache anspricht.

330 Allesamt führende Autoren der unterhaltenden Prosa der mittleren und späten Edo-Zeit, Santō Kyōden (1761-1816) bei den sharebon („Bücher der feinen Lebensart“), deren Handlungen und Dialoge um die Kultivierung der Sitten in den Bordellvierteln kreisten, Kyokutei Bakin (1767-1848) bei den yomihon („Büchern zum Lesen“), deren meist vor einer entfernten historischen Kulisse und in fantastischen und teilweise surrealen Plots agierenden Protagonisten Allegorien des Bösen und des Guten im konfuzianischen Sinne waren, Shikitei Sanba (1776-1822) bei den kokkeibon („Ulkbüchern“), welche das Leben des gemeinen Volkes in karikierender und von Sprachwitz geprägter Weise aufs Korn nahmen. Jippensha Ikku (1765-1831) war ein weiterer führender Autor von kokkeibon.

331 „Schattenreich“ für kōsen 黄泉 („Quelle der Erdfarbe“), Synekdoche zur Bezeichnung der Unterwelt im Sinne von Totenreich.

332 „Sich zuwenden“ für omomuki 覇旅, eine Verbindung des umgangssprachlichen omomuki [趣, „sich einer Richtung zuwenden“] und des schriftsprachlichen Synonyms [haryo] 覇旅.

333 Shuihu zhuan 水滸伝 (12. Jh.), chinesischer Räuberroman (bekannt in Franz Kuhns deutscher Übersetzung Die Räuber vom Liang-shan-Moor, 1934), größtenteils fiktionale, reißerische Episoden um die Abenteuer einer Art chinesischer Robin-Hood-Bande. Das Shuihu zhuan ist hier Prototyp der Abenteuerromane der Edo-Zeit: seine Stoffe und Motive wurden in nahezu allen literarischen Genres der Edo-Zeit verarbeitet, besonders kunstvoll in den erwähnten yomihon des Kyokutei Bakin (s. Anm. 331). Das Genji monogatari der Murasaki Shikibu (ca. 1010) entfaltet vor der historischen Kulisse des Kaiserhofs die fiktionalen Liebesabenteuer des Pro- 
in den Bereich der Asuras ${ }^{334}$ hinabgestoßen wurden. [5] Auf krummen und geraden Wegen $^{335}$ ergab es sich, dass deren Strafe am Gerichtshofe des Enma ${ }^{336}$ darauf festgelegt wurde, in den drei nächsten Wiedergeburten als Stumme zur Welt zu kommen - ein von einem einzigen Höllenbeamten gefälltes schwerwiegendes Urteil. [6] Doch wenn man das Wort „zum Spaße geschrieben“ aufteilt, so stellt sich heraus, dass es aus „leerer Spaß“ und „Hellebarde“ zusammengesetzt ist. ${ }^{337}$ [7] Da also schon auf dem Werbeschild ${ }^{338}$ steht, dass es sich um Unwahres ohne Lüge, um einen anderen Ausdruck für die Wahrheit, ${ }^{339}$ eine Predigt im Gewande der Unwahrheit ${ }^{340}$ handelt, bei der man aus der näheren Umgebung etwas

tagonisten Hikaru Genji. Der frommen Legende nach musste die Verfasserin, die Hofdame Murasaki Shikibu, für das Aneinanderreihen „verrückter Sprache und ausgeschmückter Worte“ (kyōgen kigo 狂言綺語) sowie „haltloser Geschichten“ (mōgo 妄語) in der Hölle büßen. Diese Legende wird in setsuwa shū 説話集 (Sammlung sagenhafter Erzählungen mit buddhistischem Hintergrund) immer wieder kolportiert, so etwa im Hōbutsu shū 宝物集 (1179) des Taira no Yasuyori 平康頼 (1146-1220) und im Ima monogatari 今物語 (1239-40) des Fujiwara no Nobuzane 藤原信実 (1176-nach 1266). Schon vor diesen Texten kam der Brauch auf, Fürbittgebete zu sprechen, welche Murasaki und ihre vermeintlich ebenfalls in der Hölle büßenden Leser (!) aus den verdienten Höllenqualen zu erlösen. Der bekannteste hierzu geschaffene Text trägt den Titel Genji ippon kyō hyōbaku 源氏一品経表白 (1168, verfasst vom Tendai-Mönch Chōken 澄憲). Auf die Tradition der Genji kuyō 源氏供養 (,Fürbittzeremonie für das Genji [monogatari]“) wird im Laufe der Literaturgeschichte immer wieder Bezug genommen, unter anderem im Nō-Theaterstück Genji kuyō von Zeami Motokiyo 世阿弥元清 (1363-1443) und im JōruriPuppentheaterstück Genji kuyō (1676) von Chikamatsu Monzaemon 近松門左衛門 (1653-1724). Einzelheiten hierzu in BALMES 2015.

334 „Bereich der Asuras“ für Shura no dōjō 修羅の道場. Asuras (jap. Ashura) sind unterhalb der Menschen rangierende, streitsüchtige Wesen, die im ständigen Kampf mit den Devas (einer Zwischenstufe zwischen Mensch und Göttern) stets unterlegen sind. Die irdische Gegenwart wird wegen ihrer vermeintlichen Streit- und Profitsucht gelegentlich auch „Asura-Welt“ genannt.

335 „Krummer und gerader Weg“ für wake 曲直, eine Verbindung des umgangssprachlichen wake [訳] („Grund“) mit dem schriftsprachlichen [kyokuchoku] 曲直 („krumm und gerade“).

336 „Enma 閻魔“ (Enma o 閻魔王, sanskr. Yama-rāja) ist der Richter, welcher am Eingang der Hölle aufgrund der Taten der Verstorbenen in ihrem Vorleben darüber entscheidet, in welchem Teil der Hölle ihnen welche Strafen auferlegt werden.

337 Der Erstbestandteil des Kompositums gesaku 戯作 („zum Spaße geschrieben“), das Zeichen ge 戯 (tawamureru, „spielen, scherzen“), besteht aus den Elementen kyo 虚 („Leere“) und hoko 七 (,Hellebarde“).

338 Wörtlich kanban 招牌, eine Verbindung von kanban 看板 („Werbeschild“) und dem schriftsprachlichen Synonym [shōhai] 招牌.

339 „Anderer Ausdruck für die Wahrheit“ für makoto no hiyu 実の比喻.

340 „Predigt im Gewande der Unwahrheit“ für hōben 方便, das hier das kurz zuvor zitierte Wort uso vervollständigt zum sprichwörtlichen Ausdruck Uso mo hōben (,Auch das Gelogene kann der Predigt dienen.“). 
nimmt und dabei etwas herauskommt, was zu Beförderung und Warnung ${ }^{341}$ dient, ist es eine Sache, welche der Unterweisung von Frauen und Kindern frommt. [8] Wenn man so etwas Nützliches zur Sünde macht und [den Verfassern] die Zunge herausreißt, dann müsste der Herr Enma demnächst auch dem ehrenwerten Verwandten Shaka ${ }^{342}$ die Zunge herausreißen. [9] Man sollte wohl von nun an die leeren Worte der Autoren von Unterhaltungsliteratur und die Lügen der Freudenmädchen aus der Liste der Ungesetzlichkeiten streichen. [10] Die von Aufklärung und Öffnung ${ }^{343}$ geprägte irdische Welt ${ }^{344}$ unserer Tage sollte hiervon lernen und sich endlich von den schlechten Sitten der Hölle reinwaschen. [11] Freilich ist es nicht so, dass in deren Werken nichts wäre, was man für Sünde halten muss. [12] Kyōden hat in seiner Sammlung alter Dinge ${ }^{345}$ Tatsachen aufgeführt und alte Quellen ${ }^{346}$ umgearbeitet - ein ganz und gar nicht leicht zu nehmendes Vergehen, aber wegen der Verdienste ${ }^{347}$ der Hefte mit gelbem oder braunem Umschlag ${ }^{348}$ steht die Sache fünfzig zu fünfzig, so dass die Rechnung ausgeglichen ist. [13] Ikku hat in seinem Auf Schusters Rappen zwar sündenfreie Unwahrheiten gesammelt und damit Verdienste erworben, seine Grundlage waren aber Aufzeichnungen verrückter Worte, ${ }^{349}$ die er haargenau so aufgenommen und der Öffentlichkeit vorgetäuscht hat, es handele sich um im eigenen Bauche ersonnene Motive. ${ }^{350}$ [14] Man darf ihm deswegen wohl mit Recht den reitenden Wüstling Pferdekopf ${ }^{351}$ beigeben. [15] Was Bakin betrifft, so reihte er entgegen seiner im Zeichen ge enthaltenen Berufung ${ }^{352}$ und im Stolz auf sein bisschen Gelehrsamkeit Spitzfindigkeiten aneinander, wo immer ihm das möglich war, disku-

341 „Beförderung und Warnung“ für kanchō 勧懲, der Kurzform von kanzen chōaku 勧善懲悪 („Beförderung des Guten und Warnung vor dem Bösen“), das moralische Postulat, dem die Erzählprosa der Edo-Zeit unterworfen war.

342 „Shaka“: eine japonisierte, abgekürzte Variante für Sākya[muni] (Buddha). Robun bezieht sich auf die in Anm. 340 erwähnte, das kleine Kind vor dem Verbrennen schützende Lügengeschichte Buddhas.

343 „Aufklärung und Öffnung“ für bunmei kaika 文明開化, Slogan der Aufklärer der frühen Meiji-Zeit. Zum Inhalt gehört unter anderem die Vorstellung, dass der Rückständigkeit Japans nur durch Übernahme der westlichen Zivilisation begegnet werden könne und die auf ihr beruhenden Fortschritte in den Wissenschaften kopiert werden müssten.

344 „Irdische Welt“ für shaba 娑婆, buddhistische Bezeichnung für das Diesseits.

345 „Sammlung alter Dinge“ für Kottō shū 骨董集, Titel der 1814-15 erschienenen Miszellensammlung.

346 Jitsuji wo age, moto wo tadasu 実事を挙、典故を訂す, worin das umgangssprachliche moto („Grundlage“) in Verbindung mit dem schriftsprachlichen tenko 典故 auf klassische Texte verweist.

347 „Verdienste“ für kudoku 功徳: karmische (und bei Robun auch moralische) Verdienste.

348 „Hefte mit gelbem Umschlag“ für kibyōshi 黄巻, eine Verbindung des Wortes kibyōshi 黄 表紙 mit dem gleichbedeutenden kimaki 黄巻.

349 „Aufzeichnungen verrückter Worte“ für kyōgen ki 狂言記, Texte der komischen Intermezzi zwischen zwei Nō-Theaterstücken.

350 „Im eigenen Bauche ersonnene Motive“ für mizukara hara mishi shukō 自ら臆見し趣向.

351 „Reitender Wüstling“ für mukan 馬漢; „Pferdekopf“ für mezu 馬頭, Höllenwesen mit einem Pferdekopf und einem menschlichen Körper, dessen Aufgabe darin besteht, Verstorbene in der Unterwelt zu quälen.

352 Siehe Anm. 337. 
tierte unablässig die Irrtümer in älteren Schriften und verfasste vor Hochmut stinkende Werke wie Ins Dunkel entlassene Worte, ${ }^{353}$ mit dem er die Allgemeinheit in Angst und Schrecken versetzte. [16] Da dies eine große Sünde ist, wäre wohl zu erwarten gewesen, dass man diesem Kerl die Zunge herausreißt, doch weil er nun andererseits die Ursachen erschloss und die Wirkungen erklärte, ${ }^{354}$ muss man ihn wohl auf dem Fluchtweg der Beförderung und der Warnung entkommen lassen. ${ }^{355}$ [17] Sanba ${ }^{356}$ war ein wahrer Autor von Unterhaltungsliteratur, welchem es gelang, mit der Pinselspitze die Wirklichkeit ${ }^{357}$ herauszubohren, in Schabernack und Späßen ${ }^{358}$ die Empfindungen der Menschen und ihre alltägliche Situation ${ }^{359} \mathrm{zu}$ treffen und die Stolperfallen ${ }^{360}$ der treibenden Welt ${ }^{361}$ aufzuspüren. [18] Da hieß es doch tatsächlich, man habe den Eindruck, es handele sich um unausgegorene und halbernste Erzählungen eines Alten, ${ }^{362}$ in den Formulierungen kämen die üblichen Ungeschliffenheiten zum Vorschein, und weil er in alberne Wortwitze $e^{363}$ verfallen sei, dürfe der Leser es niemals für eine wahrhaftige Schrift halten. ${ }^{364}$ [19] Genau dort verlaufe die Grenze zwischen Paradies

353 Die Miszellensammlung Gendō hōgen 玄同放言 ([Lose Worte des Gendō], 1818-1820) enthält Notizen, die Bakin (Pseudonym: Gendō) während der Lektüre zu Themen wie Astronomie, Geografie, Geschichte und Menschen anlegte und später für das Verfassen seiner großen yomihon (etwa das Nansō Satomi Hakkenden) auswertete.

354 Bakin erläutert in seinen Werken Handlungen der und Konsequenzen für die Protagonisten stets als unausweichliche Abfolge von Ursache und Wirkung (inga ōhō 因果応報), die im Buddhismus den Menschen zu adäquaten Vorleistungen für eine angenehme Wiedergeburt verpflichten.

355 „Beförderung und Warnung“ für kanchō 勧懲, „Beförderung des Guten und Warnung vor dem Bösen“ als Verdienst der Literatur Bakins.

356 Siehe Anm. 330.

357 „Wirklichkeit“ für jitchi 実地 (,echtes Material“).

358 „Schabernack und Witzigkeit“ für kokkei share 滑稽洒落, zugleich die Bezeichnung für die literarischen Genres der kokkeibon (,Ulkbücher“) und sharebon („Bücher der feinen Lebensart").

359 „Empfindungen der Menschen und ihre alltägliche Situation“ für ninjō setai 人情世態.

360 „Stolperfalle“ für ana 巣穴, eine Verbindung des umgangssprachlichen ana [穴] („Loch“) mit dem schriftsprachlichen Synonym [sōketsu] 巣穴.

361 „Treibende Welt“ für ukiyo 人情, eine Verbindung von ukiyo [浮世] („fließende, vergängliche Welt“) und [ninjō] 人情 („menschliche Empfindungen“).

362 „Unausgegorene und halbernste Erzählungen eines Alten“ für nama nama majime na monogatari 偶老実の物語, eine Verbindung des umgangssprachlichen nama nama majime no monogatari [生生真面目] mit dem schriftsprachlichen Synonym [gūrōjitsu] 偶老実 (,zufällige Ernsthaftigkeit eines Alten").

363 „Alberne Wortwitze“ für okashimi 笑語, eine Verbindung von okashimi [可笑しみ] („Albernheit“) und [shōgo] 笑語 (,Worte zum Lachen“).

364 „Wahrhaftige Schrift“ makoto 真書, worin das umgangssprachliche makoto (,Wahrhaftigkeit“) eine Verkürzung des hier vollständig übersetzten schriftsprachlichen Ausdrucks [shinsho] 真書 ist. 
und Hölle, ${ }^{365}$ man müsse ihn zum Flussbett der Opfergaben ${ }^{366}$ schicken - und so habe man ihn maßloserweise zu seinem Leidwesen dazu verurteilt, Erzieher ${ }^{367}$ der Kinder zu sein! [20] Diese Neuigkeiten $^{368}$ vermittelten mir die Einsicht, dass die Gerüchte über Hanzhong und die purpurne Dame ${ }^{369}$ nur die leeren Worte von Chanchan-Adepten ${ }^{370}$ und Verkäuferpriestern ${ }^{371}$ sind. [21] Deswegen zitiere ich nicht mit der Geste des Wissenden ${ }^{372}$ aus den offiziellen Geschichtswerken, vielmehr enthält Auf Schusters Rappen durch westliche Länder Wahrheiten, die aus wahllos umhergeschleuderten, unwahren Phrasen ${ }^{373}$ entstanden. [22] Sünden produzieren wir Simpeltypen ${ }^{374}$ von gesaku-Autoren also nicht, sind aber von der Sorte,

365 „Grenze zwischen Paradies und Hölle“ für gokuraku to jigoku no sakai 極楽と地獄の経境 [sic!].

366 „Flussbett der Opfergaben“ für sai no kawara 塞[sic!]の河原, korrekterweise sai no kawara 賽の河原 zu schreiben. Als Eigenname verweist der Ausdruck auf den Ort des Zusammenflusses des Kamogawa und des Katsuragawa in Kyōto. An dem von zahlreichen kleinen steinernen Buddhafiguren gesäumten Punkt fand traditionell unter Darreichung von Opfergaben (sai 賽) der Abschied von den Verstorbenen statt, deren Leichen von dort aus nur noch von Priestern zum Grab geleitet wurden. Nach anderer Überlieferung leitet sich der Ortsname daher, dass es dort eine Figur des Sae no kami 賽の神, eines shintōistischen Schutzgottes der Reisenden gab.

367 „Erzieher“ für mori 師傅, worin das umgangssprachliche mori die gleichbedeutende schriftsprachliche Lesung shitsu 師傅 ersetzt.

368 „Neuigkeiten“ für shinbun, hier wieder Anspielung auf „Zeitung“.

369 In der Provinz „Hanzhong“ (Kanchū 漢中) liegt das Liangshan-Moor, Schauplatz des Shuihu zhuan. „Purpurne Dame“ für shiki 紫姫, womit Murasaki Shikibu, die Verfasserin des Genji monogatari gemeint ist. Robun greift hier die eingangs angedeuteten Gerüchte von der Bestrafung von Autoren fiktionaler Texte (Anm. 333) auf.

370 „Chanchan-Adepten“ für chanchan bōzu 支那学士, worin in jeweils pejorativer Absicht chanchan die chinesische Sprache verballhornt, [Shina] 支那 für China sowie bōzu („Adept“) für „Mönch“ steht. Lediglich [gakushi] 学士 („Gelehrter“) ist wertneutral.

371 „Verkäuferpriester“ für maisu 売僧, pejorative Bezeichnung für einen Priester, der entgegen den Ordensvorschriften nicht durch Betteln, sondern durch Handel seinen Lebensunterhalt verdient.

372 „Wissender“ für monoshiri 愽識, worin das umgangssprachliche monoshiri die gleichbedeutende schriftsprachliche Standardlesung hakushiki 愽識 ersetzt.

373 „Wahllos umhergeschleuderte, unwahre Phrasen“ für detarame no uso 放言題の虚, worin das umgangssprachliche detarame (,wahllos“) die Standardlesung hōgendai 放言題 (,umhergeschleuderte Phrasen“), das umgangssprachliche uso die schriftsprachliche Standardlesung kyo 虚 („Leere“) ersetzt.

374 „Simpeltyp“ für katagi 朴昞, eine Verbindung des umgangssprachlichen katagi [気質] („Typ“) mit dem schriftsprachlichen [bokutotsu] 朴訥 („Schlichtheit“). 
die neuerdings aus dem Anblick umstürzender Menschenwagen die Warnung vor Pferdewagen machen. ${ }^{375}$

[23] Im 8. zyklischen Jahr zur frühlingshaften Pflaumenblüte zum Spaße verfasst von Herrn Kanagaki $[\text { Siegel }]^{376}$

Wir haben es hier mit einem Beispiel für die Annäherung der fiktionalen Prosa an den Journalismus zu tun, die für Robun nach seinem ein Jahr zurückliegenden Eintritt in die Zeitung Yokohama Mainichi Shinbun (1874) nun einen weiteren Schritt in Richtung des neuen Berufs bedeutete und in der Gründung einer eigenen Zeitung, der Kanayomi shinbun 仮名読新聞 ([Zeitung mit < Beigabe leichtverständlicher > Silbenschrift], ab 1875) ihren Höhepunkt fand. Doch beschränkte sich Robun nicht auf die Distanzierung von den Granden der Edo-Literatur (hierin ein Vorläufer von Tsubouchi Shōyō, der dies 1885-1886 in seinem Shōsetsu shinzui weidlich tat). Vielmehr verhalf der einen Platz im modernen Japan beanspruchende Autor auch dem Wirklichkeitsbegriff durch die Gleichstellung von Faktenbasis und Wirkmacht eines Textes zu neuen Dimensionen. Dass diesem Paradigmenwechsel Robuns dabei kein nachhaltiger Erfolg beschieden war, zeigt unter anderem, wie wenig die gesellschaftlich einflussreichen Kräfte auf eine grundsätzliche Reform des Realitätsbegriffs vorbereitet waren.

\section{„Europa ist toleranter in der Haltung zur fiktionalen Prosa“. Das Vorwort von Kubota Shigenobu zu Band 11 (1872) des Seiyō dōchū hizakurige}

Eine interessante argumentative Ergänzung zu der soeben gesehenen Annäherung der fiktionalen Prosa an den Journalismus liefert ein Kubota Shigenobu 久 保田重信 (Chōhō 蔦峯, fl. 1872), Schüler des Malers Suzuki Gako 鈴木䣸湖 (1816-1870). Von Chōhō ist nicht mehr bekannt als seine Aktivitäten bei Künstler-

375 Jinsha no kutsugaeru wo mite basha no imashime to su 人車の覆へるを見て、馬車の誡めと す. Diese Umschreibung für „Fehlinterpretation“ und ,übertriebene Vorsicht“ bezieht sich auf die in der frühen Meiji-Zeit aufgekommenen, modernen individuellen Personentransporte in von Menschen oder Pferden gezogenen Wagen. Beide Transportarten sind dem in der Edo-Zeit sozialisierten Robun fremd. Der Satz erfüllt gleichzeitig zwei Funktionen: (a) zum einen weist er bescheiden auf die Unfähigkeit des Autors zur Unterscheidung der beiden modernen Erscheinungen hin eine stereotype captatio benevolentiae, die sich ein weiteres mal in Band VIII-1 (2 b) desselben Titels findet; (b) zum anderen spottet Robun über die Zwangslage der Autoren fiktionaler Prosa, welche nun selbst Verkehrsunfälle pflichtschuldigst moralisch deuten (zur Ermahnung heranziehen) müssten, damit die Zensurbehörde ihren Texten die Druckgenehmigung erteilt.

376 Das Siegel weist die Zeichen für zen 善 („das Gute“) in Weiß auf schwarzem Grund und das Zeichen $a k u$ 悪 („,das Böse“) in Schwarz auf weißem Grund auf. 
und Literatentreffen (shoga kai 書画会) der frühen Meiji-Zeit, wo er auch Freundschaft mit Robun geschlossen haben dürfte. ${ }^{377}$ Offensichtlich wurde er von Robun aber für prominent genug gehalten, um auf Robuns Wunsch hin durch das im Folgenden auszugsweise übersetzte Vorwort die Veröffentlichung werbewirksam in Szene zu setzen.

Vorwort zu Band $11^{378}$ von Kubota Shigenobu 久保田重信 (1872)

[1] Auch in den verschiedenen Ländern Europas gibt es so etwas wie ${ }^{379}$ Geschichten und Allerleihefte. ${ }^{380}$ [2] Aber diese werden nicht, wie die Historisierenden Erzählungen und das zum Spaß Geschriebene ${ }^{381}$ abschätzig als China-Stil ${ }^{382}$ bezeichnet, sondern gleichrangig [mit anderen Schriften] als Bücher. ${ }^{383}$ [3] Im Allgemeinen erwachsen deren Themen und die Motivgestaltung aus in der Luft Befestigtem, ${ }^{384}$ aber was die [beschriebenen] Situationen ${ }^{385}$ betrifft, so kommt es nicht vor, dass sie dem Zustand der Gesellschaft ${ }^{386}$ nicht entsprächen. [4] Aus diesem Grund halte ich auch die Geschichten, wenn man sie aus der Sicht der Reformierung ${ }^{387}$ erörtert, für Einführungswerke, ${ }^{388}$ und ihre metaphorischen Worte ${ }^{389}$ sind Beweise des Tatsächlichen. ${ }^{390}[5]$ Wie sollten sie nichts weiter sein als

377 MiKaWA 2013b: 144.

378 Textvorlage: digitales Faksimile des originalen Bandes XI (Tōkei: Bankyūkaku 万笈閣, 1872). Eine akkurate Übertragung des Vorwortes in modernen Typendruck bietet MiKaWA 2013b: 143-144.

379 „So etwas wie“ für tagui 等類, eine Verbindung des umgangssprachlichen tagui [類い] mit dem schriftsprachlichen Synonym [tōrui] 等類.

380 „Geschichten“ für shōsetsu 小説, „Allerleihefte“ für kusazōshi 草冊子 - hier zusammengenommen für Unterhaltungsliteratur.

381 „Historisierende Erzählungen“ für haishi 稗史; „zum Spaße Geschriebenes“ für gesaku 戯作.

382 „China-Stil“ für chaina fü 支那風, eine Verbindung des englisch-japanischen Ausdrucks China fū [ちゃいな風 oder China 風] mit dem pejorativen [Shina] 支那. Aus der Sicht der britischen Großmacht war Rückständigkeit der Grund für Chinas militärische Unterlegenheit in den Opium-Kriegen (1839-1842; 1859-1860). Möglicherweise will Chōhō mit dem englischen Wort China diese arrogante Sicht anklingen lassen.

383 „Bücher“ für shojaku 書籍.

384 „In der Luft Befestigtes“ für kakū 架空, metaphorische Bezeichnung der fehlenden Faktenbasis.

385 „Situation“ für jijō 事情.

386 „Zustand der Gesellschaft“ für setai 世態.

387 „Reformierung“ für kaika 開化, Teil des Slogans bunmei kaika 文明開化 („Zivilisierung, Öffnung und Veränderung“), den die Modernisierer Japans in der frühen Meiji-Zeit zur Propagierung ihrer politischen und zivilisatorischen Reformen nutzten.

388 „Einführungswerk“ für shiori 染.

389 „Metaphorische Worte“ für gūgen 寓言. Schon seit dem chinesischen Zhuangzi (The complete works of Chuang-tzu, ca. 130 v. Chr.) verbindet sich mit diesem Ausdruck das didaktische Argument der auf metaphorischem Wege leichteren Vermittelbarkeit von Wahrheiten (S. 92).

390 „Beweise des Tatsächlichen“ für kakujitsu no shō 傕実の証, worin kaku 傕 eine inhaltlich identische Variante des Zeichens kaku 確 („Bestimmtheit“) ist. 
ein Spaß! ${ }^{391}$ [6] Was die Gelehrten daran verabscheuen, ist lediglich, dass im Stile ${ }^{392}$ [solcher Texte] Verfeinertes und Vulgäres ${ }^{393}$ vorkommt. [7] Aber wenn man in der Gegenwart angekommen ist, ${ }^{394}$ sollte man es für vernünftiger halten, ${ }^{395}$ Geschichten unserer Zeit ${ }^{396} \mathrm{zu}$ lesen, statt bis zum Ende seines Lebens das Aufwärmen innerster Geheimnisse ${ }^{397}$ weitschweifiger China-Gelehrsamkeit ${ }^{398}$ auf die Spitze zu treiben. [8] Es dürfte wohl angemessen sein, ab sofort die Bezeichnung „Historisierende Erzählung“399 abzuschaffen, aus der Bezeichnung „Spaßschreiber“ das [Wort] „Spaß“ zu entfernen ${ }^{400}$ und [die Autoren] als „sprachlich schaffende Meister“401 oder als „Meister der sprachlichen Mitteilung ${ }^{\star 402} \mathrm{zu}$ loben. ${ }^{403}[. .$.

391 „Spaß“ für tawamure 戯れ, die japanische Lesung des ersten Bestandteils des Bigramms gesaku 戯作 (Anm. 382).

392 „Stil“ für bunshō 文章.

393 „Verfeinertes und Vulgäres“ für gazoku 雅俗, womit hier das Nebeneinander von Schriftsprache und Umgangssprache gemeint ist.

394 „Wenn man in der Gegenwart angekommen ist“ für konnichi ni itarite wa 今日に至りて 八. Gemeint ist Modernität im Gegensatz zum ewiggestrigen Konservatismus.

395 „Vernünftiger sein“ für ri nari 理なり.

396 „Unsere Zeit“ für nensai 年歳 (,Jahre“).

397 „Aufwärmen innerster Geheimnisse“ für un’ō 温奥, eine Verbindung von un’o [藴奥] („Inneres Geheimnis“) und [on’ō] 温奥 („Aufwärmen des Innersten“). Der Begriff „Aufwärmen“ dient hier nicht nur zur expliziten Kennzeichnung des Objekts als nicht mehr frisch, er ist gleichzeitig eine Anspielung auf Kapitel 2 des Lunyu (Confucian Analects, 1. Jh. v. Chr.), gewissermaßen die Bibel des hier kritisierten Konfuzianismus. In Abschnitt 2.27 heißt es: 子曰、溫 故而知新、可以為師矣。(Lunyu zhushu 論語注疏 2: 7a, SKQS-Edition). ,The Master said, ,If a man keeps cherishing his old knowledge, so as continually to be acquiring new, he may be a teacher of others.' (LEGGE 1900: 18). Dieses Diktum wird häufig auf die populäre Phrase onko chishin 温故知新 („Aufwärmen des Alten, Erkennen des Neuen“) verkürzt. Chōhō kann davon ausgehen, dass das Fehlen der zweite Hälfte der Phrase („Erkennen des Neuen“) als Hinweis darauf verstanden wird, dass er den China-Gelehrten Erkenntnis des Neuen nicht zutraut.

398 „China-Gelehrsamkeit“ für kangaku 漢学, womit hauptsächlich die exegetische Literatur zu den konfuzianischen Klassikern sowie zu ihren Kommentaren und Subkommentaren gemeint sein dürfte. Kubota schlägt hier den Bogen zurück zum weiter oben zitierten, pejorativen Ausdruck chaina fū („China-Stil“, Anm. 383) und lenkt die Abwertung um, indem er sie auf die einst hochgeachtete konfuzianische Gelehrsamkeit Chinas bezieht.

399 „Historisierende Erzählung“ für haishi.

400 „Spaßschreiber“ für gesakusha 戯作者. Tatsächlich gehört das nach der hier verlangten Verkürzung von gesakusha verbleibende Kompositum sakusha (wörtlich „Schaffender“) heute zu den gewöhnlichen Bezeichnungen für Verfasser fiktionaler Prosa.

401 „Sprachlich schaffende Meister“ für chosakushi 著作師, worin cho 著 die Versprachlichung bezeichnet.

402 „Meister der sprachlichen Mitteilung“ für chojutsuka 著述家: Bezeichnung für Verfasser fiktionaler Prosa.

403 „Loben“ für tadaeru 祢える, worin die Lesung tadaeru eine Nebenform von tataeru, die Schreibung tadaeru 祢える eine inhaltlich identische Variante von tataeru 称える darstellt. 
Die sich hieran anschließende Eloge auf den Freund Kanagaki Robun ist im Zusammenhang der vorliegenden Abhandlung nicht von Belang, überdies ist das seit dem chinesischen Zhuangzi (ca. 130 v. Chr.) bekannte didaktische Argument für die fiktionale Literatur inzwischen zum Stereotyp der japanischen Literaturtheorie erstarrt, und schließlich ist auch die Gegeneinanderstellung des Substituendums „Realität“ (jitsu) und deren Substituens, die metaphorische Umschreibung (gūgen), nicht neu. ${ }^{404} \mathrm{Neu}$ ist dagegen, wenigstens in literaturhistorischer Hinsicht, der von Chōhō formulierte Anspruch, im Zuge der Adaption kultureller Errungenschaften der Europäer auch deren Wertschätzung der fiktionalen Prosa zu übernehmen. Dass Chōhō sich damit in bester Gesellschaft befindet, beweist der im Folgenden besprochene Text.

\subsubsection{Literatur als Form wissenschaftlicher Investigation der Wahrheit - Das Hyakugaku renkan (1870-1872) des Nishi Amane}

Neben Fukuzawa Yukichi trat auch Nishi Amane 西周 (1829-1897) als Kopf der Modernisierungsbestrebungen im Japan der Meiji-Zeit für die Adaption westlicher zivilisatorischer Errungenschaften ein und meinte damit vor allem deren positivistischen und utilitaristischen Aspekte, im Gegensatz zu Fukuzawa allerdings vor allem in Bezug auf die intellektuellen Traditionen. Nishi studierte von 1863 bis 1865 im niederländischen Leiden unter anderem Rechtswissenschaften, Ökonomie und Statistik bei Simon Vissering (1818-1888) sowie Philosophiegeschichte bei Cornelis Willem Opzoomer (1812-1892). Die in unserem Zusammenhang bedeutendste Frucht dieser Studien besteht in Nishis Bekanntmachung der japanischen Geisteswelt mit den alle Wissenschaften integrierenden Vorstellungen des französischen Enzyklopädisten Auguste Comte (1798-1857) sowie der auf induktiver Logik basierenden Philosophie des John Stuart Mill (1806-1873) im Hyakugaku renkan 百学連環 ([Verbindungsringe der hundert Gelehrsamkeiten], 1870-1872). Robert Havens hebt hervor, dass es sich dabei trotz des englischen Untertitels Encyclopedia und trotz gegenteiliger Behauptungen einiger Kulturhistoriker nicht um ein Nachschlagewerk in der Art französischer Enzyklopädien des 18. Jahrhunderts handele, sondern um eine Abhandlung mit klarem Schwerpunkt auf der europäischen positivistischen Philosophie des 19. Jahrhunderts. Die Basis des hier gegebenen detaillierten Überblicks über die westlichen Wissenschaften wird fast ausschließlich von

404 Okanishi Ichū 岡西惟中 (1639-1711) erklärt in Haikai mōgyū (1675) und in Haikai wakumon (1678) explizit die menschlichen Gefühle als Realität zum Substituendum (Abschn. 3.4.1.2). 
englischsprachigen Quellen gebildet, unter denen Encyclopedia of Political Science (London 1840), Biographical History of Philosophy (Verf. George Henry Lewes; London 1852), die Hauptwerke des John Stuart Mill und der Cours de philosophie positive (1830-1842) des Auguste Comte hervorragen. ${ }^{405}$ Nishi unterteilt die Wissenschaften auf der obersten Ebene in ,allgemeine“ (engl. common, jap. futsū 普通) und „spezielle“ (engl. particular, jap. shubetsu 殊別) und erklärt in der Einleitung dazu, dass die ,allgemeinen“ Wissenschaften (Geschichte, Geografie, Literatur, Mathematik) die Erkenntnisse der „speziellen“ auszudrücken hätten. Bei den „speziellen“ Wissenschaften unterscheidet Nishi zwischen den „intellektuellen“ (Theologie, Philosophie, Politik, Rechtswissenschaften, Ökonomie und Statistik) und den „physikalischen“ (Physik, Astronomie, Chemie und Naturgeschichte). Unter Rückgriff auf eine These des schottischen Philosophen William Hamilton (1788-1856) attestiert Nishi sowohl den Wissenschaften gaku 学 (science) allgemein als auch dem Teilgebiet der Künste jutsu 術 (arts) im besonderen die Aufgabe der Investigation der Wahrheit, wobei die Wissenschaften um des Wissens, die Künste um der Produktion willen investigierten. ${ }^{406}$

Die Behandlung des Feldes „schöne Literatur“ (belles lettres) muss für viele traditionell gebildete Japaner überraschend gewesen sein: Nishi ordnet sie nämlich den jutsu 術 (,arts“) zu und damit der Weiterverarbeitung konsistenter Wahrheiten, die zunächst in den gaku 学 (,science“) aus Fakten induziert wurden. ${ }^{407}$ In den liberal arts findet die „schöne Literatur“ mit ihren Teilgebieten „Poesie“ (shi 詩) und „Prosa“ (sanbun 散文) ihren Platz, wobei Nishi die Prosa im Vergleich zur Poesie (Lyrik) als rationaler und der Rhetorik näherstehend kennzeichnet. ${ }^{408}$ Nach der erwähnten Funktionsaufteilung ,allgemeiner“ und „spezieller“ Wissenschaften müssen die von den belles lettres auszudrückenden Wahrheiten (das Substituens) im Gebiet der „speziellen“ Wissenschaften liegen, also in den Gebieten der „intellektuellen“ und der „physikalischen“ Wissenschaften. Den Ausdruck (das Substituendum) dieser Wahrheiten müssen die belles lettres als Teil der liberal arts im Hyakugaku renkan auf dem Wege der Mimesis leisten - wie Musik, Malerei und bildende Kunst.

405 HAVENS 1970: 92-113 bietet eine ausführliche Synopse zum Hyakugaku renkan. Die genannten Quellentexte referiert Havens aus Asō 1942: 126-127.

406 Dass Hamilton und damit auch Nishi im Grunde auf Thesen des Aristoteles (384-322 v. Chr.) zurückgreifen, sei aus Platzgründen nur am Rande erwähnt.

407 Textbasis der folgenden Ausführungen ist der von Kitamura [Masamitsu] 北村[正光] besorgte moderne Druck der von Nishis Student Nagami Yutaka 永見裕 (1839-1902) erstellten Vorlesungsmitschrift in Bd. 4 der Nishi Amane zenshū (1981) sowie ein Nachdruck in Band 1 von Kindai Nihon shakaigaku shi sōsho 近代日本社会学史叢書 (Tōkyō 2007: 11-69).

408 NISHI 1981 [1872]: 95-99. 
[1] Wie ich schon in der Einleitung erläuterte, gehört die Poesie zu den Liberal arts (noblen Kunstfertigkeiten), und zu diesen gehören ausnahmslos sowohl die Musik (Stimme) als auch Malerei (Farbe), bildende Kunst (Gestalt), Poesie sowie das Schriftwerk (das Schriftwerk hat etwas mit Urenergien zu tun). [2] Was Stimme, Farbe und Form vollbringen, ist die imitation (Nachahmung): Ihrer aller Hauptaufgabe besteht darin, Gegenstände so nachzuahmen, dass sie die Wahrheit über sie zum Vorschein bringen. [3] Man schätzt an ihnen die Fähigkeit, durch diese Nachahmung die Empfindungen der Menschen in Bewegung zu bringen. ${ }^{409}$

Der auf sho 書 (,Schriftwerk“) bezogene Kommentar ist interlinear gesetzt, das darin enthaltene kishō 気象 („Äther und Gestalt als Urenergie“) verweist nicht (wie sonst häufig) auf meteorologische Phänomene, sondern auf jene energetische Veranlagung, die in der klassischen chinesischen Philosophie das Dasein aller Erscheinungen bedingt und steuert, darunter neben meteorologischen Phänomenen beispielsweise auch Mentalitäten. Dem „Schriftwerk“ wird durch diesen Begriff als Hauptaufgabe die Verschriftlichung von Philosophemen zugewiesen, die mit „Schriftwerk“ wahrscheinlich gemeinte Prosa wird damit in die Nähe der Wissenschaft gerückt.

Der Begriffsgehalt von „Wahrheit“ (makoto 真) bleibt im Grunde undefiniert, aber einstweilen kann nicht ausgeschlossen werden, dass mit makoto nicht nur (etwa in Bezug auf die Naturwissenschaften Physik, Astronomie, Chemie und Naturgeschichte) empirisch nachprüfbare Fakten, sondern gleichzeitig auch deren Kontextualisierungen und Interpretationen in den allgemeinen Wissenschaften gemeint sind. Unabhängig von der Konsistenz des von Nishi entworfenen Gebäudes der Wissenschaften verdient zwar besondere Beachtung, dass darin der Literatur (im Sinne von belles lettres) eine wichtigere Position zugesprochen wird als je zuvor, doch kann nicht übersehen werden, dass Nishi mit seiner Darlegung im Grunde mit jener auch aus der Edo-Zeit tradierten Lite-

409 Oyoso shi taru mono wa sude ni sōron chū ni tokishi gotoku Liberal Arts (gagei) naru mono ni shite, ongaku (koe), e (iro), chōzō (katachi), shi, sho (sho wa kishō ni kakawaru) nado kotogotoku kore ni zoku sezaru wa naku, sono koe iro katachi wo nasu wo, imitation (giji) to te, subete jibutsu ni tsuite makoto wo arawasu ga gotoku (giji) to te, subete jibutsu ni tsuite makoto wo arawasu ga gotoku giji suru wo yō shi, kono giji wo motte yoku ninjō wo ugokasu wo yoshi to su. 凡そ詩たるものは既に総論中に説きし如く Liberal Arts (雅芸)なるものにして、音楽(声)、画 (色)彫像(形)、詩、書(書は気象に係はる)等悉く之に属せさるはなく、其声色形をなすを imitation (疑似)とて、総て事物に就いて真を顕はすが如く疑似するを要し、此疑似を以て能く 人情を動かすを好しとす。(NISHI 1981 [1872]: 99). Das vorstehend zitierte Original bildet die kommentierte Mitschrift des Nishi-Schülers Nagami (Anm. 408) ab. Darin stehen die synonym intendierten Zusätze links von den in lateinischer Schrift zitierten Begriffen, gagei 雅芸 („noble Kunstfertigkeiten“) für „liberal Arts“ und giji 疑似 („Nachahmung“) für „imitation“. Die vertiefenden Zusätze stehen rechts von ihren Bezugswörtern, koe 声 („Stimme“) konkretisiert die „Musik“, iro 色 („Farbe“) die „Malerei“ und katachi 形 („Gestalt“) die bildende Kunst. 
raturanschauung übereinstimmt, nach welcher das Kunstwerk sichtbar für einen Gegenstand außerhalb der Kunst steht.

\subsubsection{Literatur im Universum, Fiktion und Wirklichkeit in Textsorten: Der Disput zwischen dem China-Gelehrten Nakamura Keiu und dem Philosophen Inoue Tetsujirō}

Nakamura Keiu 中村敬宇 (1832-1891) gehört zu den Vorreitern der japanischen Aufklärung und Modernisierung der frühen Meiji-Zeit und vertrat als solcher die Adaption der sogenannten westlichen (seiyō 西洋) Kulturen Europas und der USA. Keius Geringschätzung fiktionaler Prosa folgt der unter konfuzianischen Gelehrten der späten Edo-Zeit vorherrschenden Meinung. Lediglich seine Begründung für die Geringschätzung ist „modern“: Er bezieht sie nicht aus kanonisierten Klassikern des chinesischen Konfuzianismus, sondern etwa aus Self Help (1859) des Schotten Samuel Smiles (1812-1904), das als Anleitung zur Persönlichkeitsbildung eine Art Bibel des viktorianischen Liberalismus darstellte. Kein Zweifel, dass Keiu die in jener „Bibel“ enthaltenen Aufrufe zu Selbstzüchtigung, Ernsthaftigkeit, Handlungsorientiertheit, Standfestigkeit und moralischer Beständigkeit als nützlich für die Bildung „moderner“ japanischer Staatsbürger hielt und deswegen Self Help unter dem Titel Saigoku risshi hen 西 国立志編 ([Buch über die Aufrichtung des Willens in westlichen Ländern], 1870) in japanischer Übersetzung veröffentlichte. Das Original enthält in Kapitel 11 eine eindringliche Warnung vor der ethisch-moralischen Verderblichkeit fiktionaler Prosa, die vor allem den Versuch verdammt, nützliche Informationen in unterhaltender (pleasant) Form verdaulicher zu machen. Eine Vielzahl von Romanen (novels) ${ }^{410}$ sei vor allem diesem unguten Bestreben verpflichtet und könne zwar Verständnis wecken, nicht aber zu helfendem Handeln anleiten und sei darum praktisch irrelevant. Keius Übersetzung fasst in Unterabschnitt 11.24 seines Saigoku risshi hen die Verdammung der Literatur als das, was heute neudeutsch Infotainment genannt wird, aus dem englischen Original in teilweise veränderter Anordnung zusammen und entzieht dabei vor allem den gesaku-Autoren der frühen Meiji-Zeit, welche ja ihre Werke als didaktisch brauchbares Infotainment anpriesen, die argumentative Basis. ${ }^{411}$

410 Keiu verwendet als Übersetzungswort für novel das japanische haikan shōsetsu 稗官小説 („historisierende Romane“), die traditionelle Bezeichnung für die Abenteuerromane des Genres yomihon.

411 SMiles 1859: 341-344; Smiles-NAKAMURA 1976: 588-590. Seinen Feldzug gegen fiktionale Prosa setzte Nakamura auch nach dieser Veröffentlichung fort. Zwei Beispiele sind seine Zei- 
So sehr nun Keiu die fiktionale Prosa verdammte, so sehr stand er im Gegensatz zu anderen Mitgliedern der „westlich“ orientierten akademischen Gesellschaft Meiroku sha 明六社 („Gesellschaft des Jahres Meiji 6“ [= 1873]) der traditionellen östlichen „Chinesischen Gelehrsamkeit“ (kangaku 漢学) mitsamt der darunter vielfach subsumierten chinesischen Lyrik (kanshi 漢詩) Zeit seines Lebens positiv gegenüber ${ }^{412}$ und erwarb sich selbst als Verfasser zahlreicher Gedichte im chinesischen Stil allgemeine Anerkennung. Kurzum: Keiu hing dem aus der Edo-Zeit tradierten Gedankenmuster an und subsummierte unter bungaku neben den „realitätsbezogenen“ wissenschaftlichen Texten wenigstens diejenigen fiktionalen Texte, welche wegen ihrer Formenstrenge und Abstraktheit hohes soziales Prestige genossen.

1869, nur ein Jahr nach der Meiji-Restauration, wurde Keiu Professor am Shizuoka gakumonjo 静岡学問所, einer den „Landesstudien“, den „Chinastudien“ und den „Westlichen Gelehrsamkeiten“ (yōgaku 洋学) gewidmeten Bildungseinrichtung. Was diese Einrichtung einzigartig machte, war weniger der Fächerkanon als die Tatsache, dass hier über alle traditionellen Klassenschranken hinweg arme und reiche junge Männer eine landeskundliche und sprachliche Grundausbildung bekamen. Keiu unterrichtete am Shizuoka gakumonjo anfangs sein Spezialfach „Chinesische Gelehrsamkeit“. ${ }^{413}$ Dass Keiu wegen dieser seiner Fachkompetenz gebeten wurde, den im Folgenden präsentierten Text $\mathrm{zu}$ verfassen, liegt nahe.

\section{„Alles im Universum folgt dem einen Gesetz - von den Sternen bis zum Schrifttum“. Nakamura Keius Vorwort zum Bunshō kihan kōkai (1878)}

Das Bunshō kihan kōkai 文章規範講解 ([Kommentierte und erläuterte Version des Wenzhang guifan], 1878) ist die von Mori Tatsuyuki 森立之 (1807-1885) japanisch kommentierte Version der chinesischen Stilkunde Wenzhang guifan

tungsartikel Shōsetsu (gesakubon) wo zōsuru no shigai 小説习蔵スルノ四害 ([Vier Schäden, welche der Besitz von (Unterhaltungs-) Romanen verursacht], 1876) und Insho wo funki suru (yakisutsuru) jippō 淫書ヨ焚毀スル十法 ([Zehn Regelungen zur Verbrennung (und Vernichtung) unzüchtiger Schriften], 1876), die aber nicht das eingangs definierte Gebiet der Literaturtheorie erreichen und deswegen hier nicht weiter behandelt werden.

412 So hielt Keiu beispielsweise am 8. Mai 1883 vor dem Tōkyō Gakushi Kaiin 東京学士会院 („Tōkyōer Institut der Gesellschaft gelehrter Herren“) eine Rede, deren Niederschrift unter dem Titel Kangaku wa sutsuru bekarazaru no ron 漢学不可廃論 ([Darüber, warum man die chinesischen Gelehrsamkeiten nicht verwerfen sollte], 1883) in die Sammlung Keiu Nakamura sensei enzetsu shū 敬宇中村先生演説集 ([Sammlung der Reden unseres Lehrers Keiu Nakamura], 1888; Hg. Kibira Yuzuru 木平譲) Aufnahme fand.

413 Ab November 1869 gab Keiu auch englische, französische, holländische und deutsche Landeskunde (TAKAHASHI 1966: 54-55). 
文章軌範 ([Regeln und Beispiele für den Stil], vor 1290) des Xie Fangde 謝枋得 (1226-1289). Diese Stilkunde diente im China der südlichen Song-Dynastie (1127-1279) der Vorbereitung auf die Prüfung für Beamtenanwärter und löste gegen Ende des 16. Jahrhunderts in Japan ${ }^{414}$ das Guwen zhenbao 古文真宝 (jap. Kobun shinpō, [Wahrhaftiger Schatz alter Stile], 1366) ab, das fast 200 Jahre lang als wichtiges Musterbuch gedient hatte. ${ }^{415}$ Als Mori Tatsuyuki sich entschloss, eine japanisch kommentierte Version des Wenzhang guifan zu schaffen, hatte er sich als Sprössling einer seit Generationen die traditionelle chinesische Medizin (kanpō 漢方) praktizierenden Arztfamilie durch zahlreiche medizinkundliche Schriften Anerkennung erworben. ${ }^{416} 1854$ wurde Tatsuyuki zum Lehrer am Igakukan 医学館, der höchstrangigen Lehreinrichtung für Medizin, berufen und blieb auch über die Meiji-Restauration hinaus als Lehrer für Medizin und Verfasser medizinischer Fachbücher tätig. Seine kommentierte Version der Stilkunde Wenzhang guifang ist vor diesem Hintergrund als Nebenprodukt seiner geistigen Tätigkeit anzusehen. Das Vorwort Keius zum Bunshō kihan kōkai war also geeignet, dem in der Welt der Philologie unbekannten Tatsuyuki die gewünschte Aufmerksamkeit für sein Unternehmen zu sichern. Keiu unternimmt im nachstehend übersetzten Anfang des Vorwortes eine im eigentlichen Sinne universale Einbindung der Wortkunst in die Welt.

414 Der erste japanische Bestandsnachweis ist im Nikkōsan bunko mokuroku 日光山文庫目録 ([Schriftenverzeichnis des Nikkōsan], 1654), dem Bibliothekskatalog des Tendai-Klosters Rinnōji 輪王寺 in Nikkō, enthalten. Lektüreprotokolle japanischer Gelehrter des 16. und 17. Jahrhunderts beweisen jedoch, dass das chinesische Original schon während der Jahre 1596-1615 bekannt war.

415 Wie nachhaltig die Kanonisierung des Wenzhang guifan in Japan war und bis in die Gegenwart ist, zeigt sich auch daran, dass es in japonisierter und ausführlich kommentierter Form in den Bänden 17 und 18 Bestandteil der Reihe Shinshaku kanbun taikei 新釈漢文大系 ([Neu kommentierte große Reihe chinesischer Texte]; Meiji shoin, 1961-1962; SSKT) wurde. Diese Reihe umfasst mit ihren 119 Bänden zwar nur eine sehr kleine Auswahl des gigantischen Schatzes klassischer chinesischer Texte, gehört aber zur Standardausrüstung bei der Erforschung vormoderner japanischer Literatur.

416 Beispielsweise verfertigte er im Auftrag des bakufu am Igakukan 医学館, der höchstrangigen Medizinschule des Landes, eine korrigierte Version des Beiji qianjin yaofang 備急千金要方 ([Unbezahlbare Rezepturen für den Notgebrauch], ca. 652) des Sun Simiao 孙思选 (581-682), der wohl ältesten Diätetik Chinas. 


\section{Vorwort zum Bunshō kihan kōkai von Keiu Nakamura Masanao ${ }^{417}$}

[1] Sonne, Mond, Sterne und deren Koordinaten ${ }^{418}$ sind Muster und Urbilder ${ }^{419}$ des Firmamentes. ${ }^{420}$ [2] Berge, Flüsse, Ströme und Gebirge sind Muster und Urbilder der Erde. [3] Worte, welche den $\mathrm{Weg}^{421}$ in sich tragen, sind die Muster und Urbilder des Menschen. [4] Gäbe es am Himmel nicht Sonne, Mond, Sterne noch Zeiten, so wären Düsternis und Finsterkeit, Nichts und Verderbnis; gäbe es auf der Erde nicht Berge, Flüsse, Ströme noch Gebirge, so vergingen die Fünf Elemente; ${ }^{422}$ hätte der Mensch keine Worte, welche den Weg in sich tragen, so gäbe es in hundert Generationen keine gütige Herrschaft. [5] Dabei sollen diese drei Dinge freilich einander befördern, indem sie sich gegenseitig stützen, und nicht eines davon dürfte man verwerfen. [6] Nun ist es der Oberste Herr, ${ }^{423}$ welcher Mus-

417 Die Textbasis der nun folgenden kommentierten Übersetzung ist auf dem Titelblatt als im April 1881 besorgter Nachdruck der 1. Auflage von 1878 gekennzeichnet. Das Original ist in kanbun mit Lesehilfen und Inversionszeichen gehalten.

418 „Sterne und deren Koordinaten“ für seishin 星辰. Die „Koordinaten“ (shin 辰) der Sterne dienen als Maß der Zeitrechnung.

419 „Muster und Urbilder“ für bunshō 文章, gleichzeitig ein Begriff der nachträglichen Abstraktion vorhandener Formen wie auch der abstrakten Vorlage künftig zu produzierender Formen. Beide sind Ableitungen der Grundbedeutungen „rote und blaue Muster“ für bun 文 und „rote und weiße Muster“ für shō 章 (DKJ 5-13450-443). Nakamura zitiert mit bunshō den zentralen Terminus des Titels Bunshō kihan kōkai, also der Sammlung, der er durch sein Vorwort zu Prestige verhelfen soll. Die Standardübersetzung von bunshō in „Text“ erscheint wegen der Grundbedeutung des lateinischen Wortes textum („Gewebe“) zunächst möglich, trifft aber nicht den von Keiu zitierten wörtlichen und deswegen hier übersetzten Sinn. Im später (Abschn. 4.4.1) zu diskutierenden Bunshō ron (1889) des Futabatei Shimei steht das Wort bunshō schon für den heute vorrangigen Begriffsinhalt „Text“.

420 „Firmament“ für ten 天. Die hier entfaltete Vorstellung vom Universum als voneinander abhängender „Muster und Urbilder“ ist wohl nicht eine Erfindung Keius. Sie findet sich beispielsweise auch in einem von Matsumoto Keidō 松本奎堂 (1832-1863) verfassten, postum gedruckten Motto (dai 題) zu zwei nicht spezifizierten Bildern. Keidō bezeichnet die in den Bildern dargestellten Naturszenen (Regendunst und dichte Wälder) als Muster und Urbilder von „Himmel und Erde“ (tenchi 天地) (МАTSUMOTO 1869-I: 10b).

421 „Weg“ für dō 道, hier eine Bezeichnung für die ethisch-moralische Orientierung des Menschen.

422 „Fünf Elemente“ für gogyō 五行, die alle Dinge hervorbringenden Grundelemente Holz, Feuer, Erde, Metall und Wasser.

423 „Oberster Herr“ für jōtei 上帝 (chin. shangdi). Keius Spezialisierung auf China-Gelehrsamkeit (kangaku) würde zunächst nahelegen, jōtei als die der chinesischen Philosophie entstammende Bezeichnung eines (womöglich anthropomorphen) weltbeherrschenden Wesens zu sehen. Freilich durchliefe der Begriffsinhalt auch dann noch Wandlungen (CHANG 2000), welche die Interpretation erschwerten. Vor dem Hintergrund der Tatsache, dass Keiu sich seit 1871 zum Christentum hingezogen fühlte und 1874 vom methodistischen Pfarrer George Cochran (1834-1901) hat taufen lassen, ist hier als Signifikat allerdings eher der christliche „Gott“ anzunehmen. In diesem Sinne hat schon der italienische China-Missionar Matteo Ricci (1552-1610) das Wort shangdi verwendet. Der China-Missionar Walter Henry Medhurst (1796-1857) griff diese Übersetzung wie- 
ter und Urbilder im Himmel und auf Erden schafft, und unsereins kann nichts davon wissen. [7] Ich will aus diesem Grunde nun jene Dinge nennen, welche Muster und Urbilder des Menschen auszumachen haben und darüber sprechen. [8] Nun, also: [jene] Muster und Urbilder entstehen aus Anstand und Vernunft. ${ }^{424}$ [9] Anstand und Vernunft entstehen aus der Wissenschaft. [10] Reift die Wissenschaft, so entstehen Anstand und Vernunft, entstehen Anstand und Vernunft, so ergeben sich Muster und Urbilder. [11] Schaut man sich einmal in den Mustern und Urbildern der Weisen und Tüchtigen ${ }^{425}$ sowie bei Allen Meistern und den Hundert Schulen ${ }^{426}$ um, so sind sie alle von dieser Art. ${ }^{427}$

Im Zusammenhang der vorliegenden Abhandlung interessiert vor allem Keius Idealvorstellung von „Mustern und Urbildern“ (chin. wenzhang 文章, jap. bunshō), die als natürliche Verbindung alle Elemente des Kosmos im ursprünglichen Sinne des lateinischen Wortes textum in einen gewebeartigen Gesamtkontext bringen. Auch der Schrifttext im Allgemeinen und die in Moris Mustersammlung enthaltenen Proben der Wortkunst im Besonderen sind bei Keiu in das kosmische Gesamtsystem eingebunden und sollen dessen Gesetzmäßigkeiten genauso folgen wie das Planetensystem und die Naturerscheinungen auf der Erde: Sie sind zugleich Abbild der Idee des „Obersten Herrn“ (jōtei 上帝 im Sinne von „Gott“) wie auch Muster aller künftigen Konkretionen dieser Idee. Für Fiktion und Imagination ist in Keius Literaturmodell kein Platz: Alles ist schon gemacht, die von Keiu so heftig verdammte fiktionale Prosa (siehe Anm. 412) gehört überhaupt nicht zu den „Mustern und Urbildern“. Die Beantwortung der Frage, wie existierende fiktionale Prosa in diesem Weltbild unterzubringen wäre, also ob fiktionale Prosa nicht Teil der Realität sei, blieb Keiu schuldig und trug dieses Weltbild in die höchstrangige Bil-

der auf und vertrat sie 1843 auf einer Konferenz in Hongkong, auf der englische und amerikanische Missionare eine revidierte chinesische Übersetzung der Bibel beschlossen (YANABU 2001 [1986]: 119-121).

424 „Anstand und Vernunft“ als behelfsmäßige Übersetzung für dōri 道理. Auch hierbei gilt die Annahme, dass Keiu nicht die klassisch-konfuzianische (etwa in „Moral und Urprinzip“ übersetzbare), sondern eine an westlichen (womöglich christlichen) Werten orientierte Bedeutung im Sinne hat, beispielsweise die im Waei gorin shūsei 和英語林集成 (A Japanese and English Dictionary; with an English and Japanese Index, 1867; digitale Version recherchierbar über http://www.meijigakuin.ac.jp/mgda/waei/search/, zuletzt aufgerufen 29/09/2021) des protestantischen Missionars James Curtis Hepburn (1815-1911) gegebenen Interpretationen reason, right principle, natural rule.

425 „Weise und Tüchtige“ für seiken 聖賢, womit für China die mythischen Urkaiser und die „Gründerväter“ des Konfuzianismus (Kongzi, Mengzi) gemeint sind.

426 „Alle Meister und die Hundert Schulen“ für shoshi hyakka 諸子百家, womit für China die Exegeten der konfuzianischen Klassiker gemeint sind.

427 Hieran schließt Keiu das Argument an, dass seine Zeitgenossen im Allgemeinen die Texte des alten China nicht mehr verstünden und das von Mori Tatsuyuki zusammengestellte Musterbuch eine willkommene Abhilfe dieses Mangels sei. 
dungsanstalt des neu gegründeten japanischen Zentralstaates, nachdem er am 11. August 1881 zum ordentlichen Professor an der Universität Tōkyō (Tōkyō Daigaku 東京大学) ernannt wurde. ${ }^{428}$

\section{„Je nach Textsorte sollen Fiktion und Wirklichkeit in einem eigenen Verhältnis stehen.“ Inoue Tetsujirō als Modernisierer der Literatur}

Nur ein Jahr nach Nakamura Keiu wurde 1882 Inoue Tetsujirō 井上哲次郎 (1856-1944) als außerordentlicher Professor an die Universität Tōkyō berufen. In ihren Idealvorstellungen von Literatur hätten die beiden Kollegen verschiedener nicht sein können: Dem soeben gesehenen, erzkonservativen Literaturbild Keius stand Inoues Propagierung einer Modernisierung der Literatur nach westlichen Mustern diametral entgegen. ${ }^{429}$ Erste, mündliche Auseinandersetzungen über literaturtheoretische Fragen dürften Nakamura und Inoue kurz nach Inoues Antritt geführt haben. Den direkten Anstoß zu einer schriftlichen Diskussion mit Nakamura gab Inoue durch eine im März 1883 in Nr. 18 der Tōyō gakugei zasshi 東洋学芸雑誌 ([Zeitschrift für Gelehrsamkeiten und Kunst Ostasiens]) veröffentlichte Zuschrift des Titels Nakamura Keiu ō ni yosete sho su 寄 中村敬宇翁書 ([Dem ehrenwerten Nakamura Keiu gewidmete Zuschrift], 1883). Im Folgenden Inoues Zusammenfassung seiner sich wohl daran anschließenden Diskussion mit Nakamura. ${ }^{430}$

Neulich besuchte ich Herrn Professor Keiu und befragte ihn zu Poesie und Prosa. ${ }^{431}$ Der Herr Professor merkte an, dass er an Poesie und Prosa das Tatsächliche ${ }^{432}$ schätze, die Vorstellung ${ }^{433}$ hingegen nicht. Ich sage bei aller gebotenen Bescheidenheit, ${ }^{434}$ dass ich bei Poesie das Vorgestellte, nicht aber das Tatsächliche schätze. Das Tatsächliche ist nur in der Prosa zu schätzen. Eine absolut schöne Szenerie ${ }^{435}$ gibt es nicht allezeit zu sehen, sie erscheint zwischen Himmel und Erde nur zu einer ausgewählten Zeit. Ein absolut

$428 \mathrm{Ab} 1884$ in der Fakultät für Literaturwissenschaft (bungaku bu) „Chinesische Gelehrsamkeit“. 429 Das erste Ergebnis von Inoues Modernisierungsbestrebung war die zusammen mit Toyama Masakazu 外山正一 (1848-1900) und Yatabe Ryōkichi 矢田部良吉 (1851-1899) herausgegebene Anthologie Shintai shishō 新体詩抄 ([Exzerpte zur Dichtung neuen Stils], 1882).

430 Textbasis ist der Nachdruck in Sonken shishō 巽軒詩鈔 ([Sonkens poetische Exzerpte], 1884) (INOUE 1884-II: 11b-16a).

431 „Poesie und Prosa“ für shibun 詩文.

432 „Tatsächliches“ für jitsuji 実事.

433 „Vorstellung“ für sōzō 想像.

434 „Bei aller gebotenen Bescheidenheit sagen“ für hisoka ni iu 窕謂.

435 „Absolut schöne Szenerie“ für zekka no kei 絶佳之景, worin das Absolute nicht eine enthusiastische Emphase ist, sondern vielmehr als philosophischer Begriff das von Zeitflüssen unberührte Unwandelbare bezeichnet. Analog gilt dies auch für den Ausdruck zekki no jō 絶奇 之情 (Anm. 437). 
wunderbares Gefühl ${ }^{436}$ gibt es beim Menschen nur zu einer ausgewählten Zeit. Dieses absolut wunderbare Gefühl sowie jene absolut schöne Szenerie bildet man in einem Gedichte nach seiner Vorstellung ab. Wie sollte man dies nicht elegant nennen? Wollte man nun dagegen nur die Szenerie und das Gefühl so abbilden, wie man es vor Augen hat, so wäre [das Ergebnis] flach und vulgär. Das ist der Grund, warum der Poet in westlichen Ländern die Vorstellung zur Hauptsache macht. Man nehme als Beispiel das Paradise Lost von John Milton, ${ }^{437}$ worin es nichts gibt, das nicht aus der Vorstellung hervorgegangen wäre. Dass diese Dinge aus der Vorstellung hervorgingen, macht sie elegant. Auch sagte der Herr Professor, dass er bei Prosa die Einfachheit schätze, und Prosa nichts transportiere, wenn sie nicht einfach sei. Ich sage bei aller gebotenen Bescheidenheit, dass ich zwar der Prosa meine Wertschätzung nicht versage, wenn sie einfach gestaltet ist, doch aber im Ganzen die umsichtige Gestaltung und die Zieseliertheit zu schätzen weiß. Ich will versuchen, dies zu erörtern. Vergleiche ich chinesische Prosa ${ }^{438}$ mit der europäischen, so stellen sich große Unterschiede heraus. Die chinesische Prosa ist kurz und bündig, die europäische genau und exhaustiv, und dies nicht zufällig: Die Menschen des Westens sind in ihrer Gelehrsamkeit tiefschürfend und in die Weite blickend, in ihrem Denken präzise und detailliert. Sie sind darin dem Chinesen, der einseitig zu ornamentaler Schreibweise neigt und deswegen an der Ergründung des Prinzips ${ }^{439}$ vorbeigeht, überlegen. Nun könnte jemand einwenden, dass es auch in China genaue und exhaustive Prosa gebe. Doch nach meiner Ansicht ist diese noch immer derjenigen des Westens unterlegen.

Inoue entwirft hier ein hermetisches System der Wortkunst, der er im Gegensatz zu Keiu keinen Platz im Universum zuweist, sondern „nur“ die Rolle einer Triebkraft gesellschaftlichen Fortschritts.

\section{„Für Lyrik und Prosa gelten dieselben Gesetze - Einfachheit ist oberstes Gebot.“ Keius Verteidigung gegen Inoue}

Auf die soeben zusammengefassten Argumente Inoues antwortet Keiu in Nr. 19 der Tōyō gakugei zasshi mit seinem Beitrag Futatabi Inoue Sonken kun ni sho su 復井上巽軒君書 ([Erneut schreibe ich an Herrn Inoue Sonken], 1883), ${ }^{440}$ in dem

436 „Absolut wunderbares Gefühl“ für zekki no jō 絶奇之情. Zum Begriffsgehalt siehe Anm. 436.

437 Das von John Milton (1608-1674) verfasste, 1667 erschienene Epos Paradise Lost behandelt in zwölf Bänden den in der Bibel geschilderten Sündenfall des ersten Menschen. Inoue meint mit „Vorstellung“ wohl das Imaginäre wie Satans Wohnsitz, das Zwiegespräch zwischen Gott Vater und Sohn, das Paradies, Engel, die Schaffung der Welt, Sündenfall und Urteilsspruch sowie (in den beiden letzten Büchern) Visionen des zukünftigen Heilsgeschehens.

438 „Chinesische Prosa“ für kanbun 漢文, was hier nicht den von Inoue in diesem Schreiben selbst als Wissenschaftssprache verwendeten sinisierenden japanischen Stil meinen kann.

439 „Ergründung des Prinzips“ für kyūri 究理, was zu Inoues Schreibgegenwart neben der hier gewählten Interpretation auch für Naturwissenschaften stehen kann.

440 Tōyō gakugei zasshi 19 (1883): 512-514. Der Nachdruck in Keiu bunshū 敬宇文集 ([Sammlung von Keius Texten], 1903) variiert den ursprünglichen Titel in Inoue Sonken ni kotaete sho su 答井上巽軒書 ([Als Antwort auf Inoue Sonken schreibe ich erneut]; NAKAMURA 1903-I: 14b-18b). 
er nicht zuletzt den chinesischen Philosophen Kongzi, gewissermaßen den Urvater seiner geistigen Schulung, verteidigt.

Die Frage von Aufwändigkeit und Schlichtheit ${ }^{441}$ sowie Leere und Fülle ${ }^{442}$ betrifft gleichermaßen Poesie und Prosa. ${ }^{443}$ Indem ich nachfolgend Aufwändigkeit und Schlichtheit anhand der Prosa erörtere, will ich auch die Frage von Leere und Fülle in der Poesie erörtern. Nun also: Dass in der Prosa Aufwändigkeit und Schlichtheit von Bedeutung sind, liegt daran, dass es Schicklichkeit ${ }^{444}$ gibt. [4] Was ich nun Schicklichkeit nenne, das ist bei Riten und Zeremonien hoher und niederer Rang für Alter und Jugend. [5] Sie haben jeder für sich ein Maß, dessen Erscheinung stimmig ist. [6] So ist es auch bei der Prosa. [7] Es kommt vor, dass es recht ist, wenn sie entweder aufwändig und detailliert oder das ganze Gegenteil ist. [8] Da man sich nicht tausend Worte und Zehntausend Wörter merken kann, ist es angenehm, wenn [der Text] kurz ist. [9] Es ist keine Krankheit, wenn halbfertige Formulierungen oder Wiederholungen geringgehalten werden. [10] Die Prosa des Konfuzius kommt mit wenigen Wörtern aus, und das ist Schlichtheit.

Im Grunde wiederholt Keiu damit bei veränderter Formulierung doch nur den bereits weiter oben referierten Standpunkt, geht also genauso wenig auf Inoues Argumente ein wie umgekehrt Inoue auf die Funktion, die Keiu der Literatur zuweist.

Zuerst erstaunt, dass der konfuzianisch-konservativ argumentierende Keiu der Literatur einen größeren Wirkungsbereich zugesteht als der westlich-reformerisch argumentierende Inoue. Wir dürfen aber daneben auch nicht übersehen, dass sich im oben umrissenen Disput bei aller thematischen Sprunghaftigkeit und argumentativer Inkonsistenz doch jene prinzipiellen Fragen verdichten, welche die Entwicklung der Literaturtheorie in der Übergangsphase zwischen der späten Edo-Zeit (hier vertreten durch Keiu) und der frühen Meiji-Zeit (hier vertreten durch Inoue) prägten, nämlich:

- Gibt es ein mit allen anderen Erscheinungen der Welt auch die Wortkunst einbindendes System? Darf und soll ein solches Gesamtsystem einem einzigen Prinzip folgen?

441 „Aufwändigkeit und Schlichtheit“ für hankan 繁簡.

442 „Leere und Fülle“ für kyojitsu 虚実.

443 Mit „Prosa“ (bun) kann Keiu vor dem Hintergrund der oben geschilderten Verdammung der als haikan shōsetsu oder gesaku („zum Spaße geschrieben“) bezeichneten fiktionalen Prosa nur die wissenschaftliche Prosa meinen.

444 „Schicklichkeit“ für tō 当. 
- Welchen Einfluss hat die Auflösung des erwähnten Gesamtsystems auf dessen Bestandteile? Werden sie zwar frei, aber gleichzeitig auch für die Gesellschaft in deren Gesamtheit irrelevant?

\subsection{8 „Wahrheit“" im Wandel}

Die in den Abschnitten 4.1.1 bis 4.1.7 angeführten japanischen Literaturtheorien zur Dichotomie „Fiktion - Wirklichkeit“ der Jahre 1849-1878 erheben zwar gegenüber der fiktionalen Literatur nach wie vor den Anspruch der Nähe zur „Wahrheit“, indes verändern sich Begriffsinhalt und Wertung der „Wahrheit“. Denn altgediente Wörter wie makoto 真 („Aufrichtigkeit“), michi 道 (auch dō, „[der rechte] Weg“), ri 理 („[Ur-]Prinzip“) sowie Antonyme wie bōtan 妄誕 (,verwirrende Unwahrheiten“), itsuwari 偽り und uso 嘘 („Lügen“) sowie jitsu 実 („Wirklichkeit“), referenzieren nun andere Gegenstände.

Lebendig ist zwar noch die traditionelle Anschauung, dass wenigstens die Lyrik in der Lage sei, das „Ur-Prinzip“ abzubilden. Aber Fiktionalität wird nun auch als erkenntnisfördernd angesehen, transportiert die für die Lebenspraxis des Individuums relevante „Wahrheit“ der neuen (westlichen) Welt, Wortkunst wird zum Instrument der Exploration der „Wahrheit“, ja, fiktionale Literatur wird sogar zu einem Teil der natürlichen, die Konkreta erst befördernden UrEnergie $k i$ („Äther“). Die in der fiktionalen Literatur verarbeitete Wirklichkeit wird so zur Wirkmacht und befördert auf anderen Wegen als die empirische Überprüfung die Erkenntnis der Welt. Mit diesem begriffsinhaltlichen Wandel geht selbstverständlich eine Aufwertung der fiktionalen Literatur einher, gleichzeitig aber beginnt sie, neben der wissenschaftlichen Literatur einen eigenen Platz zu behaupten.

\section{2 ,Empfinden“ in „Leere“ und „Fülle“ der japanischen Literaturtheorien der Jahre 1850-1890}

Nach wie vor werden in diesem semantischen Bereich chinesische Schreibungen verwendet, die das Klassenzeichen „Herz“ (kokoro 心) enthalten. Wörter wie $i$ und kokoro 意 („Sinn“), shin und kokoro 心 („Herz“), jō und nasake 情 („Gefühl“) sowie shi und kokorozashi 志 („Neigung“) sind zwar untereinander nach wie vor nicht klar zu unterscheiden, aber als Ausdrücke der Gemütsbewegung außerhalb des kognitiven Bereichs bekommen sie einen anderen Akzent als vor 1850, wie die nachfolgenden Beispiele zeigen. 


\subsubsection{Nicht der Mond, sondern das Empfinden des Dichters bei dessen Anblick ist der eigentliche Sinn: Das Hitorigochi (1857) des Ōkuma Kotomichi}

Ōkuma Kotomichi 大隈言道 (1798-1868) war eigentlich zum Vorsitz seiner in Fukuoka ansässigen Kaufmannsfamilie ausersehen. Im Alter von 38 Jahren überließ er diese Aufgabe allerdings seinem jüngeren Bruder, um sich ganz der Waka-Dichtung widmen zu können und schloss sich jener Bewegung der Wende vom 18. zum 19. Jahrhundert an, welche einerseits die zentrale Position der Anthologie Kokin wakashū (914; Abschn. 3.4.2.2) bei der Prägung von Theorie und Praxis der japanischen Lyrik zu reetablieren, andererseits diese Anthologie und insbesondere die in deren Vorworten entfaltete erste japanische Poetik vor dem Hintergrund der völlig veränderten gesellschaftlichen Verhältnisse neu zu interpretieren suchte. Kotomichis Hitorigochi ひとりごち (Monologue, 1857) ${ }^{445}$ gehört zu den wichtigsten Texten eben dieser (in THOMAs 2004 ausführlich geschilderten) Bewegung und weicht bei aller sonstigen Anlehnung an Schriften des bedeutenden Theoretikers Kagawa Kageki ${ }^{446}$ in einem wesentlichen Punkt von jenem ab: Kotomichi sucht nicht nach einer universellen, die Dichtung aller Generationen vereinenden Qualität (die Kageki shirabe nennt), sondern besteht darauf, dass der Dichter und der Gegenstand seiner Dichtung (etwa ein Baum) ein jeweils individuelles „Herz“ (kokoro) habe.

[1] Bei Erörterungen mit Lernanfängern sagte ich, dass ein Lied nicht die Blüten und den Mond besinge. [2] Es spreche über das Empfinden, das ich Blumen und Mond beigebe. [3] Ich lehrte dies so, damit [die Lernenden] nicht versäumen mögen, das Herz zum Samen zu machen, um nicht zuzulassen, dass sie Kommentarlieder zu Blumen und Mond verfassten. [4] Lässt man sich selbst beiseite und spricht nur von Mond und Schnee, so mag man selbst sein wie man ist, mag ein Lied ein Lied sein, [die beiden] sind dann getrennte Dinge. [5] In späteren Zeiten gab es viele Lieder, welche in diese Richtung trieben, weswegen ich lehrte, dass man in der Absicht, jenen ursprünglichen Sinn mitzuteilen, nicht Mond und Schnee besinge. [6] Aus diesem Grunde sei es statthaft, allein vom eigenen Herzen zu sprechen und Mond wie Blumen beiseite zu lassen, es gehe um das Erstaunen über Mond und Schnee, welche man im Auge hat, über die Stimme des Vogels, welche man im Ohre hat, weil [das Erstaunen] der Samen des Liedes sei. [7] (Ich erläuterte, dass die „Empfindungen im Herzen“, von welchen das Vorwort des Kokinshū spricht, dem Gesehenen und Gehörten aufgetragen wird. [8] Es geht um Herz und Auge und Ohr.) ${ }^{447}$

445 Entstanden ist das Hitorigochi wohl um 1844 (Thomas 2004: 331; Anm. 47).

446 ÁROKAY 2010 übersetzt shirabe mit „Rhythmus“.

447 Onore hatsumanabi ni ronjite iwaku, uta wa hana tsuki wo yomu mono ni wa arazu. Sono hana tsuki ni tsukete, wa ga kokoro wo iu mono nari. Kaku oshietaru wa, kokoro wo tane to suru wo wasureji, hana tsuki no kōshakuka wo yomaseji tote iu nari. Onore wo okite, tsukiyuki nomi ieba, jishin wa ika ni arite mo, uta wa uta nite mo betsumono to naru. Kōsei kore ni nagaruru uta 
Kotomichi nennt das kana-Vorwort des Kokin wakashū explizit als Basis seiner Überlegungen und wiederholt (bei veränderter Formulierung) sowohl die Rollenverteilung als auch die Abfolge der Elemente der Dichtung: Die Empfindung ist der a priori bestehende Samen, die sprachlichen Referenzierungen außersprachlicher Gegenstände der Dichtung sind Träger, denen der Dichter a posteriori seine Empfindungen sprachlich ,aufträgt“ (tsukete iidasu). Wörter, die sich eindeutig den Begriffen „Fiktion“ und „Wirklichkeit“ zuordnen lassen, finden sich hier zwar nicht, doch ist das gesamte Hitorigochi darauf angelegt, die sprachliche Realisierung des sprachlich noch nicht Realisierten anzuleiten. Aufschlussreich in dieser Beziehung ist Kotomichis Bemerkung zur Metaphorik in der Dichtung.

[1] Dass einer gedichtet hat, eine Wasserralle klopfe gegen das Tor, kommt aus dem Herzen eines Menschen, welcher auf einen anderen wartet und deswegen selbst die Singstimme jenes Vogels so hörte, als klopfe ein Mensch an die Türe. ${ }^{448}$ [2] Lieder, in welchen

òkereba, saru moto no i wo shirashimemu tote tsukiyuki wo yomu mono ni wa arazu to oshietari. Sareba, tsuki hana [sic!] wo nozokite, wa ga kokoro wo iu nomi nite mo yoroshikarubeki wo, me ni kakaru tokoro no tsuki yuki, mimi ni kiku tokoro no torigoe, uta no tane to nareba, sore ni tsukete, kantan subeki koto nari (Kokin no jo, kokoro ni omou koto wo, miru mono kiku mono ni tsukete iidaseru nari to ieri. Kokoro to me to mimi to nari.) 己れ初学に論して曰、歌は花月を咏 むものにはあらず。その花月につけて、吾心を言ふものなり。かく教へたるは、心を種とす るを忘れじ、花月の講釈歌をよませじとて云なり。己を於きて、月雪のみいへば、自身はい かにありても、歌は歌にても別物となる。後世これにながるる歌多ければ、さる本の意を知 らしめむとて月雪をよむものにはらあずと教へたり。されば、月花をのぞきて、吾心を云ふ のみにても宜しかるべきを、目にかかる所の月雪、耳に聞くところの鳥声、歌の種となれ ば、それにつけて、感嘆すべき事なり。(古今の序、心に思ふことを、見るもの聞くものに つけていひ出せるなりと云へり。心と目と耳となり。) (ŌKUMA 1925 [1857]-I: 251). Die den letzten Satz umschließenden Klammern finden sich in der heir verwendeten Textfassung ebenso wie in ŌKUMA 1918 (S. 11). Mangels Zugang zu einer Originalversion kann ich nur annehmen, dass es sich um einen kleinen (womöglich doppelzeilig) geschriebenen Zusatz handelt. Eine komplette (allerdings ungenaue) englische Übersetzung des Hitorigochi bietet THOMAS 2004 [1857] (337-354), die von mir ins Deutsche übersetzte Passage ist als Nr. 26 auf S. 350 enthalten.

448 Kotomichi bezieht sich auf das Kapitel Akashi 明石 des Genji monogatari (ca. 1010). Akashi ist ein am Binnenmeer von Seto 瀬戸 gelegener Ort und gleichzeitig ein Beiname des dort lebenden Mönchs. Der nach einer den Kaiser kompromittierenden Liebesaffäre aus der Hauptstadt verbannte Genji flüchtet vom Verbannungsort in die Hütte des Mönchs Akashi am Meer, wo er bewirtet und mit Biwa-Musik unterhalten wird, und außerdem die schöne Tochter des Mönchs kennenlernt. Nach Aufforderung durch Akashi spielt auch Genji auf der Biwa. Die Schönheit der Tochter (die später ein Kind von Genji bekommen wird) und die Lauten-Musik erzeugen eine romantische, durch Erinnerungen an frühere Liebesabenteuer und Assoziationen aufgeladene, romantische Abendszene am See. Als Genji das einem Klopfen ähnliche Geräusch der Wasserrallen (kuina 水鷄) hört, hat er das traurige Empfinden (aware ni oboyu), jemand klopfe in vergeblicher Sehnsucht an die Türe einer Geliebten (NKBT 15: 71; MURASAKIWALEY 1960 [ca. 1010]: 265). 
ein solches Herz verlorengegangen ist, gibt es heutzutage viele. [3] Das Summen der sogenannten Zwirn-Grille kommt daher, dass einer in seiner armseligen Kleidung bei einbrechender Herbstkälte zu hören meint, dass selbst die Grillen ihn auffordern, nun [die Kleider] zusammenzulegen und zu verzwirnen. ${ }^{449}$ [4] Verliert man bei beiden Dingen deren eigentlichen Sinn aus den Augen, so steht der Sinn der Dichtung ihnen entgegen. ${ }^{450}$

Kotomichi nimmt hier gleich doppelt die Einbildung (nämlich die Genjis und die des Armen) im wörtlichen Sinne als dichterische Fassung des nicht Gegenständlichen in ein Bild, wobei er den nicht gegenständlichen Sinn (Sehnsucht, Angst vor Kälte) als den ursprünglichen Sinn (hon’i 本意) und dessen Verbalisierung in der Dichtung (yomu $i$ よむ意) als Verbildlichung begreift. Die Beziehung zwischen den beiden Sinnebenen der Wörter lässt sich freilich nur dann als die Dichotomie „Fiktion - Wirklichkeit“ interpretieren, wenn man Kotomichis expliziten Bezug auf die literarische Produktion (yоти) als eine Form der Fiktion versteht.

\subsubsection{Menschliche Gefühle bilden den mimetischen Kern der Literatur: Das Shōsetsu shinzui (1885-1886) des Tsubouchi Shōyō}

Tsubouchi Shōyō 坪内逍遥 (1859-1935) wird von der Literaturgeschichtsschreibung im Zusammenhang mit seiner Abhandlung Shōsetsu shinzui 小説神䯣 (The Essence of the Novel, 1885-1886) häufig als Vater der modernen japanischen

\footnotetext{
449 „Zwirn-Grille“ für tsuzurisase, eine verkürzte und lautlich abgewandelte Form von tsuzuresase kōrogi 綴刺蟋蟀 (zool. velarifictorus aspersus). Das Männchen dieser Art gibt bis in den November hinein nachts ein Geräusch von sich, das traditionell in der Onomatopöie ritsu ritsu versprachlicht wird. Diese Onomatopöie wiederum wird seit alters als Imperativ des Kompositverbs tsuzuresasu („zusammenlegen und mit Stichen vernähen“) und damit als Aufforderung gedeutet, für den herannahnenden Winter wärmende Kleider zu fertigen. Kotomichi spielt hier auf das von Ariwara no Muneyana 在原棟梁 (?-898) stammende Gedicht Nr. 1020 des Kokinshū (914) an. Es lautet: Akikaze ni / hokorobinu rashi / fujibakama / tsuzurisase chō kirigiri su naku 秋 風にほころびぬらしふぢばかまつづりさせてふきぎりすなく (NKBT 8: 315). „They must have been split, / those wisteria-trousers, / by the autumn wind, / for the crickets keep crying, / 'Patch up and sew! Patch and sew!', (KI-McCulLough 1985 [914]: 229).

450 Kuina no mon tataku to yomeru wa, moto hito matsu hito no kokoro yori, ka no tori no naku koe sae, hito no mon tataku ka to kikinaseru nari. Saru kokoro wo ushinaeru uta ima no yo ni ōshi. Tsuzuri sase to iu mushi mo koromo tomoshiki hito no, aki no samuku naru ni yorite, mushi sae tuzuri saseru to iu ka to kikitarinari. Futatsu nagara sono hon'i wo ushinaite wa yomu $i$ tagau beshi. 水鶏の門たたくとよめるは、もと人まつ人の心より、かの鳥のなく声さへ、人 の門たたくかと聞きなせるなり。さる心を失へる歌今の世に多し。つづりさせといふ虫も衣 ともしき人の、秋の寒くなるによりて、虫さへつづりさせるといふかと聞きたりなり。ふた つながらその本意を失ひてはよむ意違ふべし。(ŌKUMA 1925 [1857]-I: 247).
} 
Literaturtheorie dargestellt. ${ }^{451}$ Absolutheitsansprüche dieser Art sind stets mit dem Problem behaftet, dass sie andere wichtige Faktoren sowie eventuell parallel verlaufende Entwicklungen und agierende Personen ungerechtfertigt degradieren oder ganz außer Acht lassen, obwohl nur äußerst selten einzelne Personen und Faktoren historische Wendepunkte markieren. Von Tsubouchis Werken kann die Herbeiführung einer literaturhistorischen Wende nicht behauptet werden. Das Shōsetsu shinzui erweist sich vielmehr als jenen Traditionen verpflichtet, die einer Modernisierung von Praxis und Theorie der japanischen Literatur sogar entgegenstehen. ${ }^{452}$ Denn zwar tritt Tsubouchi für eine Befreiung der Literatur von Zweckbestimmungen (etwa jener der moralischen Läuterung der Leserschaft) und von der unnatürlichen Allegorisierung konfuzianischer Grundtugenden ein - stattdessen sollen nun „menschliche Gefühle“ (ninjō 人情) in den Mittelpunkt treten, die gesellschaftliche Situation sowie die Lebensführung (setai füzoku 世態風俗) sei ihnen im Roman unterzuordnen. Doch dabei setzt er „menschliche Gefühle“ mit den traditionell vom Buddhismus als Wurzel aller Leiden ausgemachten 108 Passionen gleich und verfällt so in überkommene Muster der Moralisierung. Die These, dass die Aufgabe der Literatur in der Schilderung dieser Passionen bestehe, borgt Tsubouchi (nicht zuletzt durch ein langes Zitat kenntlich) aus dem Genji monogatari tama no ogushi 源氏物語玉の小櫛 ([Kleiner Perlenkamm des Genji monogatari], 1796) des Motoori Norinaga. ${ }^{453}$ Gleichwohl sollte seine Rolle als „Geburtshelfer“ einer modernen japanischen Literaturtheorie nicht unter-

451 Aus zahlreichen möglichen Beispielen sei willkürlich Donald Keenes nachstehende Darstellung herausgegriffen: „Modern Japanese literary criticism came into being in the mid1880s with the publication of Tsubouchi Shōyō's Shōsetsu shinzui (The Essence of the Novel, 1885-1886)“ KEENE 1984-II: 505).

452 Details in UEDA 2005 und UEDA 2007.

453 „Although Shōyō recognizes imagination and fictionality as fundamental to the novel, he did not see imaginative creativity as a criterion for evaluating art. He held instead that ,dramatic structure' was essential, precisely in order to control the unfettered ramblings of the imagination. Thus he stressed that the proper aim of the novel as art ist the ,beautifully subtle effect of moving the reader by conveying the truth of human feelings'. This is the core of Shōyō's position on realism in the novel. [...] Shōyō wrote at the beginning of the chapter he entitled ,Shōsetsu no shugan“ 小説の主眼, ,The key aim of the novel is human feelings (ninjō 人情); life and the way it is lived (setai fūzoku 世態風俗) follow. ' This famous pronouncement proposes as the main aim of the novel, first the depiction of human psychology and feelings, and, second, the realitites of society and manners. However the passage continues as follows: ,What is meant by ninjō? Ninjō refers to human desires [jōyoku 情欲]; it means the 108 passions (hyakuhachi bonnō 百八煩悩 [defined by Buddhism])‘. Thus the ninjō of which Shōyō spoke are not a matter merely of psychology and feeling. They are in human life the secret of karma“ (inga no himitsu 因果の秘密); they are none other than human desires.“ (SUZUKI-TYLER 2006: 161). 
schätzt werden, alleine schon weil das Shōsetsu shinzui den Roman bereits in der generellen Einleitung zu Tsubouchis Romantheorie (Shōsetsu sōron 小説 総論) zu einer Kunstform erhob.

[1] Will man erläutern, was das Kunsthafte des Romanes sei, so muss man zunächst erfahren, was das Kunsthafte sei. [2] Will man aber erläutern, was das Kunsthafte sei, so muss man meiner Meinung nach zunächst die in der Öffentlichkeit [kursierenden] falschen Thesen demontieren und definieren, was die ursprüngliche Bestimmung der Kunst sei. ${ }^{454}$

Tsubouchi beruft sich hiernach zwar auch auf Thesen des seinerzeit in Tōkyō lehrenden, in der Tradition des Hegelianismus stehenden Ernest Fenollosa (1853-1908), die Vielzahl und Verschiedenartigkeit der im übrigen zurate gezogenen Quellen ${ }^{455}$ lässt jedoch notwendigerweise ein inkonsistentes Geflecht

454 Shōsetsu no bijutsu taru yoshi wo akiramemaku seba, mazu bijutsu no nan taru wo ba shirazaru bekarazu. Sa wa are bijutsu no nan taru wo akiramemaku hori seba, yo no byūsetsu wo haiseki shite, bijutsu no hongi wo sadamuru wo ba, mazu daiichi ni hitsuyō nari to su. 小説の 美術たる由を明らめまくせば、まづ美術の何たるをば知らざる可らず。さはあれ美術の何た るを明らめまくほりせば、世の謬設を排斥して、美術の本義を定むるをば、まづ第一に必要 なりとす。 (TsuBOUCHI 1974 [1885]: 43). „To explain what makes the novel art, we must first define the nature of art itself; and to do that, we must determine its basic principles, casting off popular misconceptions on the subject, which has long been surrounded by controversy“ (TsubouchI-TwinE 1981: 4). Eine von Nanette Twine in diese Übersetzung eingebrachte Kontroverse wird im Original nicht erwähnt. An den hiermit vorgetragenen Gedankengang schließt sich Tsubouchis Argument an, dass Literatur zwar eine charakterlich läuternde Wirkung auf den Menschen haben mag, dass aber - hier der Unterschied zu Werkzeugen wie einem Messer - die Wirkung nicht das selbe wie der Zweck sei.

455 Sugaya Hiromi legt die alleine schon wegen des Nebeneinanders früherer und späterer Versionen des Shōsetsu shinzui komplexe Intertextualität dar und plausibilisiert anhand von Gegenüberstellungen entsprechender Passagen der Endversion des Shōsetsu shinzui mit in Frage kommenden Quellen deren Verwendung. Dazu gehören nach Sugaya neben (A) japanischen Theoremen aus (a) Genji monogatari tama no ogushi (1796) des Motoori Norinaga, (b) Haisetsu tora no maki 稗説虎之巻 ([Der kurze Weg zum historisierenden Roman], 1843) des Takizawa Bakin, (c) Bijutsu shinsetsu 美術真説 ([Neue Theorie der Kunst], 1882) des Ernest Fenollosa in der japanischen Zusammenfassung von Ōmori Ichū 大森惟中 (1844-1908), (d) Dai Nihon Bijutsu shinpō chogen 大日本美術新報緒言 ([Vorwort zu den Neuen Nachrichten von der Kunst Großjapans], 1883) des Ōuchi Seiran 大内青巒 (1845-1918), (e) Shūji oyobi kabun (1884-1885) des Kikuchi Dairoku, (f) Shintaishi shō 新体詩抄 ([Dichtung neuen Stils], 1882) von Toyama Masakazu 外山正一 (1848-1900) und Yatabe Ryōkichi 矢田部良吉 (1851-1899) und (g) Kapitel 10 aus Yakusho doppō 訳書読法 ([Wie man Übersetzungen liest], 1883) des Yano Fumio 矢野文雄 (1851-1931) auch (B) westliche Quellen, unter anderem (a) The Philosophy of Style (1852) von Herbert Spencer (1820-1903), (b) English Composition and Rhetoric (1866) von Alexander Bain, (c) das Schullehrbuch Rhetoric (1869) des Erastus Otis Haven (1820-1881), (c) der Artikel über Romance aus der Encyclopædia Britannica (Auflage und Jahr 
von eingeschränkter Stringenz entstehen. Das erweist sich insbesondere bei Tsubouchis Behandlung des Realitätsbegriffes. Unter literarischem Realismus versteht er das Abbilden (utsusu 写す) der angedeuteten Passionen, der über die Schilderung sinnenhaft wahrnehmbarer Emotionen hinausgehenden, imaginierten Welt erteilt Tsubouchi eine Absage.

The novelist, then, should concentrate on psychological realism. Once his characters make their appearance in the story, he should think of them as living people. In speaking of their feelings, he should stand by as an onlooker and describe things as they really are, rather than superimposing his own ideas of emotion, good or bad, upon them. [...] The [chess-] player is the creator of the universe, his pieces are mankind. His moves are mysterious and unpredictable. [...] If a novelist wants to explore human nature and paint society as it is, then he must write as if describing a chess play he is watching other people play. Should he, as an onlooker, offer even the smallest piece of advice, the game becomes his instead of the players'! It is only when he resists the temptation to change those things he thinks he could improve on and confines himself to the facts that his work can be called a novel. [...] There is, on the whole, no external difference at all between a novel and a true story, but the hero of a novel is entirely a product of the author's imagination. Even so, once a character has made its appearance in a novel, not even an author may move him at will. He must think of him as another person, and ascribe to him only realistic behaviour. ${ }^{456}$

des verwendeten Exemplars nicht zu klären) und (d) Theories and Practice of Modern Fiction (Fortnightly Review 38, Dec. 1883, S. 870-876) eines Henry Norman (fl. 1883) (SugAYA 1979).

456 Tsubouchi-Twine 1981 [1885-1886]: 25-26. Sareba shōsetsu no sakusha taru mono wa moppara sono $i$ wo shinri 心理 ni sosogite, wa ga tsukuritaru jinbutsu nari tomo, ichido henchū 篇中 ni idetaru ijō wa, kore wo katsusekai 活世界 no hito to minashite, sono kanjō 感情 wo utsushiidasu ni, aete onore no ishō 意匠 wo mote zen'aku jasei no jōkan wo tsukurimōkuru koto wo ba nasazu, tada bōkan 傍観 shite ari no mama ni mosha 模写 suru kokoroe nite aru beki nari. [...] Sashite 囲棋者 wa zōka no ō 造化の翁 ni shite, kishi 棋子 wa sunawachi ningen nari. Sashite no sashikata 配劑 no fukashigi 不可思議 naru [...]. Yue ni shōsetsu wo tsuzuru ni atarite yoku ninjō no oku 人情の奥 wo ugachi, setai no shin wo emaku hori seba, yoroshiku tanin no shōgi wo mite, sono kyokumen no nariyuki wo ba hito ni kataru ga gotoku ni nasu beshi. Moshi ichigon ikku tari to omo okame 傍観 no jogen wo kudasu toki ni wa, shōgi wa sude ni sakusha no shōgi to narite, ta no nanigashira ga sashitaru shōgi to wa iu bekarazu. ,Ana kono tokoro wa ito tsutanashi, moshi ware nari seba, kaku nasubeshi, kayō kayō ni okonau beki ni!‘ to omowaruru kado mo aratamezu shite, tada ari no mama ni utsushite koso hajimete shōsetsu to mo iwaruru nare. Oyoso shōsetsu to jitsuroku 実録 to wa, sono gaibō ni tsukite mireba, sukoshi mo sōi no naki mono tari. Tada shōsetsu no shujinkō 主人公 wa jitsuroku no shi 主 to onajikarade, mattaku sakusha no ishō ni naritaru kyokū kasetsu 虚空仮説 no jinbutsu naru nomi. Saredomo ittan shutsugen shite shōsetu chū no hito to nari naba, sakusha to iedomo hoshiimama ni kore wo shintai 進 退 nasu bekarazu. Ataka mo tanin no yō ni omoite, shizen no omomuki wo nomi utsusu beki nari. (Tsubouchi-NAKAMURA-UmEZAWA 1974 [1885-1886] (NKiBT 3): 71-72; Faksimile in Tsubouchi-InAGAKI 1982 [1885-1886] 2: 19b - 3: 23a). Nanette Twines Übersetzung enthält auch an dieser Stelle Unschärfen, die aus Platzgründen nicht zu diskutieren sind. 
Tsubouchi spricht zwar dem Schachspieler die Funktion des „creator of the universe“ (zōka no o 造化の翁) ${ }^{457} \mathrm{zu}$, dem Autor fiktionaler Literatur aber Recht und Fähigkeit zur Kreation eines eigenen Universums eindeutig ab. Die imagination (kyokū kasetsu 虚空仮設, „aus der Leere vorübergehend Geschaffenes“ $)^{458}$ stößt hier an die Grenzen der postulierten Autarkie der Protagonisten des Romans und kommt dabei - mit Sicherheit unbeabsichtigt! - der von Kyokutei Bakin in seinen yomihon intensiv gepflegten und von Tsubouchi heftig kritisierten These von der schicksalhaften Prädestination (en 縁) der Protagonisten verdächtig nahe. Vor allem bleibt es bei Tsubouchi trotz leidenschaftlicher Bekenntnisse zum Gegenteil dabei, dass literarische Texte unrealistisch sind, jedenfalls in dem Sinne, dass sie nicht selbst Teil der Realität werden, sondern analytisch getrennt neben sie gestellt werden.

\subsubsection{Vorstellbare geheime Empfindungen: Literatur als realistische Fiktion im Ryokusa dan (1888) des Sudō Nansui}

Sudō Nansui 須藤南翠 (1857-1920) war ein prominenter Journalist der MeijiZeit. Früh der Bewegung für Freiheit und Volksrechte (jiyū minken undō 自由民 権運動) zugeneigt, ordnet er sich dem liberalen Spektrum zu. Seine journalistische Laufbahn ist von vielen zeitkritischen Artikeln geprägt und führte ihn durch mehrere von der Meiji-Regierung argwöhnisch beobachtete Zeitungen.

Mit Shosei shashin Ryokusa dan 処世写真・緑筥談 ([Wahrheitsgetreue Abbildung der Lebensführung - Gespräch des grünen Regenmantels]) legte Sudō 1888 einen Text des Genres seiji shōsetsu 政治小説 („politischer Roman“) vor. Das Vorwort dieses Romans, dessen Titelvorsatz Shosei shashin ([Wahrheitsgetreue Abbildung der Lebensführung]) die Metaebene des Realismus einführt, mag man in seiner Gesamtheit zwar nur bedingt als theoretischen Text betrachten, die im Folgenden übersetzten Passagen verdienen allerdings Beachtung.

Die großen Hauptpunkte der Strukturierung. Da der Kernpunkt des Romans in der Strukturierung [ritsuan] besteht, habe ich meine Anstrengung beim Schreiben ganz darauf gerichtet, die Gestaltung neuartig, die Schreibintention hochwertig zu halten und [den Roman] in bedeutungsvoller und überraschender Art zu gestalten. Ich will fürs Erste

457 Die Abgrenzung kreativer Kompetenzen durch Gegenüberstellung der Begriffe $z \bar{o} k a$ ([Welten]schöpfer) und sakka (Macher) ist immer wieder in der Literaturtheorie des Betrachtungszeitraums anzutreffen (siehe auch S. 16-17, Anm. 28).

458 An anderer Stelle verwendet Nanette Twine das englische imagination zur Übersetzung des japanischen Ausdrucks kasaku 仮作 (,vorübergehend gemacht“) (TsuboucHI-Twine 1981 [1885-1886]: 27) und trägt so ihrerseits zur Inkonsistenz des Textes bei. 
beiseite lassen, dass ich dies aufgrund meines flachen Wissens und eng begrenzter Begabung nur zur Hälfte erreicht habe, und möchte lediglich darlegen, was mit meinem Sinnen [seishin] zu tun hat. [...] Um es auf das Wichtigste zu reduzieren: Ich bin über die tatsächliche Beschaffenheit der Dinge [ari no mama no koto] einen Schritt hinausgegangen und habe meine Vorstellungskraft [sōzōryoku] in Gang gesetzt in der Absicht, die nicht offen auftretenden Geheimnisse menschlicher Empfindungen vollständig abzubilden, habe Dingen wie dem Undenkbaren und Seltsamen oder auch dem Appell an den Zeitgeschmack und dem Außergewöhnlichen keinen Raum in meinem Sinnen gegeben. Ich bin vorgedrungen bis zu dem Extrem, bis zu welchem die Seele der Gegenwart wohl voranschreitet, bis zu dem Punkt, bis zu welchem menschliche Gefühle sich wohl entwickeln und habe dann getrennt zwischen jenen Dingen, welche sich von dort aus entwickeln können und welche sich [von dort aus] nicht entwickeln, habe nicht die Theorie der menschlichen Psyche angewendet, sondern die Details des menschlichen Herzens nach dessen Sezierung beschrieben und mich bemüht, im Rahmen des Vorgestellten und Gedachten wahrhaftige und konkrete Gefühle abzubilden. Ich lasse die Frage, ob dies letztendlich dem Wesen der Kunst entspricht oder nicht, als gesondertes Problem beiseite, bilde das extrem Schöne mit extrem feinem Pinsel extrem [genau] ab und bemühe mich im übrigen, Vorstellungen, welche anderen Extremen zustreben, möglichst zu meiden. ${ }^{459}$

459 Ritsuan no taiyō. Shōsetsu no yō wa moppara ritsuan ni aru mono nareba, yo wa tsutomete ishō wo arata ni shi, sakui wo kōshō ni shite, kore wo genmyō fushigi no aida ni jo shi tsukusan to hakareru mono nari. Sengaku rōsai ni shite omoi no nakaba ni mitazaru wa shibaraku koko ni wa ronzezu, tada yo ga seishin no kakawaru tokoro wo shimesu nomi. [...] Yō suru ni yo wa, ari mo mama no koto wo ari no mama yori ippo susumete ninjō wo happyō sezaru shinpi ni utsushi dasan koto ni sōzōryoku wo hatarakashite, ihyō to ka fushigi to ka, moshiku wa jikō ni tōsuru to ka ariuchi igai no koto to ka ieru tagui wo sukoshi mo seishin ni yadorashimezu, yo no naka no shinri wa kono kurai ni made susumu naran, ninjō to iu mono wa kono ten ni made wa tassuru naran, koko no kanjō wa kaku aru beshi, koko no dōri wa kaku henka suru naran to iu kyokutan wo suikyū shite, sore yori hasshi ebeki kotogara to, hassezu shite seishin tomaru kotogara to wo wakachi, shinrigaku no riron mochiizu jinshin kaibō no bunshi wo egakite, sōzō suikō no aida ni shinko no kanjō wo utsusan to suru ni aru nari. Kore wo motte hatashite bijutsu no shinmenmoku ni kanaitaru mono naru ka shikarazaru ka wa betsumondai ni oki, yo wa ichi no gokubiteki wo gokuhitsu gokusha suru mo, hoka no kyokutan ni made oshitsumetaru sōzō wa narubeku saken to suru nari. 立案の大要 小説の要は専ら立案にあるものなれバ、予 八力めて意匠を新にし、作意を高尚にして、之れを玄妙不思議の間に叙し尽さんと図れるも のなり。浅学陑才にして思ひの半に充ざる八姑らく此には論ぜず、ただ予が精神の係る所を 示すのみ。 [...] 要するに予は、有の侭の事を有の侭より一歩を進めて人情の表発せざる神秘 に写し出さんことに想像力を働かして、意表とか不思議とか、若しくは時好に投ずるとか常 套以外の事とかいへる類を少しも精神に舎らしめず、世の中の心理八此の位にまで進むなら ん、人情といふもの八此の点にまでは達するならんといふ極端を推究して、夫れより発し得 べき事柄と、発せずして精神に止まる事柄とを分かち、心理学の理論を用るず人心解剖の分 子を画きて、想像推考の間に真個の感情を写さんとするに在るなり。是を以て果たして美術 の真面目に適ひたるものなるか否からざるか八別問題に措き、予は一の極美的を極筆極写す るも、他の極端にまで押詰めたる想像は成るべく避けんとするなり。(SUDŌ 1888-I: 7-9). 
Sudō überschreitet in der Theorie durch den Vermutungsausdruck naran (übersetzt mit „wohl“) die Grenze zwischen Beobachtbarem und Vorstellbarem, wobei er in bemerkenswerter Weise das Vorstellbare als Teil der Realität (des als shinko 真個 bezeichneten „Wahrhaften und Konkreten“) einführt. Der Literatur kommt so die Eröffnung eines hermeneutischen Zirkels zu, wodurch sie als Form der geisteswissenschaftlichen Auseinandersetzung mit dem thematisierten Gegenstand gekennzeichnet wird.

Nicht zum ersten Male sind wir an dem Punkt, an welchem Produktion und Rezeption der Literatur durch ihre theoretische Behandlung zum Teil eines Systems verschiedener Wissenschafts- und Erkenntnismodelle werden. Hier aber wird der prinzipiell schon 1680 von Matsuo Bashō formulierte Anspruch auf Wahrheit im Vorgestellten (Abschn. 3.4.2.4) erweitert um das mögliche Wahre Literatur kommt im Gebiet der spekulativen Wissenschaft an.

\section{3 ,Dynamik“ und ,Wesen“ in „Fiktion“ und „Wirklichkeit“ der japanischen Literaturtheorien der Jahre 1850-1890}

„Dynamik“ steht hier wie zuvor als Oberbegriff für Energie, Zeit und Bewegung sowie für die jeweiligen Antagonisten. Dabei werden weiterhin Wörter wie $k i$ 気 („Äther“), kiryoku 気力 („Kraft des Äthers“), dō 動 („Bewegung“) und ryūkō 流 行 („Strömung“) sowie weiterer Protagonisten und deren Antagonisten in diesem semantischen Feld verwendet.

Zwar sind Wörter wie „Wesen“ (seishin 精神) und deren jeweiligen Begriffsinhalte in philosophischen, religiösen Texten und auch in der Literatur (etwa im Man'yōshū, 8. Jhd.) schon lange etabliert. Aber in ihrer Verwendung als literaturtheoretische Termini beginnen sie erst in dieser Phase, sich zu verbreiten. Sie umschließen dort auch „Wesensgestalt“ ( füjin 風神), „Szenerie“ ( $k e i$ 景) und „Sinn“ ( $i$ 意). Alle diese Wörter signalisieren in den gesichteten Literaturtheorien die nicht versprachlichten Eigenschaften des sprachlich referenzierten Gegenstandes. Während in der dichotomischen Beziehung zwischen „Gestaltlosigkeit“ und „Gestalthaftigkeit“ die Gestalt das Gestaltlose ersetzt, nimmt in Theorien dieses Typs das „Wesen“ im versprachlichten „Tatsächlichen“ als pars pro toto teilweise Gestalt an. In vielen Theorien dieser Kategorie verweisen Formulierungen mit Begriffsgehalten wie „Zeit“ und „Bewegung“ als Signifikant auf Begriffsgehalte wie „Ruhe“, „Zeitlosigkeit“ und „Statik“ als Signifikat. 


\subsubsection{Bild im Gedicht, Gedicht im Bild - Im Gedicht müssen ,Leere` und ,Fülle‘ ausgewogen sein und Sinn sowie Wesensgestalt abbilden: Das Tansō shiwa (1856) des Hirose Tansō}

Das Tansō shiwa 淡空詩話 ([Tansōs Gespräche über die Poesie], 1856) ist die Aufzeichnung literaturtheoretischer Gespräche und frei formulierter Gedanken des konfuzianischen Gelehrten und kanshi-Dichters Hirose Tansō 広瀬淡空 (1782-1856). Den 27 Jahre nach dessen Tod erschienenen ersten Druck besorgte Tansōs Schüler und Adoptivsohn Hirose Seison 広瀬青邨 (1819-1884) und schrieb im Vorwort dazu, dass es sich um Exzerpte der auf die Poesie bezogenen Äußerungen im Seisai goroku 醒斎語録 ([Gesammelte Worte aus der Studierstube des Erwachens], nicht datiert) handele. Schon der Titel dieses Exzerptes kennzeichnet dessen Inhalt als Literaturtheorie im Sinne der eingangs der Abhandlung gegebenen Definition. Diese Kategorisierung bestätigt sich aus der Analyse der im Folgenden behandelten Abschnitte. Ein Großteil des Texts ist in Dialogform verfasst: Tansō antwortet auf die Fragen seiner Schüler nach dem Erlernen des Dichtens (shi wo manabu 学詩), nach Ethik, Wesen und Techniken der Poesie. Die Dialogform des Tansō shiwa bedingt dessen einfachen, der Umgangssprache angenäherten Stil. Kernpunkte in Tansōs Theorie sind die Zweckbestimmung der Poesie als Mittel zur Erziehung warmherziger und edler Menschen, die Notwendigkeit der größten Sorgfalt beim Dichten sowie die Fähigkeit, bei aller Pflege der überkommenen Dichtung (koshi 古詩) sein eigenes Wesen auszudrücken. Im Zusammenhang der vorliegenden Abhandlung sind in die im Folgenden exzerpierten Passagen von Bedeutung.

Im Gedicht ist Bildhaftes - im Bild ist Gedichthaftes. Dass zwischen bildlich darstellender und sprachlicher Kunst in der Edo-Zeit eine enge Nachbarschaft besteht, erhellt sich unter anderem aus dem Genre der bunjin ga 文人画 („Literatengemälde“) und zahllosen illustrierten Erzählungen. ${ }^{460}$ Tansō sieht nun aber in Bild- und Sprachkunst nicht nur eine enge Nachbarschaft, sondern gar eine gegenseitige Durchdringung und Überlappung und belegt dies mit dem folgenden Ausschnitt aus einem Diktum des Dichters Su Dongpo 蘇東坡 (10371101) zum Gedicht Shanzhong 山中 (In the Hill) des Wang Wei 王維 (699-759).

Wang ist geschickt im Abbilden der Szenerie. Ein Alter sagte dazu: ,Im Gedichte ist ein Bild. ${ }^{461}$

460 Als weitere Genres integraler Bild-Text-Literatur sind die kibyōshi und die daraus hervorgegangenen gōkan zu nennen.

461 HiRose-HiROSE 1883-I: 6b; NKBT 94: 359. 
Als bildhaft wird hier der statische, etwa durch Felsen repräsentierte, als gedichthaft der dynamische, etwa durch einen Fluss repräsentierte Bestandteil des Kunstwerks gekennzeichnet. Tansō spielt hier auf ein Diktum der von Cai Zhengsun 蔡正孫 (fl. 1289) zusammengestellten chinesischen Gedichtanthologie Shilin guangji 詩林広記 ([Poetisches Wäldchen und breit angelegte Notizen], 1289) an. Es heißt dort:

Dongpo sagte: ,Schmecke ich die Gedichte des Maketsu, [stelle ich fest:] in den Gedichten sind Gemälde. Betrachte ich die Bilder des Maketsu, [stelle ich fest:] in den Bildern sind Gedichte. $^{462}$

„Fülle“ und „Leere“ als Handwerkszeug. Ein Nakagawa Genkei 中川玄佳 ${ }^{463}$ fragt eingangs von Band 2, worauf beim kanshi-Dichten ${ }^{464}$ besonders zu achten sei. Tansōs verblüffende Antwort lautet wie folgt.

[1] Beim Verfassen von Gedichten betrachte ich das Bewusstein für die Position ${ }^{465}$ als vorrangig. [2] Die [Dichtungs-]Kategorien „Zuerst Fülle, danach Leere“, „Zuerst Leere, danach Fülle“, „im vierten [Vers] Fülle“ und „im vierten [Vers] Leere“ des Santi shi ${ }^{466}$ hielt ich anfangs für ganz unnötige Dinge. [3] Schaue ich aus heutiger Sicht darauf, so sind sie in der Tat obligatorisch beim Erlernen des Dichtens. ${ }^{467}$

462 Japonisierter Originaltext: Tōba iwaku, Maketsu ga shi wo ajiwaeba, shichū ni e ari. Maketsu ga e wo mireba, gachū ni shi ari. 東坡云、味摩詰之詩、詩中有畫。觀摩詰之畫、畫中有詩。(Kapitel 5, 14a; CAI-NAGASAWA 1977 [1289]: 48). „Dongpo sagte: ,Schmecke ich die Gedichte des Maketsu, [stelle ich fest:] in den Gedichten sind Gemälde. Betrachte ich die Bilder des Maketsu, [stelle ich fest:] in den Bildern sind Gedichte.“ Lilin Xiao legt dar, wie Su Dongpo das Gedicht des Wang Wei variiert und dabei die ursprünglich dynamischen (kinetic) in statische (static) Gegenstände verwandelt und umgekehrt (HSIAO 2013: 181-185).

463 Eine passende Person des Namens Nakagawa Genkei ist nicht identifizierbar. Nakamura Yukihiko weist in seinem Kommentar zum modernen Druck aber darauf hin, dass eine Textvariante in einer Abschrift der einschlägigen Passage im Seisai goroku als Urheber der Frage Nakano Nankyō 中野南強 (1799-1884) nahelege, einen Samurai aus dem Fürstentum Yanagawa (NKBT 94: 379, Anm. 18).

464 Ob über diese wörtliche Bedeutung von shi 詩 hinaus auch die „Poesie“ im Allgemeinen, also die Lyrik und gar die Prosa eingeschlossen sind, muss einstweilen dahingestellt bleiben.

465 „Position“ für ichi 位置, womit die im Folgenden Satz angesprochene Positionierung von „leeren Wörtern“ (kyo, Bezeichnungen formloser Referentia) und „vollen Wörtern“ (jitsu, Bezeichnungen formhafter Gegenstände) gemeint ist.

466 S. 69 ff. Dort auch die Definitionen zu „Leere“ und „Fülle“, deren Kenntnis Tansō voraussetzt.

467 Nakagawa Genkei tou, shi wo tsukuru no yō, nani wo motte saki to subeki ya. Shi wo tsukuru ni wa, ichi wo shiru wo motte saki to su. Santai shi no zen jitsu kō kyo, zen kyo kō jitsu, shi jitsu, shi kyo no rui, yo hajime wa muyō no koto wo nomi omoeri. Ima wo motte mireba, jitsu ni risshi wo manabu no yōmu nari. 中川玄佳問、詩 作ルノ要、何ヨ以テ先トスベキヤ。詩 $习$ 作ルニハ、位置ヨ知ル 
Verblüffend ist diese Antwort, weil Tansō die Begriffsinhalte von „Leere“ (kyo 虚) und „Fülle“ (jitsu 実) nicht definiert, mithin von einem Konsens über die Definitionen im Santi shi ausgeht und in einer Art selbstverständlichem Archaismus auf diesen in Japan seit dem 14. Jahrhundert bekannten und dem Ende des 16. Jahrhunderts populären ästhetischen Kanon zurückgreift. In diesem Kanon stehen „Leere“ für das formlose und „Fülle“ für das formhafte Referens des sprachlichen Kunstwerks.

\section{Abbildung ohne Kontakt mit dem Objekt unmöglich - Intratextuelle} Realität als Auswahl der extratextuellen Realität. In Fortsetzung der Antwort auf die bereits zitierte Frage von Nakagawa Genkei erläutert Tansō unter Rückgriff auf chinesische stilkundliche Schriften wie das Santi shi (S. 81 ff.) sowie auf Beispiele aus der chinesischen und der japanischen Dichtung seine Ansichten zu gelungenen und nicht gelungenen Gedichten. In diesem Zusammenhang führt er zur formlosen und formhaften Wirklichkeit sowie deren im Kunstwerk hergestellter (fingierter) Beziehung zum Signifikant das Folgende aus.

[1] Was die Poesie betrifft, so haben es die heutigen Menschen alle begriffen, dass das Tatsächliche ${ }^{468}$ hochzuschätzen ist. [2] Allerdings neigen sie dazu, das Nichtige und Winzige, das Abseitige und Vulgäre ${ }^{469}$ mitzuteilen und dies für das Tatsächliche zu halten. ${ }^{470}$ [3] Das Tatsächliche, von dem ich spreche, ist aber nicht von dieser Art. [4] Ich meine damit nur die unverformte und schmucklose Mitteilung der tatsächlichen Umstände und der tatsächlichen Situation der Menschen. ${ }^{471}$ [5] Doch die heutigen Menschen lieben es, obzwar noch im besten Alter, die Erscheinungen der Altersschwäche abzubilden, ${ }^{472}$ beschreiten die Beamtenlaufbahn und konzentrieren sich auf die Abbildung der Szenerie von Berg und Wald. [6] Sie berühren nicht mit den Augen, sie empfinden auch nicht im Herzen - nichts weiter tun sie, als die Worte der Altvorderen nachzuahmen. [7] Und deswegen gleichen sie einem sich verkleidenden Schauspieler, selbst wenn sie es fertigbringen, eine Situation oder eine Szenerie ${ }^{473}$ abzubilden. [8] Wie sollte man das denn Tatsächlichkeit nennen?

习以テ先卜ス。三体詩ノ前実後虚・前虚後実・四実・四虚ノ類。予始八無用ノ事卜ノミ思へ リ。今ヨ以テ観レバ、実ニ律詩习学ブノ要務ナリ。 (HIROSE-HIROSE 1883-II: 1a; NKBT 94: 379). 468 „Das Tatsächliche“ für jissai 実際.

469 Im Wortlaut: sasai hiwai 頊細鄙猥 (HIROSE-HIROSE 1883-II: 11b; NKBT 94: 387).

470 Hier liegt eine bemerkenswerte Vorwegnahme der Auseinandersetzung von Mori Ōgai 森 鴎外 (1862-1922) mit dem französischen Naturalismus von Émile Zola (1840-1902) vor.

471 Im Original: hitobito no jikkyō jitsujō wo nobete, kyōshoku naki tokoro 人々ノ実境実情 ベテ矯飾ナキ所 (HIROSE-HIROSE 1883-II: 11b; NKBT 94: 387).

472 „Abbilden“ für utsusu 写ス.

473 „Situation oder Szenerie“ für jōkei 情景, womit hier dynamische (jō) und statische (kei) Gegenstände der Beschreibung, also Geschehnisse und Gegenstände gemeint sind. 
Wirklichkeit reduziert sich hier, soweit aus den Beispielen (alte Menschen, Landschaften) zu sehen, auf das empirisch Nachvollziehbare, häufig auf das sinnenhaft Wahrnehmbare. Den Schwerpunkt des Dichtens legt Tansō, ganz wie das Santi shi, auf die Abbildung (utsusu 写, chin. xie) des sinnenhaft Wahrnehmbaren. Allerdings verweist der an zeitgenössische Dichter gerichtete Vorwurf eines mangelnden Nachempfindens („nicht mit dem Herzen berühren“) leise darauf, dass zur Empirie des Dichters neben der sinnenhaften Wahrnehmung auch die kognitive oder emotionale Reflexion gehöre. So stellt dieser Passus den Versuch dar, die teilnahmslose, gleichsam naturalistische Oberflächenbeschreibung gegen eine teilnehmende, realistische und in Bezug auf die Gegenstände selektive Beschreibung der Tiefenstruktur des Gegenstandes abzugrenzen. Realität wird so auf den Wesenskern des Gegenstandes konzentriert. Allerdings bleibt die Abgrenzung diffus, weil Tansō zwei widersprüchliche Forderungen miteinander verbindet: diejenige nach Realismus und diejenige nach Vermeidung des ebenfalls zur Realität gehörenden Vulgären.

Nicht nur die Gestalt, sondern auch den Sinn abbilden! Tansō wird gefragt, warum er die Dichtungen von Tao Yuanming 陶淵明 (365-427), Wang Wei 王維 (699-761), Meng Haoran 孟浩然 (?-717), Wei Yingwu 韋応物 (736-791) und Liu Zongyuan 柳宗元 (773-819) so liebe. ${ }^{474}$ Für Taos Dichtung hebt Tansō thematische und stilistische Klarheit hervor und zitiert zur Absicherung seiner Bewertung explizit den neokonfuzianischen Philosophen $\mathrm{Zhu} \mathrm{Xi,} \mathrm{der} \mathrm{die} \mathrm{Ge-}$ dichte Taos als „frisch und im Gedanken ruhig“ (in Tansōs Zitat shi ken ni shite $i$ shizuka 詩健而意間) gelobt habe. ${ }^{475}$ Wang wird von Tansō für dessen besonders kunstvolle Abbildung der „Szenerie“ (kei 景) gelobt. Hieran schließt sich

474 Hirose-HiROSE 1883-I: 3a; NKBT 94: 358-359.

475 Tansō zitiert hier (etwas ungenau) aus dem Lunwen 論文 ([Abhandlung über das Schrifttum]) des chinesischen Philosophen Zhu Xi 朱喜 (1130-1200). Der Text ist in der Zhuzi yulei 朱 子語類 ([Gesammelte Worte des Meisters Zhu], 1270) betitelten Aufzeichnung von Lehrgesprächen zwischen Zhu Xi und seinen Schülern enthalten. In Kapitel 140 (Lunwen xia ci 論文 下詩 [Abhandlung über das Schrifttum, II, Gedichte]) stellt Zhu Xi den folgenden Vergleich der Dichtungen des Du Fu 杜甫 (712-770) und des Tao Yuanming an: 其詩無一字做作直是自在其 氣象近道意常愛之 [...] 陶卻是有力但語健而意閑隱者多是帶性負氣之人為 (Zhuzi yulei 朱子語 類 140: 6a-6b, SKQS-Edition; Interpunktionslosigkeit nach ZHU-LI 1973-VIII: 6931-6932). „An seinen [Du Fus] Gedichten ist nicht ein einziges Wort konstruiert. Sie sind direkt und beruhen auf sich selbst. In Bezug auf den kosmischen Äther und dessen Erscheinungen sind sie dem [rechten] Wege nahe, in ihren Gedanken sind sie ihnen gegenüber von Liebe erfüllt. [...] Die [Gedichte des] Tao haben im Gegensatz dazu Kraft. Ihre Sprache ist frisch, im Gedanken sind sie ruhig. [Die Gedichte des] Eremiten [= Tao] sind häufig von natürlichen Bestimmungen umfangen, er ist ein Mensch von beherzter Art.“. 
der folgende Vergleich der Dichtungen Wangs und des ebenfalls zu den Größen der Tang-Dichtung zählenden $\mathrm{Du} \mathrm{Fu} \mathrm{an.}{ }^{476}$

[1] $\mathrm{Du}[\mathrm{Fu}]$ und Wang [Wei] sind beide geschickt im Abbilden der Szenerie, ${ }^{477}$ in der Ausrichtung ${ }^{478}$ aber gleichen sie sich nicht. [2] Du ist raffiniert bei gestalthaften Dingen, ${ }^{479}$ und angefangen bei Wind, Wolken, Regen und Schnee bis hin zu Gräsern, Bäumen, Vögeln und Insekten bildet er deren äußere Formen ${ }^{480}$ sowie auch deren Wesen ${ }^{481}$ ab. [3] In Form und Gestalt ${ }^{482}$ ist er fein und genau und geht bis in kleinste Details. [4] Was Wangs Abbildungen der Szenerie ${ }^{483}$ betrifft, so ist ihm die Abbildung des Sinnes ${ }^{484}$ das Hauptanliegen, bis in feinere Details [der Gestalt] geht er dagegen nicht. [5] Seine Wertschätzung liegt bei der Wesensgestalt. ${ }^{485}$

Was nun die Begriffsinhalte von „Szenerie“ ( $k$ ei 景), „Sinn“ ( $i$ 意), „Wesen“ (seishin 精神), und „Wesensgestalt“ (füjin 風神) sein sollen, erläutert Tansō nicht, doch auch hier dürfte Tansō von den Anmerkungen im Santi shi ausgehen. Dort stehen „Sinn“ (chin. yi 意) für den sprachlich nicht geformten, nicht sinnenhaft wahrnehmbaren Inhalt des Gedichtes ${ }^{486}$ und „Szenerie“ (kei 景, chin. jing) für den sinnenhaft wahrnehmbaren Teil der referenzierten Gegenstände. Hiernach meint logischerweise „Wesensgestalt“ (füjin 風神) das erst in einer sinnenhaft wahrnehmbaren Gestalt realisierbare Wesen des im Kunstwerk referierten Gegenstandes.

Als besondere Leistung Tansōs ist festzuhalten, dass er im Tansō shiwa in einer zuvor nicht gekannten Intensität in der Literaturtheorie die individuelle und gesellschaftliche Situation der Menschen als Referens des literarischen Kunstwerks in den Mittelpunkt stellt - ein Gedanke, dessen Erstgeburtsrecht

476 HiRose-HiRose 1883-I: 6b; NKBT 49: 359.

477 „Abbilden der Szenerie“ für kei wo utsusu 景ᄏ写ス.

478 „Ausrichtung“ für shukō 趣向.

479 „Gestalthafte Dinge“ für taibutsu 体物.

480 „Äußere Form“ für taibō 体貌.

481 „Wesen“ für seishin 精神, logischerweise der vom Dichter angenommene Charakter des Gegenstandes.

482 „Form und Gestalt“ für keiyō 形容.

483 „Abbildung der Szenerie“ für shakei 写景.

484 „Abbildung des Sinnes“ für shai 写意.

485 „Wesensgestalt“ für füjin 風神.

486 Der Bashō-Schüler Morikawa Kyoriku 森川許六 (1656-1715) verwendet statt des originalen chinesischen Terminus yi 意 („Sinn“) den Terminus kyo 虚 („Leere“) zur Abgrenzung gegen sinnlich wahrnehmbare Gegenstände (jitsu 実). Den interpretierenden Teil seiner Kommentare überschreibt er freilich jeweils mit shi” $i$ 詩意 („Sinn der Dichtung“). Einige Beispiele für diese Kommentare sind in MURAKAMI 1994 und FuJI 2015 enthalten. Am Rande sei erwähnt, dass der Begriff „Abbildung des Sinnes“ (shai 写意) vom Bildkünstler Ike Taiga in prinzipiell derselben Weise verwendet wird (HAMASUmi 2010). 
von der Literaturhistorie wohl unberechtigterweise häufig dem Shōsetsu shinzui (1885/86) von Tsubouchi Shōyō zugesprochen wird. Wir dürfen im übrigen in Tansōs Überlegungen eine Vorausdeutung auf jene von Mori Ōgai rund dreißig Jahre später vollendeten (Abschn. 4.4.2) Verwissenschaftlichung der Literatur sehen.

\subsubsection{Subjekt und Objekt sind eins - die Idee ist die Wirklichkeit: Das Jōkyōshiki kaiin roku (1859) des Harada Kyokusai}

Harada Kyokusai 原田曲斎 (1817-1874) war ein Haikai-Dichter der Minoha 美濃 派 -Schule. In dieser Eigenschaft betonte er als ästhetisches Ideal der HaikaiDichtung zunächst eine popularisierte, mit didaktischen Inhalten angereicherte Variante des von Matsuo Bashō favorisierten karomi 軽み („Leichtigkeit“). Später trat er für die Rückkehr zum Bashō-Stil ein, wurde deswegen aus der Minoha-Schule ausgeschlossen und gründete die Dichtergesellschaft Nanagusa ginsha 七草吟社.

Die Haikai-Theorie Jōkyōshiki kaiin roku 貞享式海印録 ([Verzeichnis von Abdrucken auf dem Meere im Stile der Jōkyō-Zeit]) ist das sechsbändige Hauptwerk Kyokusais. Den Druck besorgte 1859 ein von den Häusern Akitaya Tauemon 秋田屋太右衛門 (Ōsaka) und Tachibanaya Jihē 橘屋治兵衛 (Kyōto) angeführtes Verlagskonsortium. Die im Titel enthaltene Jahresdevise Jōkyō 貞享 verweist auf den Zeitraum 1684 bis 1688 und damit auf eine Wendezeit im Leben und Dichten des Haikai-Dichters Matsuo Bashō. Zwei Jahre nachdem 1682 die Brandkatastrophe von Edo auch seine Hütte in Fukagawa vernichtet hatte und ein Jahr nach dem Tod seiner Mutter, brach der Dichter zu einer Reise auf, die unter anderem im Reisetagebuch Nozarashi kikō 野ざらし 紀行 (Exposure in the fields, 1688) ${ }^{487}$ ihren dichterischen Niederschlag fand. Ebenfalls in diesen Zeitraum fällt die Entstehung des (allerdings erst 1709 gedruckten) lyrischen Reisetagebuches Oi no kobumi 笈の小文 (Manuscript in My Knapsack). ${ }^{488}$ Bemerkenswert ist aus literaturhistorischer Sicht die von KonISHI 1963 analysierte Wende, die Bashōs Dichtung in dieser Zeit weg vom traditionellen, weltzugewandten DanrinStil zur konsequent gewahrten ästhetischen Distanz zu Material und Rezipient sowie zur damit verbundenen Tranquilität führt. Den Grund für diesen Stilwandel sieht Konishi weniger in den genannten Ereignissen (Brand, Tod der Mutter)

487 Titelübersetzung nach KEENE 1978: 80: Vollständige Übersetzung unter dem Titel „The Records of a Weather-exposed Skeleton“ in MATSUO-YUASA 1974 [1688]: 51-64.

488 Titelübersetzung nach KEENE 1978: 92. Vollständige Übersetzung unter dem Titel „The Records of a Travel-worn Satchel“ in MATSUO-YuASA 1974 [1688]: 71-90. 
als vielmehr in Bashōs Berührung mit dem Zen-Buddhismus (KonISHI 1963: 10-11). In der Tat bekannte Bashō in der Rückschau, seine Begegnung mit dem ZenMönch Butchō zenshi 仏頂禅師 (1641-1715) ${ }^{489}$ habe ihn zeitweilig gar zu der Überlegung gebracht, selbst Zen-Mönch zu werden. ${ }^{490}$

Kyokusai verweist aber in Jōkyōshiki kaiin roku nicht direkt auf die genannten Bashō-Texte, sondern zitiert mit Jōkyōshiki einen von mehreren Nebentiteln der literaturtheoretischen Schrift Nijūgo jō 二十五条 (gedruckt 1736, [Fünfundzwanzig Paragrafen]). ${ }^{491}$ Diese Schrift stammt vom Bashō-Schüler Kagami Shikō und transportierte schon vor ihrem Erstdruck in geheimer Überlieferung innerhalb der Minoha-Schule die aus Gesprächen und Aufzeichnungen Bashōs zusammengefassten Prinzipien der Haikai-Dichtung. Die von Kyokusai an das Titelzitat angeschlossene Metapher kaiin 海印 („Abdruck auf dem Meere“) bezeichnet in der Zen-Schule die allumfassende Weisheit Buddhas, welche sämtliche Erscheinungen der Welt trotz ihrer gigantischen Dimensionen als eine Einheit klar und ruhig, dabei spiegelverkehrt abzubilden vermag wie in der gegenständlichen Welt die Meeresoberfläche das Firmament. ${ }^{492}$

Vor diesem Hintergrund erweist sich der Titel Jōkyōshiki kaiin roku 貞享式 海印録 ([Verzeichnis von Abdrucken auf dem Meere im Stile der Jōkyō-Zeit]) als komplexes Verweissystem. Das Zitat des hauptsächlich innerhalb der MinohaSchule verwendeten Nebentitels einer literaturtheoretischen Schrift verweist auf Kyokusais Verbundenheit mit eben dieser Schule und zudem auf den literaturtheoretischen Anspruch seines eigenen Textes. Außerdem beansprucht der Titel für Kyokusais Text die Behandlung oder Auswertung angeblicher oder tat-

489 Takagi Sōgo weist in seiner Butchō-Biografie anhand der Tagebücher der jeweiligen Tempel nach, dass die Begegnung entgegen einer gängigen Behauptung nicht im zur Sōtō 曹洞Schule gehörenden, ebenfalls in Edo-Fukagawa gelegenen Tempel Chōkeiji 長慶寺 stattgefunden hat, sondern im Rinsen’an 臨川庵 (in Fukagawa Daiku chō 深川大工町), ein externes Dormitorium des in Kajima 鹿島 gelegenen Tempels Konponji 根本寺, in das Butchō sich zeitweilig zurückgezogen hatte. (TAKAGI 1955-1961). Die Begegnung zwischen Bashō und dem Mönch Butchō wird von den Bashō-Biografen einhellig als der Anlass zu Bashōs intensiven Studien des Zen-Buddhismus der Rinzai-Schule gesehen.

490 Genjūan no ki 幻住庵記 (Aufzeichnungen aus der Klause des Wahns, 1691) (NKBT 46: 186; QUENZER 1996: 153-154).

491 Vgl. Abschn. 3.4.4.1. Drucke erschienen auch unter den Titelvarianten Bashō ō nijūgo kajō ([Die fünfundzwanzig Paragrafen des alten Bashō]) und Haikai nijūgo kajō ([Die fünfundzwanzig Paragrafen des Haikai]). Ein anderer innerhalb der Minoha-Schule verwendeter Nebentitel lautet Hakuba kyō 白馬経 ([Sutra des weißen Pferdes]). Einen modernen Nachdruck bietet KAGAMI-ŌISO 1970 [1736]. Dass Kyokusai mit der gewählten Titelform indirekt auf den archaischen Charakter seiner Theorie - oder, anders gesagt, auf deren Zeitlosigkeit verweist, soll als möglicher Ausdruck von Eskapismus zunächst ohne Interpretation festgehalten werden. 492 Details hierzu: SHImamuRA 2009. Siehe außerdem Anm. 506. 
sächlicher ästhetischer Normen Bashōs. Sodann verweist der „buddhistische“ Anteil des Titels auf den Bezugspunkt von Kyokusais Literaturtheorie: die Erscheinungswelt, deren metaphysischer Urgrund sowie deren Verhältnis zu ihrer Abbildung. Und schließlich verweist die Titelkomponente „im Stile von“ (shiki 式) implizit auf die Möglichkeit, denselben Inhalt in einem anderen Stil zu präsentieren, mithin auf die Grundsätzlichkeit des Inhaltes und seiner Unabhängigkeit von der individuellen Konkretion.

Auf die im Titel angedeuteten Begrifflichkeiten geht Kyokusai in seinem „Eigenen Vorwort“ (jijo 自序) näher ein. Wichtig ist die im Titel enthaltene Textsortenbezeichnung jo 序, weil sie die Erwartung des zeitgenössischen Rezipienten prägt. Wie dieser einen als jo angekündigten Text liest, vermittelt das aus einem Jahrtausend chinesischer Literaturgeschichte schöpfende und in Japan weit verbreitete Wakokubon Buntai meiben 和刻本文体明弁 ([Japanische Fassung des Wenti mingbian], 1852). ${ }^{493}$ Nach der dortigen Definition wird der Leser von Kyokusai eine Einführung in den logischen Aufbau und die Qualitäten des ihm folgenden Haupttextes erwarten, also eine normative Ansprüche vermittelnde Theorie. ${ }^{494}$ Vor dem Hintergrund dieser Lesererwartung ist der im Folgenden übersetzte Text zu rezipieren. ${ }^{495}$

\footnotetext{
493 Das Buntai meiben ist ein aus Definitionen und Textbeispielen bestehendes Verzeichnis von Textsorten. Dessen Vorlage ist das chinesische Wenti mingbian 文体明弁 ([Klare Erläuterungen der Schriftstile]) des Xu Shiceng 徐師曾 (1517-80), das seinerseits auf dem chinesischen Wenxin dialong basiert. Das Wenti mingbian (resp. das Buntai meiben) fand in Japan vom 17. Jahrhundert bis in die Meiji-Zeit vielfältige Verbreitung: Die japanische Regierung der Edo-Zeit (Bakufu) unterhielt eine eigene Bibliothek, deren Katalog Gobunko mokuroku das chinesische Original seit 1642 verzeichnet, japonisierte Versionen liegen seit 1666 vor und wurden in großer Auflage nachgedruckt. Noch in der Meiji-Zeit findet das Buntai meiben vielfältigen Einsatz. Zu den prominenten Eigentümern eines Exemplars zählte auch Tsubouchi Shōyō (SHIMIZU 1983-1985). Im Ganzen oder in Auszügen diente der Text als Lehrbuch für den chinesischen Stil (kanbun) so etwa für das Shogaku Buntai meiben 初学文体明弁 ([Das Buntai meiben für den Lernanfang“, 1879) eines Torigoe Miyoshi 鳥越未誉至. Die Textsortendefinitionen werden immer wieder wörtlich zitiert, so etwa im Kiji ronsetsu buntai kihan 記事論説文体規範 ([Stilvorlagen zu Artikeln, Erörterungen und Erläuterungen], 1886) eines Fukui Jun 福井淳 (Nachdruck in NKiST 16: 261-282).

494 Xu 1982 [1852]: 1245.

495 Quellen: (a) das über http://archive.wul.waseda.ac.jp/kosho/bunko31/bunko31_a1371/ in der Bibliothek der Waseda-Universität erreichbare digitale Faksimile des Originals und (b) HARADA-IWAYA-ITŌ 1930 [1859]: 32.
} 
Eigenes Vorwort. [1] Der Altmeister ${ }^{496}$ hatte den Weg ${ }^{497}$ anfänglich bei Ginsō 吟兒 498 erlernt und sich dem Dasein in einer ganz aus Schilf gefertigten Hütte hingegeben. ${ }^{499}$ [2] Doch bedauerte er es sehr, dass er in Naniwa ${ }^{500}$ auch nicht eine einzige Besonderheit hatte aufspüren können, ${ }^{501}$ labte sich an den Wäldchen und Quellen von Fukagawa, ${ }^{502}$ wusch endlich seine Wunden aus und reinigte seinen Blick. ${ }^{503}[3]$ Eines Tages drehte er an der Gebetsmühle, ${ }^{504}$

496 „Altmeister“ für das honorative $\bar{o}$ 翁, das hier auf Matsuo Bashō verweist.

497 „Weg“ für $d \bar{o}$ 道, bildlicher Ausdruck für so verschiedene Begriffe wie „Moral“ und „Kunstfertigkeit“, hier auf die rechte Art des Haikai-Dichtens bezogen.

498 Ginsō ist ein Pseudonym des Shimokōbe Chōryū 下河辺長流 (1627-1686). Der in Westjapan (Kyōto, Ōsaka) beheimatete Ginsō dichtete Waka und renga (Verkettungen von Waka), erreichte Anerkennung aber vor allem durch seine Forschungen zur Lyrik-Anthologie Man'yōshū (9. Jh.), die ihm den Ruf eines Pioniers der „Landesstudien“ (kokugaku), der Rückbesinnung auf die genuin japanische Dichtung, eintrug. (Eine kurze Biografie bietet KEENE 1978: 308.) Es gibt keinen Beweis dafür, dass Bashō je Ginsō begegnet wäre. Hier ist wohl nur gemeint, dass Bashō dessen Werke genau studierte.

499 „Ganz aus Schilf gefertigte Hütte“ für ashi no maroya あしのまろや [葦の丸屋], bildlicher Ausdruck für äußerste Bescheidenheit der Einrichtung des irdischen Daseins.

500 „Naniwa“浪速: alter Name für die westjapanische Metropole Ōsaka, zusammen mit Kyōto zur Mitte des 17. Jahrhunderts das eigentliche Zentrum der Haikai-Dichtung. Geografisch hätte es für Bashō nähergelegen, aus dem heimatlichen westjapanischen Ueno in dieses Zentrum umzusiedeln, als er 1672 beschloss, Anschluss an das Podium der Haikai-Dichter zu suchen. Stattdessen wählte er aber Edo, möglicherweise wegen des dort geringeren Konkurrenzdrucks (KeENE 1978: 75).

501 Die hier nur angedeutete Phrase hitofushi aru tei 一節有る体 (,Stil, bei dem es einen Wendepunkt gibt“) steht in der Poetik für eine stilistische Pointe.

502 „Wäldchen und Quellen“ für rinsen 林泉, eine Art locus amoenus des von der Welt zurückgezogen lebenden Dichters. Bashō zog 1680 in das damals am Rande von Edo gelegene, unzugängliche und stets überflutungsgefährdete Viertel Fukagawa.

503 „Wunden“ für kizu 傷. Harada spielt hier wohl auf die erwähnten Brüche in Bashōs Biografie (Brand von Edo, Tod der Mutter) und die läuternde Wirkung seiner Reise der Jahre 1684-1685 an, doch bleibt auch die abgeleitete Bedeutung, nämlich „handwerkliche Fehler eines Gedichtes“, durchaus realisierbar.

504 „Gebetsmühle“ für rinzō 輪蔵, ein häufig in der Mitte buddhistischer Tempel aufgestelltes, rotierbares Regal mit Texten des buddhistischen Sutrenkanons. Harada spielt auf die Begegnung Bashōs mit dem Zen-Mönch Butchō an. Eine Gebetsmühle gab es in dem Dormitorium des in Anmerkung 490 erwähnten Konponji allerdings nicht, ihre Erwähnung in dieser Passage ist ein bildlicher Ausdruck für Bashōs Studium buddhistischer Texte. 
nahm die Sutra der Verse der Lehre ${ }^{505}$ in Augenschein und befasste sich eingehend mit dem Sinn $[\text { des Diktums] }]^{506}$

505 „Sutra der Verse der Lehre“ für Hokkugyō 法句経 (chin. Faju jing), eine Übersetzung des zum buddhistischen Urkanon gehörenden indischen Dhammapada (,Worte der Wahrheit“). Es handelt sich dabei um eine in Versform verfasste Aufzeichnung der mündlich vorgetragenen Lehren Buddhas. Die wie ein Zitat behandelte Passage ist im Hokkugyō allerdings nicht enthalten, und Kyokusai verweist auf das Sutra lediglich als Gegenstand des Kommentarwerkes, auf den er eigentlich anspielt: das Bussetsu Hokkugyō so 仏説法句経疏 ([Kommentar zur Sutra der Verse der Lehre]). Dort heißt es: Sanra oyobi banshō / ippō no shoin / izure ippōjū to iu 參羅及万象 / 一法之所印 / 云 何一法中 (Nr. 2901; T 85: 1435a): „Die miteinander verflochtenen und nebeneinander stehenden Zehntausend Formen / sind Abdrücke des einen Gesetzes / und das sagt, dass sie alle im einen Gesetze enthalten sind“. Haradas „Zitat“ ist eine Auslegung dieser Verse.

506 Harada geht in der selben Zeile ohne syntaktische Zäsur vom eigenen Text in den folgenden, mit Inversionszeichen versehenen kanbun-Text über. Der originale Wortlaut der hier übersetzten Passage ist: Shinra oyobi banshō ippō no insuru tokoro no ippō to iu wa, iwayuru isshin nari, kore motte sunawachi issai seken shusse [no] hō wo sesshi, sunawachi kono ippō kaidai sōsō hōmon [no] tei [nari]. Tada mōnen ni yotte shabetsu ari. Moshi mōnen wo hanareba tada yuiitsu shinnyo [nari]. Yue ni kaiin zanmai to iu nari. 森羅及万象一法之所印、言一法所謂一心 也、是以即摂一切世間出世間法。即是一法界大総相法門体。唯依妄念而有差別。若離妄念唯 一真如。故言海印三昧也。In dieser Form ist das Zitat wörtlich der von Fazang 法藏 (643-712) verfassten Abhandlung Shū Kegon ōshi mōjin gengen kan 修華嚴奧旨妄盡還源觀 (The Ending of Delusion and Return to the Source) entnommen (Nr. 1876; T 45: 637b; Erläuterung und Übersetzung in FAZANG-ClEARY 1994 [712]: 147-169). Fazang, dritter Patriarch der buddhistischen Huayan- 華嚴 (jap. Kegon-) Schule, führt dort aus, dass alle Erscheinungen des Universums interdependent seien und deswegen in ihrer inividuellen Erscheinung die Existenz aller anderen Erscheinungen implizierten. Die Existenz jedes Elements des Universums schließe die Existenz des ganzen Universums ein, jedes Element sei so extensiv wie das Universum selbst (FAzANGCLEARY 1994 [712]: 7). Thomas Cleary bietet folgende Zusammenfassung der dem Zitat zugrundeliegenden Lehre des Kegon-Buddhismus: „The first gateway, the revelation of one essence, means the essence that is inherently pure, complete, and luminous - this is the essence of the nature of things within the matrix of the issue of thusness. Since it is fundamentally complete of its own nature and is not defiled in the midst of impurity and not purified by cultivation, it is inherently pure. Since its natural essence shines everywhere and no hidden recess is not lit up, it is completely luminous. [...] Next, the activation of two functions based on the essence means activating two functions based on the aforementioned pure essence. One is the eternal function of the oceanic reflection of the web of forms. The ,oceanic reflection' means the fundamental awareness of true thusness. When delusion ends, the mind is clear and myriad forms equally appear; it is like the ocean, where waves are created by the wind - when the wind stops, the water of the ocean grows still and clear, reflecting all images“ (FAZANG-CLEARY 1994 [712]: 151152; der hier zitierten Paraphrase folgt eine ausführliche Übersetzung). Eine Erläuterung der Metapher kaiin 海印 („Abdruck auf dem Meer“) bietet SHIMAMURA 2009. 
[4] Die miteinander verflochtenen und nebeneinander stehenden Zehntausend Formen ${ }^{507}$ sind Abdrücke des einen Gesetzes; [5] „das eine Gesetz“ meint das ganze Herz, welches die Gesetze aller in der Welt bestehenden und erscheinenden Dinge umfasst; [6] dieses eine Gesetz ist die Verkörperung der Lehre Buddas von der großen Welt als Ganzes. ${ }^{508}$ [7] Ein Unterschied [zwischen den Dingen] besteht lediglich bei Verwirrung der Gedanken. ${ }^{509}$ [8] Löst man sich aus der Verwirrung der Gedanken, so bleibt das wahre Sosein. ${ }^{510}$ [9] Dann spricht man von der Versunkenheit im Abdrucke auf dem Meere.

[10] Dies rüttelte ihn auf, er streifte den alten Geruch eingetrübt leerer Unwahrheiten $^{511} \mathrm{ab}$, erneuerte [die Dichtung] und brachte den rechten Stil ${ }^{512}$ einer vollkommen gereinigten [Verbindung von] Leere und Tatsächlichkeit ${ }^{513}$ hervor. [11] Zwar scheint es auf den ersten Blick so, als seien ihm die Gesetzmäßigkeiten ${ }^{514}$ nicht beständig präsent gewesen und er habe sich ganz von seinem eigenen Herzen treiben lassen, doch dass er niemals in Widerspruch zum Prinzip der Dinge zwischen Himmel und Erde geriet, hat seinen Grund darin, dass er lediglich den Mond an sich erscheinen lässt oder einzig von den auf dem Meere abgedruckten Blumen singt. ${ }^{515}$ [12] Diesen zentralen

507 Die hier wörtlich übersetzte Phrase shinra banshō 森羅万象 (im engeren buddhistischen Zusammenhang shinra manzō zu lesen) steht stellvertretend für alle physischen und metaphysischen Erscheinungen des Universums.

508 „Als Ganzes“ für sōsō 総相, insbesondere in der buddhistischen Kegon-Schule einer der sechs Aspekte aller Erscheinungen, im Allgemeinen das alles durchdringende Prinzip.

509 „Verwirrung der Gedanken“ für mōnen 妄念, womit der irrige Glaube an die Unterschiedenheit der Erscheinungen gemeint ist. Diesem Irrglauben wird im Folgenden die Erkenntnis der Interdependenz und Einheit aller Erscheinungen gegenübergestellt.

510 „Das wahre Sosein“ für shinnyo 真如, die sinojapanische Übersetzung des Sanskrit-Wortes tathatā. Im Kegon-Buddhismus steht shinnyo für die tatsächlichen, so seienden Erscheinungen des Universums.

511 „Eingetrübt leere Unwahrheiten“ für nigoriteshi kyotan 濁てし虚誕. „Leere“ (kyo) meint in dem bereits angeklungenen Kegon-Buddhismus das durch Aufhebung der Dichotomie von Subjekt und Objekt erreichte Ideal absoluter Reinheit. „Eingetrübt“ (nigoriteshi) verweist hier auf die nur unvollständige Aufhebung der Dichotomie.

512 „Rechter Stil“ für seifü 正風.

513 „Leere und Tatsächlichkeit“ für kyojitsu 虚実. Gemeint ist der von irrigen Vorstellungen eines Gegensatzes zwischen Leere und Tatsächlichkeit der Erscheinungen „vollkommen gereinigte“ (kiyomitaru) Dichtstil. Harada bezieht sich auf die in Anmerkung 193 zitierte Passage aus dem Nijūgo kajō (1736) des Kagami Shikō.

514 „Gesetzmäßigkeiten“ für hōsei 法制, womit hier die oben erwähnten Gesetze $(h \bar{o})$ gemeint sind.

515 Gemeint ist damit, dass Bashō bei der Wahl seines dichterischen Gegenstandes sowohl die Konkretionen der Dinge in der Erscheinungswelt (,an sich“) als auch das daraus extrapolierte (,,auf dem Meer abgedruckte“), unveränderliche Prinzip literarisch verarbeitet. An der Nennung von Blume und Mond ist erkennbar, dass Harada sich auf die folgende Passage aus dem Oi no kobumi (Manuscript in my Knapsack, 1709) bezieht: Miru tokoro, hana ni arazu to iu koto nashi, omou tokoro, tsuki ni arazu to iu koto nashi. Katachi hana ni arazaru toki wa iteki ni hitoshi. Kokoro hana ni arazaru toki wa chōjū ni rui su. Iteki wo ide, chōjū wo hanarete, zōka ni 


\begin{abstract}
Mechanismus $^{516}$ fasste er in fünf Paragrafen zusammen und geruhte, sie zwei oder drei Meistern zukommen zu lassen. ${ }^{517}$ [13] Weil das Herzstück dieser [Paragrafen] eine abgesicherte Erörterung über das die Zehntausend [Dinge] durchdringende eine Prinzip ${ }^{518}$ ist, so erstreckt sie sich über alle Dinge zwischen Himmel und Erde, besingt die Vier Zeiten, ${ }^{519}$ angefangen bei den Wendungen von Mond, Sonne und Sternen, dem Schnee, welcher sich in die vom Winde getriebenen Regenwolken mischt, [besingt die] im Herbste verfallenden Bäume und Gräser sowie die Lebhaftigkeit der Fische und Vögel im Frühjahr, [handelt auch von] den wunderbaren Szenerien der Berge und des Wassers, und da es sich um göttliche Auslegungen ${ }^{520}$ handelt, so sind darin das Wandelbare und das Unbeständige, alle Annehmlichkeiten eines Menschenlebens, Kleidung, Essen, Geräte, Material und die täglichen Verrichtungen. [14] So dichtete er fort und fort ${ }^{521}$ unter Einsatz aller Mittel der Sprachkunst ${ }^{522}$ von den Schriftzeichen bis hin zu den grammatischen Partikeln. [15] Und da er die unendlich vielen Sandkörner am Strande ${ }^{523}$ in einem tausend hiro tiefen Meere ${ }^{524}$
\end{abstract}

shitagai zōka ni kaere to nari. 見る處、花にあらずといふ事なし、おもふ所、月にあらずと いふ事なし。像花にあらざる時は夷狄にひとし。心花にあらざる時は鳥獣に類す。夷狄を 出、鳥獣を離れて、造化にしたがひ造化にかへれとなり。 (NKBT 46: 52). „Nothing one sees is not a flower, nothing one imagines is not the moon. If what is seen is not a flower, one is like a barbarian; if what is imagined is not a flower, one is like a beast. Depart from the barbarian, break away from the beast, follow the Creative, return to the Creative." (BARNHILl 2005: 29). Auf die als schädlich bewertete Trennung von physischer und metaphysischer Welt geht Harada weiter unten (Anm. 530) erneut ein.

516 „Zentrale Funktion“ für kikan 機関.

517 Es soll ausdrücklich festgehalten werden, dass hier von fünf Paragrafen (gojō 五条) die Rede ist, nicht von jenen fünfundzwanzig, die Bashōs Schüler Shikō aufzählt (Anm. 492).

518 „Abgesicherte Erörterung über das die Zehntausend [Dinge] durchdringende eine Prinzip“ für ichiri bantsū no kakuron一理萬通の確論.

519 „Vier Zeiten“ für shiji 四時 im Sinne der vier Jahreszeiten.

520 „Göttliche Auslegungen“ für shinshaku 神釈 (DKJ 8-24673-277).

521 „Fort und fort dichten“ für yomi to yomiyuku. Das darin enthaltene finale Verb yuku (,gehen“) bringt diese Phrase zur Überlappung mit der anschließenden Phrase yuku hama no masago, ihrerseits ein unvollständiges Zitat aus einem Gedicht des Shin Kokin wakashū (siehe Anm. 524).

522 „Sprachkunst“ für koto no ha no dō 言の葉の道.

523 „Unendlich viele Sandkörner am Strande“ für hama no masago 濱の真砂, Synekdoche einer sehr großen Zahl, hier bezogen auf das umfangreiche Opus Bashōs. Locus classicus dieser Synekdoche ist das Waka Nr. 745 in Buch 7 (Kaga 賀歌, Glückwunschgedichte) des Shin Kokin wakashū 新古今和歌集 ([Neue Sammlung japanischer Lieder aus alter und neuerer Zeit], 1205) in dem es heißt: Yaoka yuku / hama no masago wo / kimi ga yo no / kazu ni toranan / okitsu shima mori やをかゆくはまのまさごを君がよのかずにとらなんおきつ島もり (NKBT 28: 176): „Oh, Wächter der Insel, nimm die Zahl der Sandkörner, welche an achthundert Tagen am Strande du überschreitest, als die Zahl der Lebensjahre unseres Herrschers!“ Für den in klassischer Waka-Dichtung bewanderten Leser verweist Haradas Zitat Bashō klar auf die Position des Dichterfürsten.

524 Hiro 尋: Längenmaß, ca. $182 \mathrm{~cm}$. Der Ausdruck „tausend hiro“ steht wörtlich für etwa $2.000 \mathrm{~m}$ und bezeichnet die große Tiefe des Meeres. 
umfing, griffen allerorts Schüler sie mit ganzer Hingabe auf und bildeten sie nach, machten sie zum Spiegel ${ }^{525}$ ihrer ganz eigenen Schule, leuchteten sich an und machten einander die Beweise streitig; ${ }^{526}$ und auch der, welcher hier [seinen Text] „Verzeichnis von Abdrucken auf dem Meere im Stile der Jōkyō-Zeit““527 betitelt, vermittelt womöglich den Eindruck haltloser Bilder und einer Entfernung vom Ursprunge, ${ }^{528}$ und hätte er sein Herz in Bashōs Abdrucken auf dem Meere geklärt, so würden Wogen und Winde der Unterscheidung, von welchen jener sprach, ${ }^{529}$ sich nicht erheben. [16] Diese [Abdrucke], Erinnerungsstücke unseres Altmeisters, sind wie die Stange des Bootsführers, ${ }^{530}$ von der geleitet wir in alte Welten zurückkehren, an deren Knorren ${ }^{531}$ wir nicht zweifeln mögen. [17] In der Erwartung, dass die Blumen aus den Meeresströmungen in der Bucht auftauchen, ${ }^{532}$ will ich die Rückkehr zum alten, wahren Stil bewirken und hoffe, dass wir alle uns im selben Wasser vergnügen. ${ }^{533}$ [18] Der dazu die Herren der vier Stilrichtungen ${ }^{534}$ einlädt, ist einer aus Shūnan 周南, aus der Tsuzumi 鼓 -Bucht. ${ }^{535}$

Subjekt und Objekt sind eins - die Idee ist die Wirklichkeit. Schon der im Titel enthaltene, aus dem Buddhismus entliehene Terminus kaïn 海印 („Abdruck auf dem Meere“) kennzeichnet den Text als Bestandteil einer die Welt in ihrer Gesamtheit behandelnden Ontologie, die das Problemfeld von Wahrnehmung und deren Darstellung im Allgemeinen umfassen soll: Die im Kegon-Buddhismus

525 „Spiegel“ für kagami 鑑, hier gleichzeitig das optisch reflektierende Gerät und das Vorbild. Harada greift hier den im Titel eingeführten bildlichen Ausdruck der klaren und unverfälschten Abbildung aller Erscheinungen auf der ruhigen Meeresoberfläche wieder auf.

526 Nur etwa 60 Haikai-Dichter waren tatsächlich Schüler Bashōs, die Zahl derjenigen, die „nur“ von dessen Schülern unterwiesen wurden oder den Status eines direkten Nachfolgers gänzlich unberechtigt in Anspruch nahmen, liegt bei 2000.

527 Harada greift hier den Titel seiner Sammlung, Jōkyōshiki kaiin roku, wieder auf.

528 Das Formulierung mōkaku kengen 妄画懸源 ist nicht verifizierbar und dürfte von Harada spontan gebildet sein.

529 „Unterscheidung“ für shabetsu 差別, womit Harada die negativ bewertete Unterscheidung zwischen den (eigentlich interdependenten und dasselbe Gesetz ausdrückenden) Dingen der Erscheinungswelt (Anm. 507) wieder aufgreift.

530 „Stange des Bootsführers“ für minarezao 水馴竿 („Stange der Orientierung im Wasser“): Bambusstange zu Steuerung und Prüfung des Tiefgangs.

531 „Knorren“ für fushi 節, die maßgebenden Ringe der erwähnten Bambusstange des Bootsführers, hier bildlich für die stilistische Orientierung des Dichters.

532 „Meeresströmungen“ für shio 潮, hier bildlich für die diversen Stilrichtungen, die sich auf Bashō berufen. „Bucht“ für ura, hier bildlich für den Ausgangs- und Zielpunkt aller Stilrichtungen.

533 Aufruf zur Überwindung der Spaltung in verschiedene Schulen und Rückbesinnung auf als allgemeingültig empfundene Regeln der Haikai-Dichtung.

534 „Herren der vier Stilrichtungen“ für yomo no fūshi 四方の風士, die Vertreter verschiedener sich auf Bashō berufender Dichterschulen.

535 Shūnan ist die im Fürstentum Suō 周防 (heute Präfektur Yamaguchi) gelegene Geburtsstadt Haradas. „Bucht von Tsuzumi“ für Tsuzumi ga ura 鼓ヶ浦, womit der heute Kokai 鼓海 genannte Stadtteil von Kushigahama gemeint ist. 
propagierte Aufhebung der Dichotomie von Subjekt und Objekt macht das sprachliche Kunstwerk zur Realität, das zweidimensionale sprachliche Zeichen „Mond“ ist demnach um nichts weniger der reale Mond als der dreidimensionale Erdtrabant. Drei Besonderheiten verdienen hier Betonung.

Die erste Besonderheit des Textes ist, dass Kyokusai zwar aus der HaikaiTheorie zitiert, sich aber mit seinem Zitat nicht explizit auf die Haikai-Lyrik bezieht, sondern auf die Sprachkunst (koto no ha no dō 言の葉の道) im Allgemeinen. Die zweite Besonderheit besteht in der Dreiphasigkeit der Rezeption der Theorie: Die erste Phase ist die in Lehrgesprächen von Schülern notierte Theorie des 1694 verstorbenen Bashō, die zweite Phase die schriftliche Fixierung 42 Jahre nach dem Tode des Meisters, die dritte Phase Haradas Zitat 123 Jahre nach Kagamis schriftlicher Fassung - und 165 Jahre nach deren mündlicher Grundlegung.

Als dritte Besonderheit des Jōkyōshiki kaïn roku kommt der geschichliche Ort des Zitates hinzu. Anfang 1859 verfügt das bakufu mit der Öffnung der Häfen von Nagasaki, Hakodate und Kanagawa für die Landung ausländischer Schiffe auch die Freiheit von Erwerbstätigkeit, Wohnsitz und Handel für Ausländer; fünf Monate später verfügt das bakufu die Gültigkeit ausländischer Münzen und genehmigte deren Prägung, kurz darauf landet der britische Generalkonsul Rutherford Alcock (1809-1897) in Japan, fast gleichzeitig tritt Townsend Harris (1804-1878) erstmals offiziell als Botschafter der USA auf, zu Anfang des 6. Monats 1859 wird der japanisch-holländische Freundschaftsvertrag unterzeichnet, zwei Monate später wird Gustave Duchesne, Prince de Bellecourt (1817-1881) erster Gesandter Frankreichs in Japan. Mit einem Wort: Das technologisch, politisch und ökonomisch weit überlegene westliche Ausland ist in einem nie zuvor gekannten Maße in Japan präsent. Immer mehr hochrangige Mitglieder des Mito-Clans und der formal noch herrschenden Tokugawa-Familie werden unter Arrest gestellt oder zur Zurückhaltung in politischen Fragen verpflichtet. Es ist die Zeit der politischen Säuberungen der Ansei-Zeit (18581859), allein 1859 sterben Aktivisten wie Umeda Unpin 梅田雲浜 (geb. 1815) und Yoshida Shōin 吉田松陰 (geb. 1830). Das alte Regime verliert seine politische Macht, ein neues hat die Lage noch nicht unter Kontrolle. Anfang des 7. Monats kehrt der deutsche Arzt Philipp Franz von Siebold (1796-1866), diesmal in politischer Mission, nach Nagasaki zurück. Im Herbst landet der protestantische Missionar Guido Verbeck (1830-1898) in Nagasaki. Dies sind nur die Anfänge grundsätzlicher Änderungen im Geistesleben des Landes. Im gleichen Jahr 1859 sterben Geistesgrößen wie der Naturwissenschaftler Sugita Seikei 杉田成卿 (geb. 1817) und der konfuzianische Gelehrte Satō Issai 佐藤一 斎 (geb. 1772). Schon das gesellschaftliche Umfeld war zur Schreibgegenwart also sicherlich nicht mehr dasjenige, in dem der inzwischen zweiundvierzi- 
gährige Harada aufgewachsen ist, und es ist schlechterdings undenkbar, dass er von den in ihrer Turbulenz hier nur angedeuteten, irreversiblen gesellschaftlichen Veränderungen unberührt geblieben sein sollte. Auch die Entwicklungen in der Literaturgeschichte sind dramatisch. Ein Blick in die im Literaturverzeichnis genannten chronologischen Tabellen macht klar, dass die Zahl der Neuerscheinungen sich zwischen 1850 und 1867 auf ein Viertel des zuvor erreichten Durchschnitts reduzierte. ${ }^{536}$ Zur quantitativen kommt die qualitative Entwicklung, die daran abzulesen ist, dass in der Erzählprosa fast nur noch Fortsetzungen und epigonale Verarbeitungen abgenutzter Stoffe erscheinen. ${ }^{537}$

Nimmt man Haradas Schreibgegenwart vor diesem Hintergrund als eine Zeit der Fragmentierung der „Welt“ wahr, erscheint die Berufung auf Matsuo Bashōs Dichtung nicht nur als Ausdruck eines archaisierenden Eskapismus. Das in der Eloge auf den Meister zurückersehnte ,eine Prinzip“, das ,alle Dinge zwischen Himmel und Erde“ zusammenhält, soll vielmehr die fiktionale Literatur zu einem Mittel der Defragmentierung der „Welt“ machen.

\subsection{3 ,Seelenleben' und ,Geistesleben' sind die Wirklichkeit: Das Sō jitsu ron (1890) des Ishibashi Ningetsu}

Zu den herausragenden Leistungen des Sō jitsu ron 総実論 (Über die Idee und das Wirkliche, 1890) des Literaturkritikers Ishibashi Ningetsu 石橋忍月 $(1865-1926)^{538}$ gehört der Entwurf eines shi 詩 („Poesie“) genannten, regional unabhängigen und allgemeingültigen Begriffs der sprachlichen Kunst, unter dem Ishibashi exemplarisch chinesische, deutsche, französische, japanische, norwegische und russische Literatur auf einer Ebene subsumiert und außerdem die traditionelle Beschränkung des „Poesie“-Begriffs auf die Kunst in gebundener Sprache aufhebt: Neben Lyrik gehören für ihn auch Erzählprosa und Dramatik zur „Poesie“. Ishibashi postulierte damit den Abschluss einer historischen Phase der japanischen Literaturtheorie, in welcher die Literaturen Chinas und Japans als denen des „Westens“ unterlegen dargestellt wurden. Einer der Vorläufer Ishibashis in dieser Hinsicht war der bereits erwähnte Kubota Shigenobu (S. 131). Die angebliche Unterlegenheit

536 Diese freilich grobe Relation berechnet sich für die Erzählprosa auf der Basis von MAY 1983: 8 (Tab. 1).

537 OKITSU 1954-1960 schildert ausführlich den Rückgang der Kreativität.

$538 \mathrm{Zu}$ Biografie und Werdegang von Ishibashi Ningetsu sei hier auf WoLDERING 2017-2018 verwiesen. Dort findet sich auch eine komplette kommentierte Übersetzung des Sō jitsu ron (1890), aus dem im Folgenden nur die für die vorliegende Arbeit direkt relevanten Punkte zusammengetragen werden. 
der japanischen Literatur legte dagegen beispielsweise Inoue Tetsujirō in Nakamura Keiu ō ni yosete sho su (S. 142 f.) dar.

Was einen Text poetisch mache, sei, so Ishibashi, die vom „Wesen“ (seishin 精神) bewerkstelligte Harmonisierung von Gefühlen und Gedanken (kannen 感 念) im wechselseitigen Bezug von Idee ( $s \bar{o}$ 想) und Wirklichem (jitsu 実). Gegenstände der „Poesie“ könnten daher, so Ishibashi, nur solche sein, die im Text von jeglicher Dynamik von Zeitverläufen unabhängig, gewissermaßen ewig gültig gemacht werden können. Eine solche Transformation sei Aufgabe des Poeten, wobei das Gelingen nicht vom Textumfang oder der stofflichen Breite abhänge. Dass Ishibashi damit die Grundgedanken des kantianischen Idealismus auf die japanische Literatur überträgt, ist ihm, der sich auf den Theologen, Philosophen und Literaturhistoriker Werner Hahn (1816-1890) bezieht, augenscheinlich nicht bewusst gewesen. Das ändert allerdings nichts an der historischen Bedeutung des Sō jitsu ron.

Außerdem aber aktualisiert Ishibashi im Sō jitsu ron jene im Grunde aus Aristoteles' Poetik stammende, bei Ishibashi aber auf die Hamburgische Dramaturgie (1767-1769) des Gotthold Ephraim Lessing (1729-1781) zurückgehende Forderung nach Konsistenz der Erzählzeit, der Szene und der Protagonisten und mahnt schließlich zu sorgfältiger Gestaltung bei der literarischen Produktion. Diese wird in der Summe aller Einzelforderungen des Sō jitsu ron zu einem intensiv reflektierten intellektuellen Prozess, der sich von der wissenschaftlichen Darstellung hauptsächlich durch Ishibashis im Folgenden aus Kapitel 3 (Sō, jitsu no seishitsu 想、実の性質, „Der Charakter der Idee und des Wirklichen“) referierten Realitätsbegriff unterscheidet.

Grob unterschieden gibt es zwei Urquellen der Poesie. Die eine nenne ich die Idee, die andere das Wirkliche. Die Idee ist die gestaltlose Vorstellung, das Wirkliche ist die wahrnehmbare Gestalt. ${ }^{539}$ Die wahrnehmbare Gestalt kann man festhalten, die gestaltlose Vorstellung kann man nicht festhalten. So ist also das äußerste Ende der Seele das Wirkliche, das äußerste Ende des Geistes ${ }^{540}$ die Idee. Das Material der Poesie ist schließlich überall zu finden, und deswegen ist der Poet auch an jedwedem Ort in Stadt und Land zu Hause.

539 „Wahrnehmbare Gestalt“ für shinkei 真景 bezeichnet hier die außerhalb der Poesie bestehende, empirisch nachvollziehbare Wirklichkeit (Erscheinungswelt). „Gestaltlose Vorstellung“ für kyoshō 虚象. Als literaturtheoretischer Terminus ist diese Zusammensetzung nicht verifizierbar. Das darin enthaltene kyo 虚 ist hier im Sinne von „Abwesenheit“ (DKJ 9-32709) zu interpretieren, shō 象 im Sinne von „Gestalt“ (DKJ 10-36372). Ishibashi meint hier die noch nicht in eine (sprachliche oder sonst darstellende) Form gegossene Idee und bezieht sich inhaltlich deutlich auf die seit Futabatei Shimeis Shōsetsu sōron 小説総論 (Allgemeine Abhandlung über den Roman, 1886) geführte Diskussion der begrifflichen Dichotomie „Form“ - „Idee“ (bei Futabatei in den Termini fōmu 形 [< engl. form] und aidia 意 [< engl. idea]).

540 „Seele“ für seijō 性情; „Geist“ für ishi 意思. 
Das Gewichtigste aber, auf das der Poet sein Augenmerk richtet, ist das Leben des Menschen. Aus diesem Grunde gehört das Leben, welches der Mensch bereits erfahren hat oder zu erfahren im Begriffe ist, zum Wirklichen, das noch nicht erfahrene Leben dagegen zur Idee..$^{541}$

In einem Satz zusammengefasst ist die bereits bestehende Welt in ihrer Gesamtheit die Wirklichkeit, die bisher nicht bestehende, aber denkbare Welt ist die Idee, und der Poet gestaltet in seinem fiktionalen Text die denkbare Welt auf der Grundlage der bestehenden Welt zu einer neuen Wirklichkeit.

Die „Leere“ zur eigentlichen Wirklichkeit zu erklären, hat Matsuo Bashō schon 1690 in Oi no kobumi unternommen (S. 36). Und nennt Bashō dabei mit „Leere“ auch nur den einen der beiden Teile seines fiktionalen Textes, bildet seine literaturtheoretische Leistung doch einen wichtigen Einschnitt in der Geschichte der japanischen Literatur. Aber, soweit zu sehen, hat in der japanischen Literaturtheorie (in ihrem für diese Abhandlung gesteckten Rahmen) niemand während des Zeitraums von Oi no kobumi (1690) und Sō jitsu ron (1890) die Fiktion an sich, also die aus „Leere“ und „Fülle“ erschaffene Wirklichkeit der intratextuellen Welt in dieser Klarheit als Wirklichkeit bezeichnet. Dass vor diesem Hintergrund die Geringschätzung des Literaturhistorikers Donald Keene gegenüber Ishibashi Ningetsu nicht nur schlecht argumentiert, sondern gar deplaziert ist, ${ }^{542}$ sei nur am Rande erwähnt. Von zentraler Bedeutung ist hingegen die aus dem Vergleich von Oi no kobumi und Sō jitsu ron zu gewinnende Erkenntnis, dass der begriffliche Gehalt von „Leere“ und „Fülle“ in der japanischen Literaturtheorie über mehrere historische Umwälzungen hinweg Bestand hat.

541 (3) Der Charakter der Idee und des Wirklichen // (3) Sō, jitsu no seishitsu // Shi no hassei suru engen, taiyaku Wakatte futattsu to nasu. Iwaku sō, iwaku jitsu. Sō wa kyosō nari, jitsu wa shinkei nari. Shinkei wa toraubeshi. Kyosō wa toraubekarazu. Seijō no shūkyoku wa jitsu to nari, ishi no shūkyoku wa sō to naru nari. Shiryō hikkyō itaru tokoro ni ari. Yue ni kōko itaru tokoro kore shijin no ie nari. Shikaredomo shi no omo naru mokutekibutsu wa jitu ni ningen no seikatsu ni ari. Yue ni ningen ga sude ni keiken shitaru ka moshiku wa keiken shitsutsu aru seikatsu wa jitsu to nari, imada keiken sezaru seikatsu wa sō to naru (三)想、実の性質 // 詩の発 生する淵源、大約別ッて二ッつとなす、日く想、曰く実、想八虚象なり、実八真景なり、真 景八捉ふべし、虚象八捉ふべからず、性情の終極八実となり、意思の終極八想となるなり、 詩料畢竟到る処に在り、故に江湖到る処是れ詩人の家なり、然れども詩の重 [sic!] なる目的 物八実に人間の生活にあり、故に人間が既に経験したるか若しく八経験しつっある生活は実 となり、未だ経験せざる生活八想となる、(Sō jitsu ron (1892 [1890]): 346-347; die Interpunktion des Originals beschränkt sich auf das Komma 、.). Übersetzung: WoLDERING 2017b: 601-602).

542 „Ningetsu's criticism is no longer of interest. A recent scholar [...] left him without a shred of intellectual respectability.“ (KeENE 1984-2: 512). 


\section{4 ,Wesen“ und ,Idee“ in „Leere“ und „Fülle“ der japanischen Literaturtheorien der Jahre 1850-1890}

Wir sind an der Grenze der Analysierbarkeit angekommen, denn bislang voneinander getrennt gehaltene inhaltliche Schwerpunkte in den japanischen Literaturtheorien $\mathrm{zu}$ „Leere“ und „Fülle“ überlappen sich, so weit aus dem Korpus extrapolierbar, mehr als zuvor - immer unter dem Vorbehalt, dass nur die explizite Verwendung von Begriffen berücksichtigt werden kann. Jedenfalls aber drängen sich die inhaltlichen Parallelen etwa zwischen dem Jōkyō shiki kaiin roku (1856; Abschn. 4.3.2) und den im folgenden $\mathrm{zu}$ besprechenden Theorien des Futabatei Shimei regelrecht auf.

\subsubsection{Der Text ist die Silhouette des Sinnes: Die Abhandlungen Shōsetsu sōron und Bunshō ron (1889) des Futabatei Shimei und der deutsche Idealismus}

\section{„Form ist Materialisierung der Idee“: Das Shōsetsu sōron (1886) des Futabatei Shimei}

Futabatei Shimei 二葉亭四迷 (1864-1909; Hasegawa Tatsunosuke 長谷川辰之助) bezieht sich mit zwei wichtigen Abhandlungen direkt auf das in Abschnitt 4.2.2 besprochene Shōsetsu shinzui des Tsubouchi Shōyō, nämlich mit Bijutsu no hongi 美術の本義 (Das grundlegende Prinzip der schönen Künste, 1885) und Shōsetsu sōron 小説総論 (Allgemeine Abhandlung über den Roman, 1886). Der zuerst genannte Titel greift mit hongi einen Terminus aus der Einleitung von Tsubouchis Shōsetsu shinzui auf, ${ }^{543}$ der zweite Titel übernimmt wörtlich den Titel desselben Einleitungskapitels. Futabatei, noch in der Rolle eines Adepten, fühlte sich durch die (vom „Meister“ Tsubouchi in Gesprächen anerkannten) Defizienzen dessen Textes dazu angeregt, die theoretische Grundlage neu und besser zu legen, indem er unter Rückgriff auf die Philosophie des deutschen ästhetischen Idealismus hegelianischer Prägung und der russischen Literaturkritik eine schärfere Trennung von aus der Edo-Zeit überkommenen Traditionen (etwa der Allegorisierung moralischer Tugenden) versuchte. Was er dabei erreichte, wird in WOLDERING 2015a im Detail analysiert und muss hier nicht wiederholt werden. Im Zusammenhang der vorliegenden Abhandlung ist Futabateis Einführung der begrifflichen Dichotomie „Idee - Form“ (aidiā 意 < engl. idea; fōmu 形 < engl. form) in die theoretische Diskussion der Literatur der entscheidende Faktor, dies aber nicht etwa, weil die 
Vorstellung von formlosem Kernmaterial und dessen sprachlicher Materialisierung zuvor in der japanischen Literaturtheorie nicht thematisiert worden wäre. Futabatei knüpft in diesem Punkt vielmehr an Texte wie das Wenxin diaolong (ca. 520, siehe Abschnitt 3.3.1) an - womöglich ohne sich dessen im Detail bewusst zu sein. Die eigentliche Leistung des Shōsetsu sōron besteht vielmehr darin, die japanische Literaturtheorie aus der Isolation einer sogenannten „Nationalliteratur“ und deren Theorie herausgeführt zu haben. Sie stand fortan gleichrangig neben „westlichen“ Diskussionen literaturtheoretischer Fragen von grundsätzlicher Relevanz, nicht zuletzt auch dadurch, dass sie keinerlei Abhängigkeiten zu konkreten Texten der japanischen Literatur entstehen lässt.

\section{„Der Text ist die Silhouette des Sinnes“: Das Bunshō ron (1889) des Futabatei Shimei}

In Futabateis mehrteiliger tagebuchartiger Notizensammlung Ochiba no hakiyose 落葉のはきよせ ([Abgefallenes Laub, zusammengekehrt]) - Futa kagome 二籠め ([Zweiter Korb], 1889) ist unter dem Titel Bunshō ron 文章論 ([Über den Text]) ein Artikel enthalten, in dem Futabatei die Kernaussagen aus verschiedenen literaturtheoretischen Texten des chinesischen Gelehrten und Historikers Wei Xi 魏禧 (= Wei Shuzi 魏叔子, 1624-1681) zusammenfasst. Für die Weigerung, den für die Beamteneingangsprüfung obligatorischen, in Form und Inhalt stark reglementierten Aufsatz des Typs bagu wen 八股文 („Text der acht Gliedmaßen“) zu verfassen, nahm Wei den Ausschluss von der mit dieser Prüfung verbundenen Karrierechance in Kauf, zog sich in die abgelegene Bergregion Tsuiwei feng 翠微峰 zurück und gründete dort einen Kreis von Gelehrten, die wie er bevorzugten, als Eremiten ihr wissenschaftliches Interesse zu pflegen. Futabatei selbst brach kurz vor dem Examen 1885 sein Russisch-Studium an der „Tōkyō Schule für Fremdsprachen“ (Tōkyō gaikokugo gakkō) ab, nachdem bekannt wurde, dass diese mit der „Tōkyō Schule für Handel und Kommerz“ (Tōkyō shōgyō gakkō) zusammengelegt werden sollte. Diese und ähnliche biografische Parallelen legen Futabateis Sympathie für Weis Absage an die Karriere nahe. Hinzu kommt freilich, dass die Texte des Wei Shuzi wichtiges Unterrichtsmaterial im von Futabatei zwischen 1875 und 1883 an drei verschiedenen kangaku-Schulen genossenen kanbun-Unterricht waren (YANAGIDA 1967: 363-367). Futabatei zählt später die Werke des Wei Shuzi zu seiner wichtigsten Lektüre (YANAGIDA 1967: 366; TERAYOKO 1978: 85).

Hier nun Futabateis Darlegung der Kernaussagen von Wei Shuzi über die Fiktion in der Literatur. 
Über den Text. Wei Shuzi sagt: „Das Wunderbare des Textes liegt in dessen Verdichten des Prinzips ${ }^{544}$ und dessen Ausarbeitung des Zeichens. “545 Was das Prinzip ${ }^{546}$ angeht, so ist es die ursprüngliche Gestalt des Sinnes [kokoro 心]. Ich vergleiche es mit einem Gebirge. Von Anfang bis Ende ist es fest und wandelt sich nicht. Was das Zeichen anbelangt, so ist es jenes Ding, welches das Tun des Sinnes vollendet. Zudem ist es jenes Ding, welches dem Rohmaterial den Schliff gibt. Ich vergleiche es mit dem Wasser. Es richtet sich von Anfang bis Ende nach den Gegenständen und hat noch nie eine feste Gestalt gehabt. Ich sage: [Wei Shuzi] kommt [der Wahrheit] nahe. Der Text ist die verschriftete Version der Sprache des Menschen. Die Sprache des Menschen aber ist das, was als Klang hervortritt, nachdem der Sinn in Einzelteile zerlegt ist. Ich habe noch nicht davon gehört, dass es unter dem Himmel ein Ding gebe, dessen Silhouette gerade sei, obwohl dessen Gestalt verbogen ist. Der Sinn treibt leer dahin und hält nicht still, und ich habe auch noch nicht davon gehört, dass es ein Ding unter dem Himmel gebe, das in der Sprache oder im Text fähig gewesen wäre, die Gefühle der Menschen zu bewegen und [gleichzeitig] den Zehntausend Welten zur musterhaften Lehre zu gereichen. ${ }^{547}$ Wenn man Verbiegungen der

544 „Verdichten des Prinzips“ für sekiri 積理, „Ausarbeitung des Wissens“ für renshiki 鍊識. Wei verwendet beide Begriffe in seinen Abhandlungen häufig (TERAYOKO 1978: 85).

545 Als Verwendungsbeispiel für sekiri führt Terayoko Takeo das Zong zi fawen ji xu 宗子発文 集序 ([Vorwort zur Sammlung von Texten des Meisters Zong]) an (WEI-WANG 1973 [1681]-III: 1023-1027; Japonisierung in TERAYOKO 1978: 89-90). Die Wahl dieses Beispiels ist überzeugend, denn neben dem Begriff sekiri werden dort auch die „Sechs Leitfäden und Vier Bücher“ genannt. „Vier Bücher“ (shisho, chin. sishu 四書): die konfuzianischen Klassiker Lunyu 論語 (Confucian Analects, 5. - 4. Jh. v. Chr.), Mengzi 孟子 (ca. 290 v. Chr.), Daxue 大学 (The Great Learning, 1. Jh. v. Chr.) und Zhongyong 中庸 (The Doctrine of the Mean, 4. Jh. v. Chr.). „Sechs Leitfäden“ (rikukei 六経, chin. liu jing): die konfuzianischen Klassiker Yijing 易経 (The I Ching, ca. 700 v. Chr.), Shijing 詩経 (Book of the Odes, 6. Jh. v. Chr.), Shujing 書経 (The Shoo King or The Book of Historical Documents), Liji 礼記 (Book of Rites, ca. 200 v. Chr.), Chunqiu 春秋 (The Ch'un Ts'ew, with the Tso Chuen, 4. Jh. v. Chr.) und das im Jahr 213 v. Chr. bei der Bücherverbrennung des Kaisers Qin Shihuangdi 秦始皇帝 verlorengegangene Yuejing 楽経 ([Leitfaden der Musik]). Futabatei führt also den Kanon der kangaku als Muster für gute Texte ins Feld. Als Verwendungsbeispiel für renshiki nennt Terayoko Takeo das Da Shiyu Shanshi dushu 答施 愚山侍読書 ([Antwort auf den kaiserlichen Lektor Shiyu shan]; WEI-WANG 1973 [1681]-II: 719724; TERAYOKO 1978: 90), worin Wei Texte des Dichters Shi Runzhang 施閏章 (1618-1683) kommentiert. Offensichtlich hat Futabatei die eingangs seines Textes zitierte Phrase aus folgender Passage entnommen: Gū katsute omoeraku bun wo tsukuru no dō, takuzen toshite mizukara tenka ni tatan to hossureba, ri wo tsumite shiki wo neru ni ari. 思嘗以謂為文之道、欲卓然自立 于天下、在于積理而練識。 (WEI-WANG 1973 [1681]-II: 721; Japonisierung nach TERAYOKO 1978: 91). „Wie ich es mir in meiner Einfalt schon länger denke, so liegt, wenn man im Reiche eine herausragende und selbstständige Stellung einzunehmen bestrebt ist, die Kunst des Verfassens von Texten darin, das Prinzip zu verdichten und das Wissen auszuarbeiten.“.

546 „Prinzip“ für $r i$ 理. In der hier anklingenden neokonfuzianischen Weltsicht handelt es sich um die Ureinheit, aus der sich der spezifische Äther (die individuelle Ausformung allen Seins) entwickelt (S. 74 f.).

547 „Zur musterhaften Lehre gereichen“ für shihyō taru 師表たる. Futabatei trennt in diesem Satz [13] zwischen Emotion und Verstand. Dabei spricht er dem Text die Fähigkeit ab, gleich- 
Gestalt verabscheut, ist nichts besser, als zunächst die Gestalt gerade zu machen. Wenn man sich Feinheit von Sprache und Text wünscht, so ist nichts besser, als zunächst deren Sinn fein zu machen. Ich sage deswegen: Der Text ist die Silhouette des Sinnes, der Sinn die Substanz des Textes. ${ }^{548}$ Der Wissenschaftler mag [den Dingen] nahekommen, wenn er deren Ursprung und Ende erkennt, doch welchen Weg gibt es, [den Sinn] herauszupolieren? Ich sage: Da gibt es nur das Verdichten des Prinzips und die Ausarbeitung des Wissens. ${ }^{549}$ Ist der Sinn nicht beim Prinzip, so ist er leichtfertig. Erreicht der Sinn nicht das Wissen, so erstarrt er. Man mag wohl sagen, dass das Prinzip ohne Wissen nicht das wahre Prinzip ist. Dies gründet sich darin, dass es nicht einer Tatsache entspricht. Was das Wissen ohne Prinzip anbelangt, so mag es wohl existieren, doch ist es genau so, als existierte es nicht. Dies gründet sich darin, dass ihm jenes Ding fehlt, das es anleitet. Erst wenn es sowohl das Prinzip als auch das Wissen gibt, können [beide] ihre Bestimmung erfüllen. ${ }^{550}$ Deswegen muss derjenige, welcher [nach dem Wege] strebt, auf dem er seinen Sinn herauspoliert, auf jeden Fall diese beiden in sich vereinen. Eben dies ist doch der Grund, warum die Vier Bücher und die Sechs Leitfäden ${ }^{551}$ der ganzen Welt zur musterhaften Lehre gereichen! Allerdings sollte man sich über diese Dinge mit Wissenden unterhalten. Mit gewöhnlichen Herrschaften [zokushi 俗士] und engstirnigen Gelehrten [kuju 狗儒] sollte man nicht darüber sprechen. ${ }^{552}$

zeitig beides anzusprechen. Im Grunde ist dies die Trennung zwischen Wissenschaft und Literatur.

548 „Silhouette“ (kage 影) in der Bedeutung einer von der eigentlichen Lichtquelle (kokoro= „Sinn“) abhängige Erscheinung. „Substanz“ (tai 体) ist das, was in der „Silhouette“ Gestalt annimt.

549 „Wissen“ für shiki 識 (chin. shi), was auch „Zeichen“ bedeuten kann. Beide Bedeutungen sind in diesem Text logisch konsistent realisierbar. Nimmt man für shiki als Bedeutung „Zeichen“ an, stehen sich das „Prinzip“ ( $r i)$ als der nicht geäußerte Gehalt und „Zeichen“ als der geäußerte Gehalt gegenüber.

550 Die Sätze [22]-[26] entsprechen in Logik und Rhetorik der Einleitung des Shōsetsu sōron, in der Futabatei darlegt, dass auf der Ebene des Soseins (mochimae 持前) eines Gegenstandes zwar die Idee ohne deren Materialisierung in einer Form, nicht aber die Form ohne eine Idee existieren könne (Original NKiBT 3: 404). Siehe auch HATA 1965: 4-5.

551 Siehe Anm. 545.

552 Originaltext: Bunshō ron. Gi Shukushi iwaku: Bunshō no myō sekiri to renshiki ni ari. Ri to wa kokoro no hontai nari. Kore wo yama ni tatou. Shūshi gen ni shite hen sezu. Shiki to wa kokoro no yō wo mattō suru yuen no mono nari. Mata sainō no setsubi suru yuen no mono nari. Kore wo mizu ni tatou. Shūshi mono ni shitagaite henka shite katsute teikei aru koto nashi. Yo iwaku: chikashi. Bunshō wa hito no gengo wo hisshitaru mono nari. Shikōshite hito no gengo wa kokoro no kudakete oto ni arawaretaru mono nari. Katachi yugamite sono kage naoki mono wa imada tenka ni kore aru wo kikazu. Kokoro fukyo sadamarazu shite gengo bunshō yoku hito wo kandō shite bansei ni shihyō taru mono mata imada tenka ni kore aru wo kikazu. Moshi sono kage wo yugameru wo nikumaba mazu sono katachi wo naō sen ni wa shikazu. Moshi gengo bunshō no myō naru wo hosseba mazu sono kokoro wo myō ni sen ni wa shikazu. Yue ni iwaku: Bunshō wa kokoro no kage nari. Kokoro wa bunshō no karada nari. Gakusha honmatsu suru tokoro wo shireba sunawachi shoki shi, shikaraba sunawachi kokoro wo marei suru no dō wa ikan. Iwaku iwayuru sekiri to renshiki to ni aru nomi. Kokoro ri ni arazareba sunawachi karoshi. Kokoro shiki wo ezareba sunawachi 
Im Lichte des zuvor besprochenen Shōsetsu sōron wirkt die Wahl der terminologischen Quelle im Bunshō ron auf den ersten Blick konservativ: Futabatei interpretiert hier in affirmativer Weise die Literaturtheorie des Wei Shuzi, der seinerseits einen zentralen Begriff des neokonfuzianischen Weltbildes verwendet: $l i$ 理 (jap. ri), die Ureinheit, das „sehr große Äußerste“ (chin. taiji 太極), aus dem alles Sein sich als Spezifikum des Äthers erst entwickelt. Entsprechend sind das statische Innere und dessen dynamische Veräußerlichung die beiden Grundelemente des Textes (wenzhang 文章, jap. bunshō). Ein weiterer der Tradition entsprechender Verweis führt zum erwähnten Kanon der klassischen chinesischen Philosophie (Anm. 546). All das sind zu Futabateis Zeiten längst feste Topoi der Literaturtheorie Chinas und Japans.

Der zeitliche Abstand der beiden Texte ist nicht zuverlässig bestimmbar, weil die einzelnen, wie „abgefallene Blätter zusammengekehrten“ Notizen des Ochiba no hakiyose durchaus früher entstanden sein mögen. Aber wichtiger ist ohnehin, dass ein und dieselbe Person denselben Gegenstand in zwei unabhängigen Texten auf sehr verschiedene Weise theoretisch bearbeitet. Der von Hata Yūzō ${ }^{553}$ unternommene Vergleich dieser Theorien liegt also nahe, und im Lichte der textlogischen Einbindung scheinen in der Tat folgende von Hata festgestellten begrifflichen Entsprechungen gegeben.

\footnotetext{
todokōru. Kedashi shiki naki no ri wa makoto no ri ni arazu. Sono jijitsu ni atarazareba nari. Ri naki no shiki wa ari to iedemo naki ni onaji. Sono kore wo hikiyuru mono nakereba nari. Ri ari shiki ari shikōshite nochi sono yō mitashi. Yue ni kokoro wo marei [suru no dō wo] sen to hossuru mono wa kanarazu ya kono nisha wo kane sonaezaru bekarazu. $\bar{A}$ kore Shisho Rikukei no bansei ni shihyō taru yuen nari. Tada kono koto chisha to katarau beshi. Zokushi kuju to kataru bekarazu. 文章論 魏 叔子曰文章之妙在干積理而錬識 理と八心の本体なり之を山に譬子終始儼として変せす識と 八心の用を完ふする所以のものなり又才能の切劘する所以のものなり之を水に譬ふ終始物に 随ひて変化し曾て定形あることなし 余曰く近し 文章は人の言語を筆したるもの也 而して人 の言語は心の砕けて音にあらハれたるものなり 形歪みてその影直きもの八未た天下に之れ有 るを聞かず 心浮虚定まらすして言語文章能く人を感動して万世に師表たるもの又未た天下に 之れ有るを聞かず若し其影の歪めるを悪ま八先づ其形を直ふせんに八如かす若し言語文章の 妙なるを欲せバ先つ其心を妙にせんに八如かす故に曰く文章は心の影なり 心は文章の体なり 学者本末するところを知れ八則ち庶幾し 然ら八則心を磨庽するの道は如何 曰く所謂積理と錬 識とにあるのみ 心理にあらされハ則ち軽し 心識を得され八則ち滞る 蓋し識なきの理八真の 理にあらずその事実に中らされバなり理なきの識は有りと雖とも亡きに同しその之を率ゆる ものなけれハなり理有り識有り而して後その用完たし 故に心を磨庽〔するの道を〕せんと欲 する者は必すや此二者を兼ね具へさる可らす鳴呼是れ四書六経の万世に師表たる所以なり只 此事智者と道ふ可し 俗士狗儒と語る可らず (FUTABATEI-NAKAMURA 1971 [1889]: 140).
}

553 HATA 1965: 4-5. 
Tabelle 7: HATA 1965: Begriffliche Entsprechungen zwischen Idealismus (Shōsetsu sōron) und Neokonfuzianismus (Bunshō ron).

\begin{tabular}{lll}
\hline Shōsetsu sōron (1886) & Bunshō ron (1889) & (Kommentar) \\
\hline „Idee“ (aidia 意) & „Prinzip“ ( $r$ 理) & $\begin{array}{l}\text { Kernmaterial jedweder Erscheinung, in } \\
\text { sich statisch, aber energiegeladen }\end{array}$ \\
\hline „Form“ (fömu 形) & $\begin{array}{ll}\text { „Zeichen“ (shiki } \\
\text { [= shirushi] 識) }\end{array}$ & Abbild des Kernmaterials \\
\hline $\begin{array}{l}\text { „Wahres Prinzip“ } \\
\text { (shinri 真理) }\end{array}$ & „Sinn“ (kokoro 心) & $\begin{array}{l}\text { für Futabatei die zentrale Funktion der } \\
\text { Literatur: die Suche nach einer } \\
\text { statischen Wahrheit (shinri) }\end{array}$ \\
\hline
\end{tabular}

Der Effekt dieser Entsprechungen, ob von Futabatei in den beiden Texten nun bewusst herbeigeführt oder nicht, ist die theoretische Annäherung der Literatur an die Wissenschaft sowohl in der traditionellen wie auch der methodisch völlig verschiedenen, modernen Literaturtheorie. Futabateis Bild von der Literatur als besonderer Form des Erkenntnisstrebens erhellt sich auch aus dem folgenden Tagebucheintrag zum 24. Juni 1889 aus dem Ochiba no hakiyose Futakago me:

Was soll daran unstatthaft sein, wenn ich mir selbst Seelenruhe verschaffe und gleichzei-
tig den gewöhnlichen Menschen bei der Alltagsbewältigung zur Hilfe gereiche, indem ich
den [Schreib]pinsel ergreife, den Charakter, die Sitten und das Bestreben des Volkes ab-
bilde, die allgemeine Lage der Nation beschreibe oder die Wahrheit an Orten ergründe,
an welche die Augen der Wissenschaftler wie auch der Morallehrer nicht herankommen,
indem ich dem Leben des Menschen [im Text] eine Gestalt gebe?5

Die Sicht auf die Literatur als Weg zur Erkenntnis teilt Futabatei Shimei mit dem im folgenden zu besprechenden Mediziner und Literaten Mori Ōgai. Während jedoch Futabatei in seiner Theorie Wissenschaft und Literatur einander nahebringt, trennt Ōgai diese beiden Wege zur Erkenntnis deutlich voneinander.

554 Originaltext: Isshi no fude wo torite kokumin no kishitsu füzoku shikō wo utsushi kokka no taisei wo egaki mata wa ningen no seikatsu wo keiyō shite gakusha mo dōtokuka mo me no todokanu tokoro ni oite shinri wo saguridashite motte mizukara anshin wo motome kanete shüjin no yowatari no tasuke to mo naraba ani ka narazu ya! 一枝の筆を執りて国民の気質風俗 志向を映し国家の大勢を描きまた八人間の生活を形容して学者も道徳家も眼のとぶかぬとこ ろに於いて真理を探り出して以て自ら安心を求めかねて衆人の世渡の助ともならバ豈可なら すや (FUTABATEI-NAKAMURA 1971 [1889]: 148). 


\subsubsection{Wissenschaft und Literatur als verschiedene Wege zur Erkenntnis: Das ,Bungaku to shizen“ wo yomu (1889) von Mori Ōgai}

Als direkte Antwort auf den sich literaturtheoretisch gerierenden, eigentlich aber nur allgemein wertenden Aufsatz Kokumin no tomo dai yonjūhachi gō Bungaku to shizen 国民之友第四十八号文学と自然 (Literatur und Natur in Nummer 48 der [Zeitschrift] „Kokumin no tomo“, April 1889 in Nr. 159 der Zeitschrift Jogaku zasshi 女学雑誌) von Iwamoto Yoshiharu 螈本善治 (1863-1942) veröffentlichte Mori Ōgai einen Monat später in Nummer 50 von Kokumin no tomo den Beitrag ,Bungaku to shizen“wo yomu 「文学卜自然」Э読ム (Bei der Lektüre von ,Literatur und Natur'). ${ }^{555}$ Wäre ,Bungaku to shizen“ wo yomu ausschließlich als Antwort auf Iwamoto intendiert gewesen, hätte Ōgai mit seiner terminologischen und literaturtheoretischen „Kanone“ auf einen unbedarften „Spatzen“ geschossen. Aus WoLDERING 2015b wird aber ersichtlich, dass Ōgai den Aufsatz Iwamotos lediglich zum Anlass genommen hat, auf der Grundlage moderner europäischer Philosophie eine Wende in der japanischen Literaturtheorie einzuleiten, indem er Kunst und Wissenschaft zum einen methodisch deutlich voneinander trennt, zum anderen auf die selbe Wertstufe stellt.

Der im Zusammenhang der vorliegenden Abhandlung zentrale Begriff in Ōgais Abhandlung ist „Transsubstantiation“ (toransu-subusutanchiachion 点化 [tenka]). ${ }^{556}$ Ōgai zitiert einerseits in der chinesischen Schreibung [tenka] 点化 die daoistische Bezeichnung der Neuschöpfung aus einer vorhandenen Schöpfung, andererseits mit „Transsubstantiation“ die folgende von Rudolph von Gottschall (1823-1909) in Poetik: Die Dichtkunst und ihre Technik (1858) entwickelte These:

In der produktiven Phantasie lebt die Idee in ihrer Reinheit, und durch sie wird das stoffartig Schöne zum Ideal geläutert. Doch dies Bild der reinen Schönheit ist nur ein innerliches. Die Phantasie hat das Naturschöne zerstört, aber nur, um es schöner wieder aufzubauen. Das innere Bild bedarf derselben äußeren Wirklichkeit, wie das Naturschöne. Dazu aber gehört der sinnliche Stoff, in den es die Phantasie hineinarbeitet. Diese Einheit des Naturschönen und der Phantasie ist die Kunst; sie ist die Thätigkeit, die sie im einzelnen Gebilde lebendig hinstellt für die Anschauung aller. [...] Der Genius ist die innere, das Kunstwerk die äußere Offenbarung der Idee; das künstlerische Schaffen, welches höchste Begeisterung und Besonnenheit in sich vereinigt, die Verwandlung der inneren Offenbarung in die äußere. Diese Verwandlung ist ihrem Wesen nach eine nicht analisierbare [sic!] Transsubstantiation; ihre äußere Form ist die künstlerische Technik. ${ }^{557}$

555 Eine Analyse der Entstehungsbedingungen für Ōgais Beitrag sowie dessen kommentierte Übersetzung bietet WOLDERING 2015b.

556 WOLDERING 2015b: 47, Anm. 194.

557 GotTSCHALL 1877 [1858]: 29; Sperrdruck des Originals durch Kursive ersetzt. 
Ōgai charakterisiert also durch sein Zitat das künstlerische Schaffen als der Natur-Mimesis diametral entgegenstehenden Akt der Erschaffung einer neuen Realität, die Ausgangspunkt neuer Erkenntniswege ist. Der Fortschritt gegenüber der Literaturtheorie des Futabatei Shimei (Abschn. 4.4.1) ist dabei freilich nicht nur die Loslösung der Literaturtheorie von den bei Futabatei noch latent vorhandenen neokonfuzianischen Denkmustern - hier vollendet sich vielmehr die etwa dreißig Jahre zuvor von Hirose Tansō (Abschn. 4.3.1) angestoßene Annäherung des Erkenntniswertes der Kunst und der Literatur an den Erkenntniswert der Wissenschaft.

\subsubsection{Literaturtheorie als, ,kosmopolitisches Projekt': Das Bungaku ron (1907) von Natsume Sōseki - ein Ausblick auf die weitere Entwicklung der Literaturtheorie}

Der Literat, Wissenschaftler und Journalist Natsume Sōseki 夏目漱石 (18671916) wurde von der Regierung im Jahr 1900 zum Studium des Englischen und der englischen Literatur nach London entsandt, kehrte 1903 von dort zurück nach Japan und wurde im selben Jahr Professor für englische Literatur und Literaturtheorie (bungaku ron 文学論) an der Universität Tōkyō. In seinen Vorlesungen (1903 bis 1905) verarbeitete er die modernsten Standardwerke britischer Soziologie, Anthropologie, Politologie, Sozialphilosophie, Psychologie und Naturwissenschaften $^{558} \mathrm{zu}$ einer Literaturtheorie, deren revidierte Version er unter dem Titel Bungaku ron 文学論 (Theory of Literature) 1907 monografisch publizierte. ${ }^{559}$

Bungaku ron behandelt unter anderem Fragen von Klassifikation, quantitativer Entwicklung, Charakter und Interrelation der Literatur sowie deren mögliche Inhalte. Schwerpunkte liegen dabei auf psychologischen, soziologischen und naturwissenschaftlichen Aspekten. Der hohe Grad der Systematizität und der Abstraktion machen Natsumes Bungaku ron zu einer allgemeinen Literaturtheorie, die weder auf eine Epoche noch auf eine Region oder gar eine Person beschränkt ist. Als Beleg für den hohen Abstraktionsgrad sei hier aus Platz-

558 BouRdaGHS-UEDA-MuRPHY 2010 [1907] nennt in der Einleitung („Introduction: Natsume Sōseki and the Ten-Year Project“, 1-35) die wichtigsten Titel aus Natsumes nachweisbarer Lektüre und der verarbeiteten Werke. Die Apostrophierung als „kosmopolitisches Projekt“ übernehme ich aus BouRdaGHS-UEDA-MuRPHY 2010 [1907]: 17.

559 Original: Tōkyō: Ōkura shoten 大倉書店, dessen digitales Faksimile ist unter info:ndljp/ pid/871770 in der NDL erreichbar. Moderne Nachdrucke unter anderem in MBgZ 9. Auszüge in englischer Übersetzung bieten BOURDAGHS-UEDA-MURPHY 2010 [1907]. 
gründen nur Natsumes Definition der formalen Anlage des Inhaltes (naiyō no keishiki 内容の形式) literarischer Texte in englischer Übersetzung zitiert.

One can perhaps approach the form of literary substance [naiyō no keishiki] with the expression $(\mathrm{F}+\mathrm{f}) . \mathrm{F}$ here indicates impressions or ideas at the focal point of consciousness, while $f$ signifies the emotions that attend them. In this case, the formula stated above signifies impressions and ideas in two aspects, that is to say, as a compound of cognitive factor F (,large F”), and the emotional factor $\mathrm{f}$ (,small f”). Thus, the impressions or ideas we experience in everyday life can be divided into three types: 1. (F) but no (f), that is, cases where the intellectual factor is present but is unaccompanied by the emotional factor; for example, when the idea of a triangle is present to consciousness but unaccompanied by any further emotion. 2. (F) gives rise to an accompanying (f), as in the idea of a flower or a star, and so forth. 3. in the case where there is only (f), and one is unable to cognize a corresponding (F), as in „fear of everything and fear of nothing.” The sense of dread with no accompanying object, for example, belongs to this category. [...] Of the three types delineated above, it is case (2) that constitutes the substance of literature, that is to say, experience that takes the form of $(\mathrm{F}+\mathrm{f}){ }^{560}$

Der Text stellt mit dieser Definition und ihrer Anwendung auf potentiell alle literarischen Texte in der Geschichte der japanischen Literaturtheorie einen Meilenstein dar. Im Zusammenhang der vorliegenden Abhandlung ist der Text aber auch zur retrospektiven Analyse des Betrachtungszeitraums 1850-1890 geeignet. Es interessieren in der Rückschau sowohl mögliche Ansätze als auch die von den Theorien des Betrachtungszeitraums nicht geleisteten Ansätze zu der von Natsume in Bungaku ron entwickelten Theorie. Damit ist die Grenze zum nächsten und letzten Kapitel der vorliegenden Abhandlung erreicht.

560 BouRdaghs-UEDA-MURPHY 2010 [1907]: 52-53. Original: NATSUME 1907: 1. 